Camila Sardeto Deolindo

\title{
ANÁLISE DE MICROESTADOS NA CURVA DO HOMEM MORTO: consciência situacional em ambientes dinâmicos e complexos
}

Tese apresentada à Faculdade Israelita de Ciências da Saúde Albert Einstein para a obtenção do Título de Doutor em Ciências da Saúde. 


\section{Camila Sardeto Deolindo}

\section{ANÁLISE DE MICROESTADOS NA CURVA DO HOMEM MORTO: consciência situacional em ambientes dinâmicos e complexos}

Tese apresentada à Faculdade Israelita de Ciências da Saúde Albert Einstein para a obtenção do Título de Doutor em Ciências da Saúde.

Orientadora: Profa. Dra. Elisa Harumi Kozasa

Coorientador: Prof. Dr. Birajara Soares Machado 
D418a

Deolindo, Camila Sardeto

Análise de microestados na curva do homem morto : consciência situacional em ambientes dinâmicos e complexos / Camila Sardeto Deolindo. -- São Paulo, 2020.

xiii, $73 \mathrm{f}$.

Tese (Doutorado) - Faculdade Israelita de Ciências da Saúde Albert Einstein. Instituto Israelita de Ensino e Pesquisa Albert Einstein. Programa de Pós-Graduação em Ciências da Saúde.

Título em inglês: Microstate analysis in the dead man's curve: situation awareness in dynamic and complex environments.

1. Eletroencefalografia. 2. Mapeamento encefálico.

NLM - WL 150

Elaborada pelo Sistema Einstein Integrado de Bibliotecas 
FACULDADE ISRAELITA DE CIÊNCIAS DA SAÚDE ALBERT EINSTEIN

Coordenador do Curso de Pós-Graduação: Prof. Dr. Luiz Vicente Rizzo 


\section{Camila Sardeto Deolindo}

\section{ANÁLISE DE MICROESTADOS NA CURVA DO HOMEM MORTO: consciência situacional em ambientes dinâmicos e complexos}

Presidente da banca: Profa. Dra. Elisa Harumi Kozasa

BANCA EXAMINADORA

Membros titulares:

Prof. Dr. André Mascioli Cravo

Prof. Dr. Edgard Morya

Prof. Dr. Renan Cipriano Moioli

Membros suplentes:

Profa. Dra. Paula Ricci Arantes

Prof. Dr. Raymundo Machado de Azevedo Neto

Aprovada em: 20/08/2020. 


\section{Dedicatória}

Dedico esta tese a todos os mestres e professores, que trabalham incansavelmente para dissipar a ignorância. 


\section{Agradecimentos}

Aprendi com meus professores que o cultivo da gratidão é um dos elementos chaves para direcionar nossa mente à felicidade genuína. A gratidão nos possibilita uma visão mais ampla e, portanto, uma das grandes alegrias de finalizar um curso acadêmico é escrever a seção de agradecimentos. Acredito que em cada encerramento de uma etapa deveríamos fazer o exercício de humildade em reconhecer que o sucesso nunca é alcançado sozinho. Khandro Rinpoche chega a dizer que nós somos não mais do que a reunião da bondade dos outros. Assim, apesar de o meu nome constar como principal na autoria deste trabalho, ele é um produto de muitas mãos, que direta e indiretamente foram essenciais para que ele existisse. Portanto, gostaria de iniciar agradecendo a toda a gigantesca cadeia de seres que tornaram esta conquista possível.

Em especial, agradeço a meus pais Helena e Michel, à minha irmã Isabela, à minha avó Nina e a toda minha família, pelo amor, apoio e paciência incondicionais e indispensáveis ao longo deste caminho. Ao Pedro não só pelo amor, mas pela amizade e pela parceria de vida. Pela troca e respeito mútuo que desenvolvemos ao longo destes anos. À Lola pela companhia doce, fiel e inabalável e por toda a alegria que me acompanha desde que entrou em minha vida.

Minha gratidão também a todos os meus amados amigos que engrandecem o meu conceito de "família" ao longo desta jornada e que foram uma fonte de apoio incessante. Agradeço a todos pelas visitas à minha casa, pelo companheirismo, pelos cafezinhos, pelas conversas no telefone e pelas deliciosas risadas. Aos amigos antigos, por nossa história e por permanecermos juntos ainda que tenhamos trilhado rumos tão diferentes, em especial, Claudia, Gabi, Rapha, Passarinho, Xuxa, Shirley e Bizuleu. Agradeço também a todos os amigos que a academia me trouxe, por terem me permitido entrar em suas vidas, compartilharem suas histórias e me fazerem crescer tanto junto com vocês. Levo todos como um presente, em especial Madeh, Josi, Inessa, Nádja, Débora, Rui, Cássia, Fábio, Camilinha, Cora, Carlos, lago e especialmente meu grande "irmão", Mau. Um agradecimento especial também para as queridas Lilian, Quel, Ana, Karina, Lana, Cerys e para o Tsewang. 
Aos orientadores, Elisa Harumi Kozasa e Birajara Soares Machado pelo apoio e pela confiança em meu trabalho, por me inspirarem e me desafiarem para que eu pudesse expandir meus limites e me desenvolver, atingindo novos horizontes. Aos professores Edson Amaro Junior e Thomas König, pelas contribuições neste trabalho. Ao Ten. Cel. José Ricardo Scarpari, ao Brig. José Elias Matieli e aos professores Carlos Henrique Forster, Luiz Vicente Rizzo e Roberto Gil Annes da Silva, pela parceria sem a qual este trabalho não seria possível.

Agradeço ao Instituto de Pesquisas e Ensaios em Voo (IPEv) e à Sociedade Beneficente Israelita Brasileira Albert Einstein pelo apoio financeiro para realização deste estudo.

Agradeço ao Adriano, por sua alegria e simplicidade e pela lição de superação em nome de todos os funcionários do Einstein.

Agradeço também de todo o coração ao Gustavo, à Jeanne, ao Henrique e a toda a comunidade e aos amigos do CEBB, pelo refúgio, pelo acolhimento, por cada palavra de sabedoria, e pela companhia e incentivo na incessante jornada de cultivo do melhor de nossas mentes. E finalmente, não tenho palavras para expressar minha gratidão incomensurável ao Lama Padma Samten, ao Lama Alan Wallace, à Lama Elizabeth Mattis-Namgyel e a todos os grandes professores que personificam a compaixão e a sabedoria, por se doarem incansavelmente para dissipar a ignorância e o sofrimento. 
"Wisdom does not arise because of good answers.

Wisdom comes from very good questions."

(B. Alan Wallace, 2010) 


\section{Sumário}

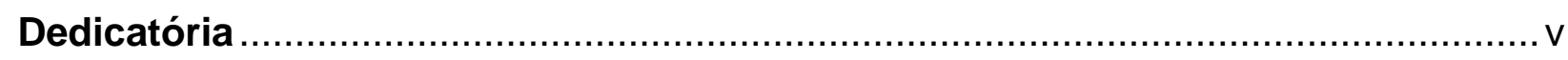

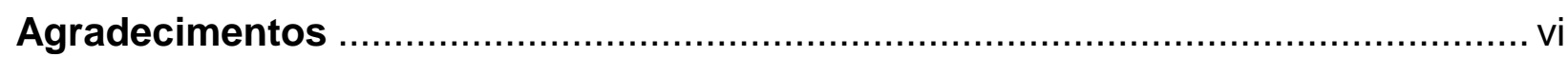

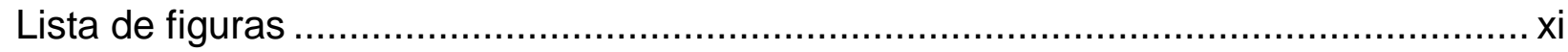

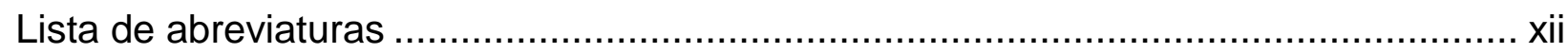

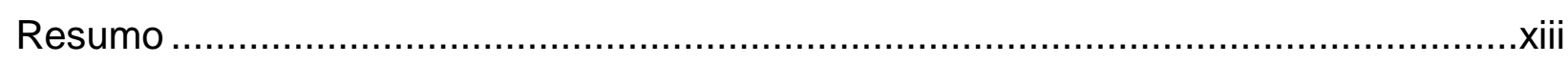

1 INTRODUÇÃO

1.1 Consciência situacional e atenção ..............................................................

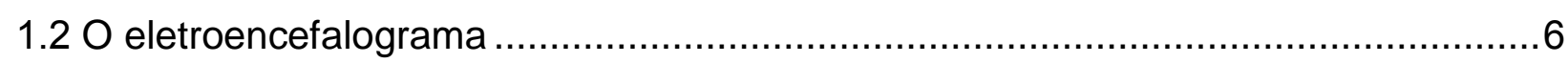

1.2.1 Eletroencefalograma: considerações sobre o hardware ....................................

1.2.2 Eletroencefalograma: oscilações e suas associações com o comportamento ........9

1.2.3 Eletroencefalograma: considerações sobre artefatos ...................................... 10

1.2.4 O eletroencefalograma como uma ferramenta de neuroimagem: a reconstrução

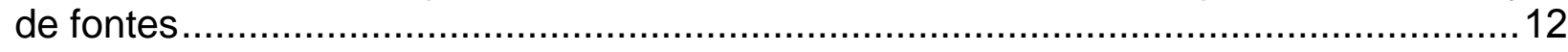

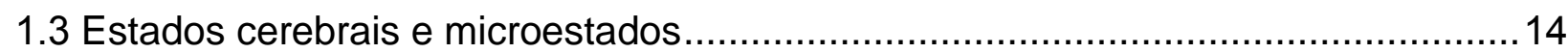

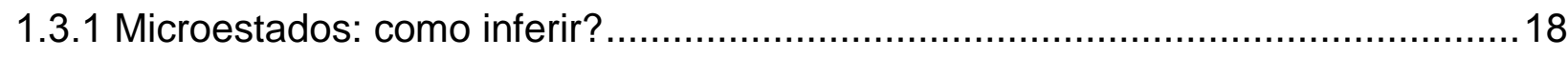

1.3.2 Microestados: quantas classes de microestados existem? ...............................20

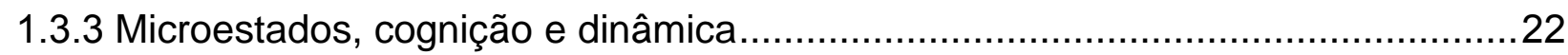

1.4 Autorrotação ao redor da "curva do homem morto" .................................................... 30

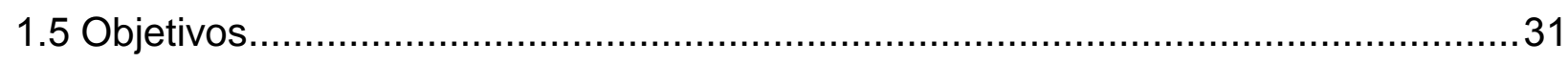

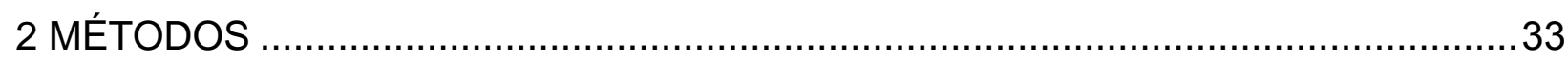

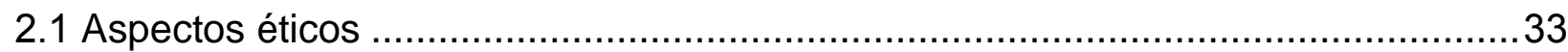

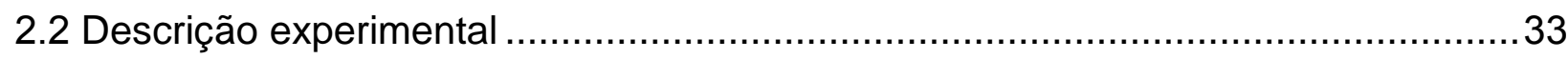

2.3 Processamento dos dados de eletroencefalograma.............................................. 37

2.3.1 Pré-processamento: remoção de artefato do eletroencefalograma .......................38

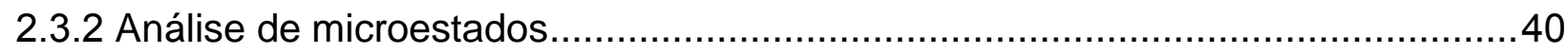

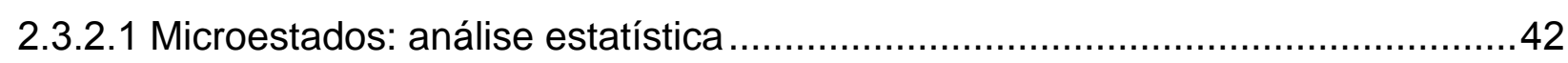

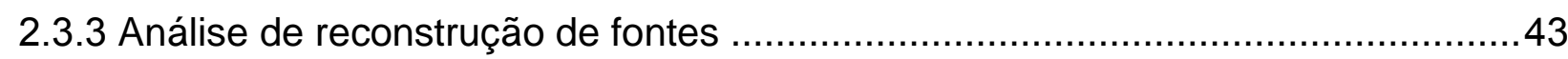

2.3.3.1 Reconstrução de fontes: análise estatística ................................................4

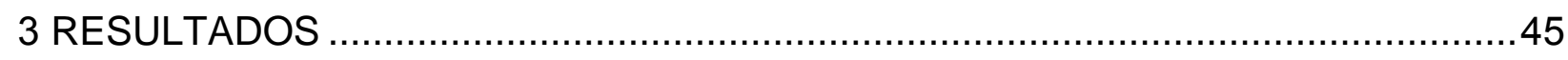

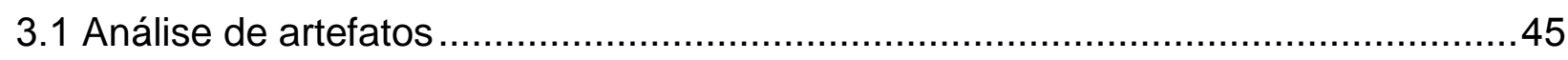




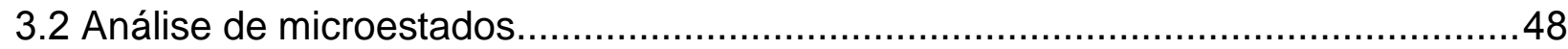

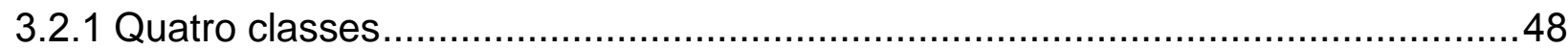

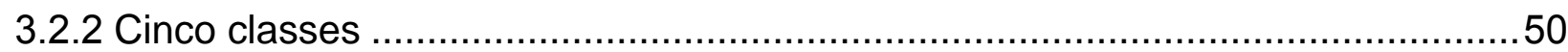

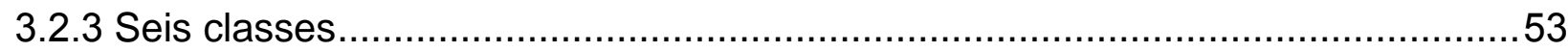

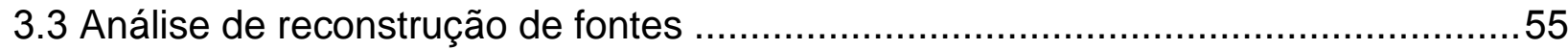

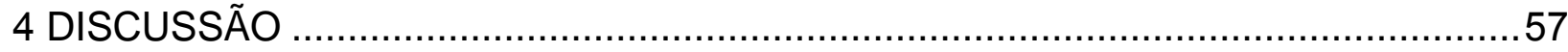

4.1 Microestados são neurocorrelatos robustos, mesmo em situações extremas..........57

4.2 A modulação dos microestados num cenário ecológico: concordâncias e

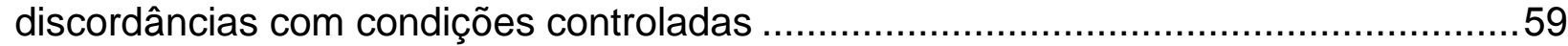

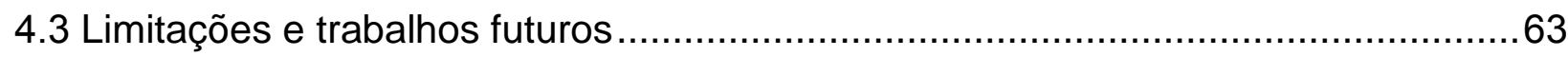

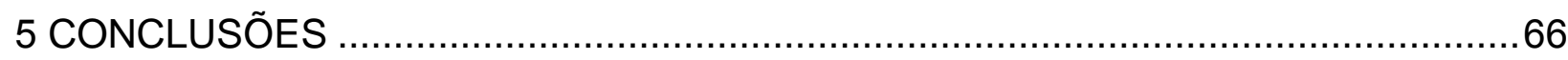

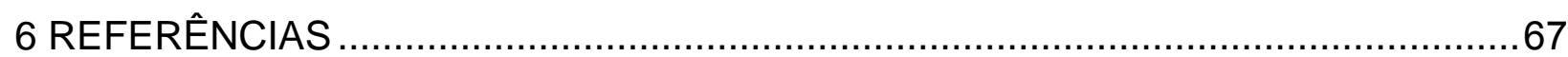

Abstract 


\section{Lista de figuras}

Figura 1. Modelo de consciência situacional de três etapas de Endsley .............................3

Figura 2. Padronização das posições dos eletrodos no escalpo ...................................... 8

Figura 3. Microestados reportados por uma série de trabalhos na literatura .....................17

Figura 4. Segmentação e clusterização do sinal de eletroencefalograma a partir dos máximos do poder de campo global, em busca de topografias representativas que melhor expliquem a variância de cada cluster ...... 19

Figura 5. Representação do passo-a-passo para a análise de microestados 20

Figura 6. Redes obtidas a partir da convolução da ocorrência de cada classe de microestados com a função hemodinâmica padrão …………………………………...23

Figura 7. Áreas associadas à atividade de 7 classes de microestados .............................24

Figura 8. Áreas associadas à atividade de 6 classes de microestados, computados a partir da reconstrução de fontes de dados de eletroencefalograma para uma tarefa de evocação de memória

Figura 9. Representação esquemática da manobra de autorrotação e da curva do homem morto 30

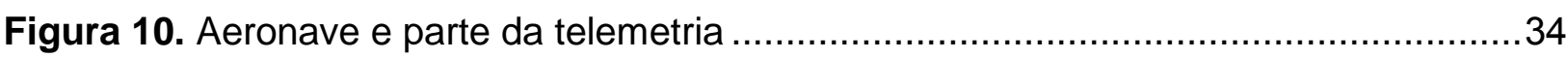

Figura 11. Pontos ao redor da curva do homem morto selecionados para avaliação ........36

Figura 12. Sensoriamento dos pilotos para aquisição de dados fisiológicos ......................36

Figura 13. Alguns exemplos de ruídos caracterizados pela análise de componentes

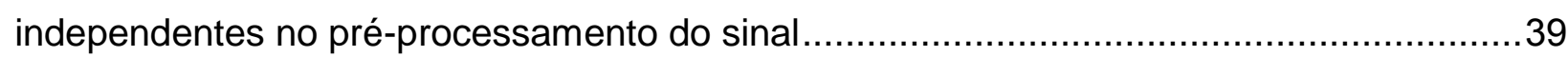

Figura 14. Desenho esquemático do pré-processamento dos dados de eletroencefalograma 40

Figura 15. Arranjo montado com os dados para a determinação dos templates de microestados

Figura 16. Efeito da mudança de referência no sinal: Espectro de um segmento do eletroencefalograma bruto do eletrodo $\mathrm{Cz}$ antes e durante o voo ....................................46

Figura 17. Topografia média dos microestados para 4 classes.....................................49

Figura 18. Dinâmica dos microestados correspondentes a 4 classes ..............................50

Figura 19. Topografia média dos microestados para 5 classes......................................51

Figura 20. Dinâmica dos microestados correspondentes a 5 classes .............................52

Figura 21. Topografia média dos microestados para 6 classes......................................53

Figura 22. Dinâmica dos microestados correspondentes a 6 classes ..............................55

Figura 23. Localização das fontes utilizando o sLORETA …………………………......56 


\section{Lista de abreviaturas}

\begin{tabular}{|c|c|}
\hline AAHC & Atomize and Agglomerate Hierarchical Clustering \\
\hline ACC & Córtex cingulado anterior (anterior cingulate cortex) \\
\hline AR & Autorrotação \\
\hline CS & Consciência Situacional \\
\hline DMN & Rede de modo padrão (Default Mode Network) \\
\hline EB & Exército Brasileiro \\
\hline ECG & Eletrocardiograma \\
\hline EDA & Atividade eletrodérmica (Electrodermal Activity) \\
\hline EEG & Eletroencefalograma \\
\hline eLORETA & LORETA exato (exact LORETA) \\
\hline EMG & Eletromiograma \\
\hline FAB & Força Aérea Brasileira \\
\hline FEF & Campo Visual Frontal (Frontal Eye Field) \\
\hline FFT & Transformada Rápida de Fourier (Fast Fourier Transform) \\
\hline GEV & Variância global explicada (Global Explained Variance) \\
\hline GFP & Poder de Campo Global (Global Field Power) \\
\hline GLM & Modelo Linear Generalizado (General Linear Model) \\
\hline IC & Componente independente (Independent Component) \\
\hline ICA & Análise de componentes independentes (Independent Component Analysis) \\
\hline IPEv & Instituto de Pesquisa em Ensaios em Voo \\
\hline \multirow[t]{2}{*}{ LORETA } & Tomografia eletromagnética cerebral de baixa resolução (Low Resolution \\
\hline & Brain Electromagnetic Tomography) \\
\hline mPFC & Córtex pré frontal medial (medial prefrontal cortex) \\
\hline OCG & Giro occipital (occipital gyrus) \\
\hline PET & Tomografia por emissão de pósitron (Positron Emission Tomography) \\
\hline REM & Rapid Eye Movement \\
\hline $\mathrm{RMf}$ & Ressonância Magnética funcional \\
\hline RSN & Rede de repouso (Resting State Network) \\
\hline sLORETA & LORETA padronizado (standard LORETA) \\
\hline \multirow[t]{2}{*}{ SPECT } & Tomografia computadorizada por emissão de fóton único (Single Photon \\
\hline & Emission Computed Tomography) \\
\hline UTI & Unidade de Terapia Intensiva \\
\hline
\end{tabular}




\section{Resumo}

Introdução: A consciência situacional consolidou-se como uma grande área dentro das pesquisas em fatores humanos e é especialmente relevante ao considerarmos ambientes de operação dinâmicos e complexos, em que o operador está sujeito a uma miríade de sinais que mudam suas condições ao longo do tempo. Compreender o processo de tomada de decisão do operador é importante para aumentarmos níveis de segurança e diminuirmos as taxas de erros, porém, estudos avaliando a dinâmica cerebral do operador em situações realísticas são escassos na literatura. Neste projeto avaliamos a fisiologia de pilotos de helicóptero experientes durante a manobra de autorrotação ao redor da curva do homem morto, através de uma análise de microestados dos sinais de eletroencefalografia em contraste com o estado de repouso. Há evidências da associação destes neurocorrelatos com percepção e atenção. Objetivos: Demonstrar que microestados são neurocorrelatos robustos em situações realísticas; analisar a dinâmica dos microestados, comparando o estado de repouso com os instantes ao redor da manobra. Métodos: $O$ ensaio de autorrotação foi realizado em um aeródromo homologado em um helicóptero AS-350 por pilotos experientes da Força Aérea Brasileira. Adquirimos um conjunto de dados fisiológicos sincronizados com o sistema de telemetria da aeronave. Neste trabalho utilizamos os dados de eletroencefalografia para a análise de microestados e posteriormente fazemos uma análise de reconstrução de fontes. Resultados: É possível verificar que as topografias características de microestados obtidos com 4, 5 e 6 classes são congruentes com a literatura e que eles apresentam modulações ao contrastarmos a tomada de decisão durante a execução da manobra com o repouso. Além disso, a reconstrução de fontes indica uma atividade no córtex pré-frontal medial, que é associado às redes de regulação emocional. Conclusão: Nossos resultados demonstram a robustez da análise de microestados em uma situação limítrofe, num ambiente intrinsecamente ruidoso e com movimentação dos participantes, o que fortalece a utilização destes neurocorrelatos e expande o horizonte de aplicação da técnica para o estudo da cognição em condições mais realísticas.

Descritores: Eletroencefalografia; Mapeamento encefálico 


\section{INTRODUÇÃO}

Esta seção apresenta a motivação deste trabalho e inicia-se com uma introdução ao conceito de consciência situacional e o papel central atribuído para a atenção no processo de tomada de decisão. Na sequência, seguimos para uma breve descrição do sinal de eletroencefalografia, discorremos sobre estados cerebrais, introduzimos o conceito de microestados e algumas evidências de sua relação com cognição e comportamento. A seguir, apresentamos o cenário do nosso estudo, descrevendo brevemente a curva do homem morto e os desafios de pilotagem na ocorrência da falha de motor em uma aeronave de asa rotativa. A seção encerra-se com o detalhamento da justificativa, hipótese e objetivos da tese.

\subsection{Consciência situacional e atenção}

À medida que a complexidade dos sistemas tecnológicos aumentou, novas estratégias foram incorporadas ao processo de desenvolvimento de produto a fim de minimizar a ocorrência e propagação de erros de design. Métodos trazidos pela engenharia de sistemas e pela engenharia de segurança, como a gestão de requisitos e análise de árvore de falhas (Fault Tree Analysis), tornam-se mais relevantes na indústria, ${ }^{(1)}$ já sendo inclusive de uso mandatório por algumas agências reguladoras. ${ }^{(2)}$

$\mathrm{O}$ amadurecimento destas metodologias evidenciou que uma grande parcela das falhas/acidentes/incidentes envolvendo sistemas complexos não se restringe a falhas no equipamento, mas também se associa ao operador. $O$ aumento da complexidade dos equipamentos demanda mais treinamento e precisão, ou até mesmo a coordenação de múltiplos indivíduos. Assim, a figura do operador se torna um elemento crucial na performance geral dos sistemas, e o processo de design precisa considerar e incorporar soluções adequadas a suas capacidades psicomotoras e cognitivas, no sentido de diminuir a carga de trabalho e facilitar o processo de tomada de decisão para, consequentemente, diminuir as taxas de erros. Os maiores problemas do operador não envolvem necessariamente a falta de informação, mas localizar e organizar a informação necessária no momento certo: sobrecarga de dados, dados não integrados, incompreensão de processos de automação e de sistemas complexos, excesso de demanda de atenção e muitos outros fatores podem ser detectados e 
corrigidos no processo de desenvolvimento. ${ }^{(3)}$

Neste contexto, a partir da década de 80 , o estudo da consciência situacional (CS) do operador consolidou-se como uma grande área dentro das pesquisas em fatores humanos, crescendo em importância no desenvolvimento de novos produtos e no design de interfaces. Segundo Endsley, ${ }^{(4)}$ o conceito de CS deve ser expandido a mais do que "meramente atentar-se a vários pedaços de informação", pois ele envolve diretamente os processos cognitivos para a compreensão do significado de elementos temporais e espaciais percebidos no ambiente e sua extrapolação para cenários futuros. Além disso, para cada operador em específico, a CS pode estar definida em termos das metas e decisões embutidas em sua atividade. Assim, a CS combina em diferentes momentos de tempo processos de reconhecimento de padrões, análise, composição de narrativa e processos metacognitivos, e é uma área do conhecimento que busca abordar a questão de como o indivíduo atribui significado ao meio. ${ }^{(3)}$

O modelo de CS de três etapas de Endsley (Figura 1) ${ }^{(4)}$ é um dos mais discutidos na literatura e considera que os processos de CS são precursores essenciais do processo de tomada de decisão, incorporando tanto fatores do sistema quanto individuais. Os três estágios são:

- Percepção: a percepção de informações e fatores relevantes do ambiente é a base do processo, pois se o operador não conseguir perceber/discernir claramente as informações importantes ele dificilmente irá dispor de boa CS. Dessa maneira, os processos atencionais do indivíduo, sua experiência e suas expectativas impactam substancialmente a interação do operador com o ambiente;

- Compreensão: a próxima etapa consiste em atribuir um significado funcional a toda a informação percebida na primeira etapa, ou seja, ela é processada, integrada, descartada ou armazenada dependendo de sua relevância e o indivíduo pode reconhecer e interpretar padrões. Todos estes processos são bastante exigentes em memória de trabalho;

- Projeção: finalmente, no nível mais alto, está a habilidade do indivíduo de, a partir de informações atuais e da dinâmica do sistema, projetar suas ações no futuro e julgar que impacto elas trazem ao ambiente operacional. 


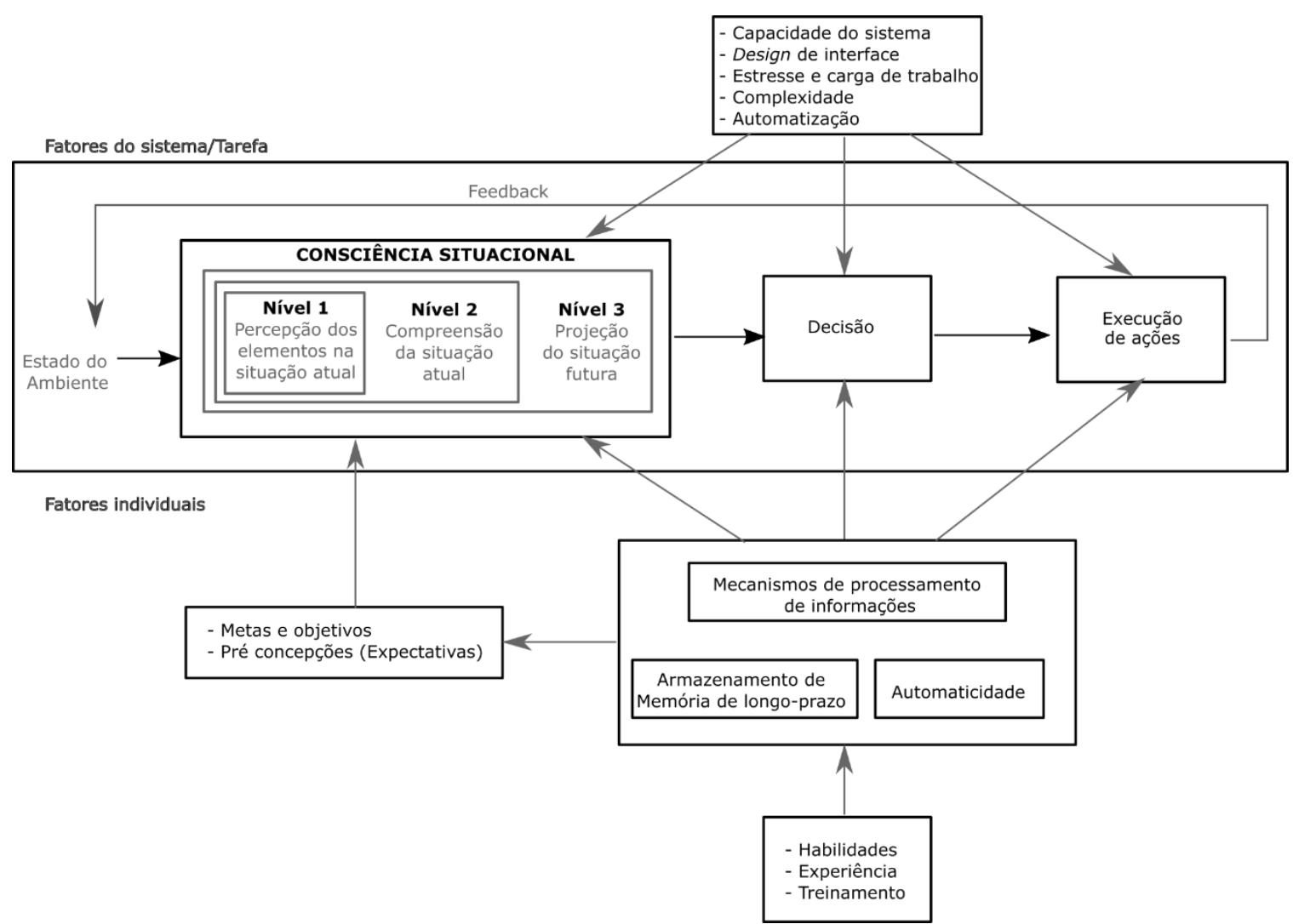

Fonte: Traduzido e adaptado de Endsley MR. Toward a theory of situation awareness in dynamic systems. Hum Factors. 1995 3;37(1):32-64.(4)

Figura 1. Modelo de consciência situacional de três etapas de Endsley

Em suma, num ambiente dinâmico e complexo, o operador tem o desafio de receber, compreender e interpretar uma enorme quantidade de informações do ambiente que geralmente mudam muito rapidamente. Além disso, ele precisa criar/adotar estratégias cognitivas para atualizar suas percepções a todo momento, de maneira que sua CS também se mantenha atualizada, pois o conhecimento atual do operador realimenta um ciclo que define o modo com que ele adquire informações e interpreta o meio nos próximos instantes de tempo.

Em geral, os operadores desenvolvem um modelo mental do ambiente, que vai sendo refinado à medida que eles adquirem mais experiência e pode chegar a níveis de automatismo. Esta estratégia facilita o manejo de recursos cognitivos limitados, tais como a atenção e a memória de trabalho e auxiliam o julgamento do ambiente e a prever seu comportamento. No entanto, esta simplificação nem sempre é vantajosa e uma informação importante pode ser preterida em detrimento de outra. Alguns vieses de seleção advém dos níveis de saliência intrínsecos aos estímulos ambientais, das estratégias distintas utilizadas na varredura do ambiente, das metas/expectativas específicas de cada operador (há uma tendência 
em vermos aquilo que esperamos ver), de seu histórico de interação com o sistema, do nível das instruções recebidas e da complexidade do modelo mental, que pode não corresponder à realidade. ${ }^{(3)}$

Desta maneira, fica evidente que os limites da memória de trabalho do operador impactam a CS, especialmente em um ambiente complexo e composto por uma miríade de fontes de informação. Uma sobrecarga na memória de trabalho foi associada ao esquecimento de informações previamente percebidas, distrações e interrupções na execução de uma tarefa. Algumas estratégias gerais utilizadas para lidar com a sobrecarga envolvem a priorização e a simplificação da informação, a subamostragem do ambiente, e sua reestruturação ativando as memórias a partir de pistas externas. $^{(3)}$

A atenção também tem um papel decisivo na seleção das porções do ambiente que seguem para a elaboração de um modelo de CS. O operador precisa também balancear a abertura de sua atenção, alternando entre níveis globais e mais generalistas, ou locais, trazendo o foco para uma maior quantidade de detalhes de uma porção mais estreita do ambiente. ${ }^{(3)}$

Uma das maneiras de categorizar os diferentes processos de atenção faz alusão ao processamento sensorial e os classifica em duas categorias: $(5,6)$ de baixo para cima (bottom-up), ou também chamada de exógena, um processo automático de processamento de informação desencadeado por objetos/estímulos externos com características marcantes ou inesperados; e de cima para baixo (topdown), ou também chamada de atenção endógena, um processo interno no qual o controle da seleção da informação é volitivo. Em ambientes dinâmicos e complexos é necessário que o operador comute dinamicamente entre os mecanismos endógeno e exógeno para que não tenhamos falhas na percepção ou interpretação dos estímulos. ${ }^{(3)}$

No entanto, do ponto de vista neurológico, estas funções possuem regiões em comum. Assim, Petersen et al. ${ }^{(7)}$ sugerem que o sistema atencional é separado anatomicamente de outros processos cognitivos envolvidos no processamento sensorial e na tomada de decisão. A atenção é categorizada em três subredes, responsáveis por aspectos cognitivos distintos:

- Rede de alerta, atenção sustentada ou vigilância: capacidade de sustentar o foco de atenção em um único objeto por um intervalo de tempo. Neste 
contexto, geralmente se associa ao monitoramento de um evento raro e imprevisível. Tem sido associada com regiões talâmicas, frontal e parietal;

- Rede de orientação, atenção seletiva ou atenção dividida: refere-se a nossa capacidade de focar um subconjunto de estímulos dentre a variedade de opções disponíveis no ambiente, ao custo que outros serão atenuados ou ao desengajamento da atenção de um alvo e seu redirecionamento a um novo alvo. Tem relação com o campo visual frontal (FEF - Frontal Eye Field) e com o lobo parietal;

- Atenção executiva, rede de chaveamento, atenção focal: refere-se ao processo de utilizar a atenção para priorizar demandas em um contexto em que elas competem entre si ou na detecção de um alvo. É associada com o córtex cingulado anterior (ACC - anterior cingulate cortex) e com o córtex prefrontal lateral.

Uma série de metodologias já foram propostas para mensurar a CS do operador, ${ }^{\left({ }^{(8)}\right.}$ e alguns trabalhos já analisam a fisiologia da tomada de decisão nestes contextos, ${ }^{(8,9)}$ mas, até o momento, ainda temos pouca clareza dos processos cognitivos utilizados e da robustez dos neurocorrelatos fora de ambientes controlados. Neste trabalho endereçamos a caracterização fisiológica do operador em uma situação limítrofe, utilizando microestados. Este método é interessante porque há indicativos que os neurocorrelatos retornados por ele para as redes de atenção e para as redes de percepção são distintos entre si, o que nos permite estudar a dinâmica destas redes no processo de tomada de decisão. Endsley ${ }^{(3)}$ diferencia os processos cognitivos utilizados para obter a CS, ou seja, o processo ativo de aquisição da informação, denominado situation assessment, do estado resultante e um campo a ser explorado é se estes processos também são distintos ou de que maneira se integram do ponto de vista fisiológico.

A fim de explorar o fluxo de informação entre estas diferentes redes, é interessante que utilizemos um instrumento de medida com uma precisão temporal similar ao tempo de resposta dos diversos estímulos que recebemos do meio, ou seja, da ordem de milissegundos. O eletroencefalograma (EEG) é um equipamento não invasivo e de custo relativamente baixo que consegue registrar a atividade elétrica do cérebro nesta escala temporal, composto por oscilações com maior potência na faixa de 1 a $30 \mathrm{~Hz}$. A seguir apresentamos uma descrição mais aprofundada do sinal e do aparato de EEG. 


\subsection{0 eletroencefalograma}

O sinal de EEG é obtido através de uma técnica não invasiva para o registro/monitoramento da atividade elétrica do cérebro, sendo largamente utilizado na prática clínica devido a seu relativo baixo custo. Os primeiros registros em humanos são atribuídos a Berger, ${ }^{(10)}$ onde ele realizou um estudo sistemático da atividade elétrica através de eletrodos posicionados no escalpo e conectados a um galvanômetro. Ele descreveu alguns padrões observáveis em pacientes e em sujeitos saudáveis.

O sinal que pode ser detectado no escalpo é uma medida direta e robusta da atividade elétrica sincronizada de um grande conjunto de neurônios do córtex cerebral. ${ }^{(11)} \mathrm{O}$ campo elétrico se irradia ao longo do tecido biológico, sendo atenuado e aumentando sua área de abrangência à medida que o detector se distancia da fonte de corrente. Este fenômeno é conhecido como condução volumétrica (volume conduction) e cada eletrodo de EEG mede uma parte deste campo. Consequentemente, um eletrodo de EEG pode registrar a atividade de fontes afastadas e não apenas a atividade de áreas diretamente abaixo de si. Além disso, uma fonte tem o potencial de afetar múltiplos eletrodos, existindo, portanto, uma correlação intrínseca entre o registro de alguns eletrodos. ${ }^{(12,13)}$

Sendo uma medida de atividade elétrica, o EEG tem uma elevada resolução temporal, ou seja, as mudanças no sinal podem ser verificadas em um intervalo bastante curto de tempo, da ordem de milissegundos. No entanto, sua resolução espacial é baixa em comparação a técnicas de imagem, por exemplo, e a atividade medida se refere a áreas corticais mais amplas. Em outras palavras, apenas são detectáveis por este instrumento mudanças que influenciem uma grande quantidade de neurônios, mas estas respostas são observáveis com uma baixíssima latência. Este conjunto de características torna o EEG uma tecnologia promissora para o diagnóstico de epilepsia, alterações no sono, avaliação de alguns estados de consciência, lesões, doenças psiquiátricas, acidente vascular cerebral e outras encefalopatias. ${ }^{(12,14)}$ Além disso, o EEG é amplamente utilizado para o estudo de conexões funcionais de curta duração entre áreas distintas do cérebro. ${ }^{(15)}$ 


\subsubsection{Eletroencefalograma: considerações sobre o hardware}

Os primeiros sistemas de EEG introduzidos no mercado eram analógicos, baseados em uma caneta que registrava as variações de voltagem em longos pedaços de papel. Em geral, os circuitos analógicos dissipam mais calor, são maiores em tamanho, e têm uma susceptibilidade ao ruído muito maior, o que é oneroso quando se está interessado em sinais com pequena amplitude, como o EEG. A incorporação de gravações digitais e seu armazenamento em fitas permitiram conclusões adicionais sobre os correlatos neurais, já que possibilitaram a aplicação de técnicas mais complexas de processamento como, por exemplo, a Transformada Rápida de Fourier (FFT - Fast Fourier Transform) que permitiu a caracterização de sinais no domínio da frequência. Além disso, cabe ressaltar que a incorporação de aparelhos digitais de EEG não foi instantânea. ${ }^{(12,16)}$

Devido a limitações tecnológicas, os primeiros equipamentos dispunham de poucos eletrodos, mas os atuais já conseguem registrar simultaneamente mais de 256 canais.(17) Além disso, já existem tecnologias que permitem o casamento ativo de impedância entre o eletrodo e o escalpo e, portanto, dissipam menos energia; e sets de eletrodos projetados para o uso no interior do aparelho de ressonância magnética.

À medida que o equipamento se popularizou, o posicionamento dos eletrodos passou a ser padronizado a partir de referências anatômicas padrão no crânio e levando em conta suas mudanças de forma. Para a prática clínica, buscou-se distribuir os eletrodos ao longo de toda a cabeça. A Federação Internacional de Neurofisiologia Clínica incorporou os guidelines elaborados por Jasper, ${ }^{(18)}$ que cunhou um sistema baseado na distância relativa entre o Nasion (pequena depressão entre os olhos) e o Inion (uma proeminência do osso occipital na base do crânio) no plano sagital, e entre os pré-auriculares, no coronal para a distribuição de 19 eletrodos.

A cabeça foi dividida através de planos espaçados entre si na sequência $10,20,20,20,20$ e 10\% nos planos sagital e coronal e estas distâncias proporcionais entre eletrodos adjacentes levaram o sistema a ser nomeado como 10/20. A nomenclatura proposta baseia-se principalmente na localização anatômica dos eletrodos, através de siglas: Os eletrodos da área órbito-frontal receberam a sigla Fp (fronto polar); os frontais, F; os centrais, C; os parietais, P; os temporais, T; e os 
occipitais, O. Os eletrodos do lado direito receberam números pares, e os do esquerdo, ímpares. Já os eletrodos posicionados na linha média do plano sagital receberam o complemento " $z$ " (zero). Atualmente existem distribuições derivadas do 10/20 tradicionais, com alguns eletrodos adicionais, e outras propostas como 0 10/10 e o 10/5, mais densas, que permitem o posicionamento de um maior número de eletrodos na cabeça (Figura 2). ${ }^{(17)}$

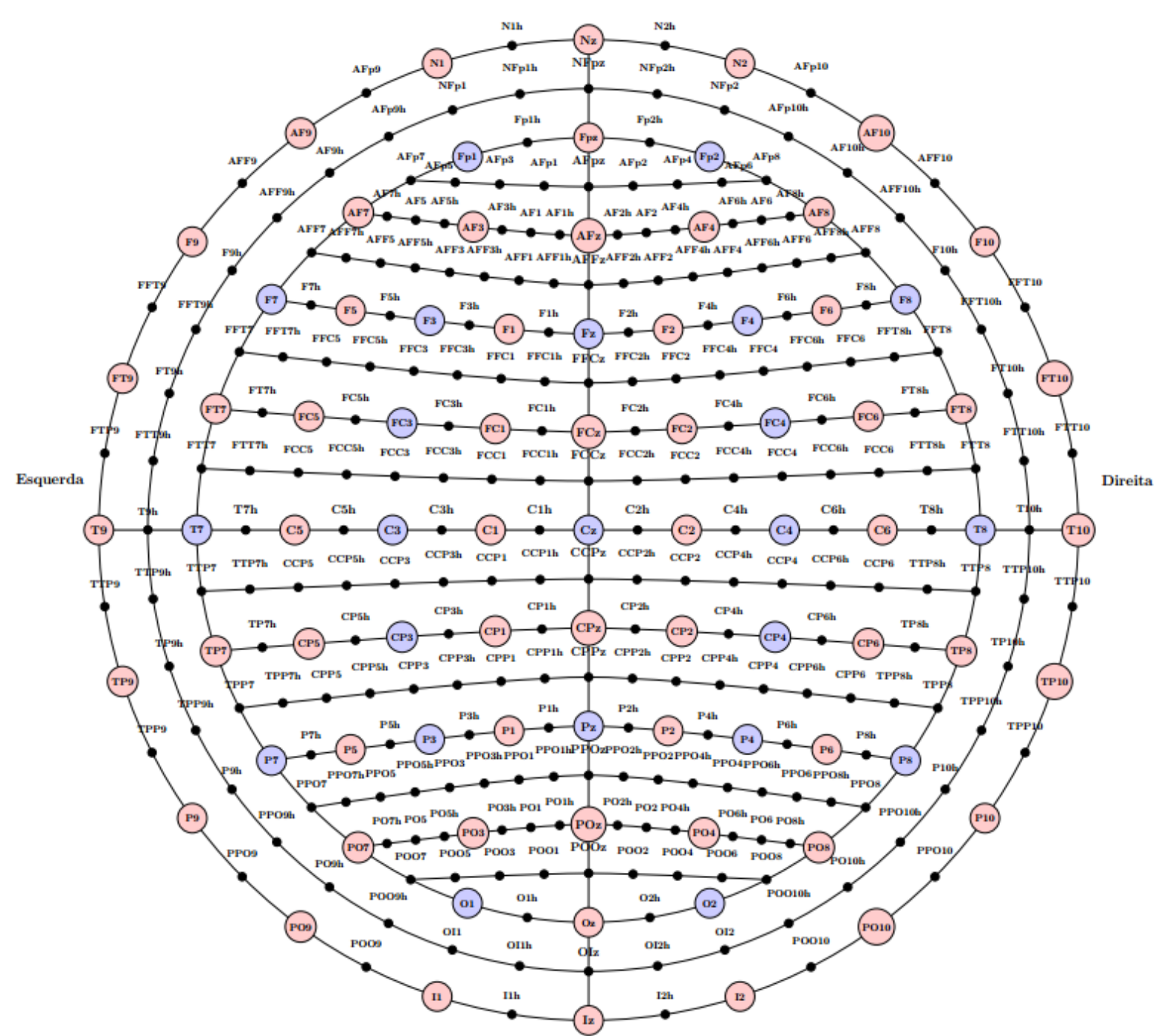

A figura expõe todas as posições do sistema $10 / 5$ e destaca nos círculos em azul as posições do sistema 10/20 e em rosa as posições extras do sistema 10/10.

Fonte: Adaptado de Jurcak V, Tsuzuki D, Dan I. 10/20, 10/10, and 10/5 systems revisited: their validity as relative head-surface-based positioning systems. Neuroimage. 2007;34(4):1600-11. ${ }^{(17)}$

Figura 2. Padronização das posições dos eletrodos no escalpo 


\subsubsection{Eletroencefalograma: oscilações e suas associações com o comportamento}

Existe um grande conjunto de evidências experimentais que estabelece uma relação entre as oscilações rítmicas do cérebro e a integração da informação para o processamento cognitivo. ${ }^{(19)}$ As oscilações e os fenômenos de sincronização/acoplamento são tidos como um mecanismo eficiente do ponto de vista energético para a coordenação temporal e distribuída da atividade neuronal em múltiplas escalas ${ }^{(6,12,20)} \mathrm{e}$, portanto, atuariam como um mediador na comunicação de redes neuronais funcionais. ${ }^{(21)}$ Ondas mais lentas atuariam como um mecanismo mais difuso, abrangendo áreas cerebrais maiores, e ondas mais rápidas, no sentido de assegurar que agrupamentos locais de neurônios sejam ativados simultaneamente. ${ }^{(22)}$

O EEG é composto por uma série de oscilações, sendo as de maior potência observadas entre 1 e $30 \mathrm{~Hz}$. As frequências são divididas em bandas, mas seus limites específicos ainda não são um consenso ${ }^{(19)}$ e existem sugestões na literatura no sentido de delimitá-las levando em consideração as especificidades de cada indivíduo. ${ }^{(23)}$ As faixas mais comuns, com seus nomes e limites aproximados são listadas a seguir, e eles são associados a uma série de resultados comportamentais. No entanto, ressaltamos que nenhum ritmo específico é sozinho responsável pela execução de uma tarefa cognitiva, mas sim um conjunto de faixas espectrais e que o ritmo medido pode variar dependendo da técnica e do ponto utilizados para registro.

- Delta $(0.5-4 \mathrm{~Hz})$ : é a frequência predominante no estado de sono profundo e é associada com aprendizado e motivação. ${ }^{(24,25)}$ Tem relação com o reconhecimento facial e suas expressões ${ }^{(21)}$ e é proeminente durante uma série de processos patológicos, como a epilepsia. ${ }^{(12,26)}$

- Theta $(4-8 \mathrm{~Hz})$ : as ondas theta são associadas com regulação emocional, facilitando a codificação de estímulos mais salientes. ${ }^{(21,25)}$ Sincronizações de fase do ritmo theta com o ritmo gamma são associadas ao recrutamento de áreas relacionadas à reconsolidação de memória, ${ }^{(22)}$ à memória de trabalho e à fala. ${ }^{(20)}$ Assim, a atividade em theta aumenta durante o repouso, memória e tarefas cognitivas. ${ }^{(23)}$

- Alfa $(8-14 \mathrm{~Hz})$ : as oscilações em alfa aumentam na região occipital em um estado relaxado, de olhos fechados e em vigília (podendo ser observadas a olho nu) enquanto diminuem com olhos abertos e durante o sono REM (Rapid Eye 
Movement). ${ }^{(23)} \mathrm{O}$ ritmo já foi tomado como um indicador de um estado mínimo de atividade cortical, mas hoje é associado à inibição de regiões corticais que não são relevantes para a execução de uma tarefa específica. Maiores amplitudes são associadas a uma maior inibição, o que resulta em janelas temporais menores para o disparo neuronal, o que, portanto, resulta em disparos temporalmente mais precisos. Em contrapartida, amplitudes menores resultam numa excitação cortical por maiores intervalos de tempo. ${ }^{(26)}$ Portanto, o ritmo é associado à atenção e estados de alerta, memória de trabalho e memória de curta duração. ${ }^{(20,27)}$ Uma dessincronização em alfa também está relacionada à função cognitiva e à memória. ${ }^{(23)}$

- Beta $(14-35 \mathrm{~Hz})$ : esta faixa tem associação com a preparação, com as contrações musculares e com o início do movimento voluntário, além da manutenção do estado sensoriomotor ou estado $\operatorname{cog}$ itivo ${ }^{(28)}$ e a realização de tarefas cognitivas em geral. ${ }^{(26)}$

- Gamma (acima de 35Hz): a banda gamma é largamente estudada, porém, a maioria dos trabalhos utiliza registros de microeletrodos implantados, já que a razão sinal ruído desta banda no escalpo é baixa. Esta faixa de frequências é associada à criação e manutenção de assembleias neurais, à representação visual de múltiplos itens, aos processos de memória e atenção. ${ }^{(20,29)}$

\subsubsection{Eletroencefalograma: considerações sobre artefatos}

Artefatos correspondem a atividades elétricas espúrias, i.e., sinais registrados que não advém da atividade cortical, e são um aspecto importante na análise do EEG. Os artefatos mais comuns e mais difíceis de serem removidos são os oriundos da atividade muscular da cabeça e do pescoço. Além disso, geralmente contamos com a contaminação da rede elétrica e da atividade muscular dos olhos, que possui uma assinatura característica nos registros de EEG. Todos estes artefatos ocorrem na mesma banda de interesse que sinais neuronais típicos, mas eles possuem uma amplitude muito maior. O sinal também é susceptível ao ruído dos equipamentos, movimentos espúrios dos cabos e ao mau posicionamento dos eletrodos ${ }^{(12,30)}$ (Tabela 1). 
Tabela 1. Artefatos no eletroencefalograma: descrição de diferentes tipos e suas origens

\begin{tabular}{|c|c|c|c|c|c|c|}
\hline \multicolumn{7}{|c|}{ Tipos de artefatos e origens } \\
\hline \multicolumn{4}{|c|}{ Fisiológico/ Interno } & \multicolumn{3}{|c|}{ Extra-fisiológico/Externo } \\
\hline Ocular & Cardíaco & Músculo & Outros & Instrumental & Interferência & Movimento \\
\hline Piscada & $\begin{array}{c}\text { Pulso de } \\
\text { Eletrocardiograma }\end{array}$ & Mascar & Suor & $\begin{array}{c}\text { Mau } \\
\text { posicionamento } \\
\text { dos eletrodos }\end{array}$ & Elétrica & Cabeça \\
\hline $\begin{array}{l}\text { Movimento } \\
\text { do olho }\end{array}$ & & Engolir & Respiração & $\begin{array}{l}\text { Perda de } \\
\text { contato do } \\
\text { eletrodo }\end{array}$ & Magnética & Corpo \\
\hline $\begin{array}{l}\text { Vibração } \\
\text { dos olhos }\end{array}$ & & Apertar & & $\begin{array}{l}\text { Movimento dos } \\
\text { cabos }\end{array}$ & Som & Membros \\
\hline \multirow[t]{3}{*}{ Sono REM } & & Cheirar & & $\begin{array}{l}\text { Problemas de } \\
\text { aterramento }\end{array}$ & Óptico & Tremor \\
\hline & & Falar & & & $\begin{array}{c}\text { Ondas } \\
\text { eletromagnéticas }\end{array}$ & $\begin{array}{c}\text { Outros } \\
\text { movimentos }\end{array}$ \\
\hline & & $\begin{array}{l}\text { Contração } \\
\text { do escalpo }\end{array}$ & & & & \\
\hline
\end{tabular}

Fonte: Traduzido de Islam MK, Rastegarnia A, Yang Z. Methods for artifact detection and removal from scalp EEG: a review. Neurophysiol Clin. 2016;46(4-5):287-305. ${ }^{(30)}$

Diferentes estratégias foram desenvolvidas para lidar com artefatos e remover padrões de atividade não-corticais incorporados ao sinal, desde a simples exclusão de alguns segmentos até o uso de algoritmos mais complexos. ${ }^{(30)}$ Atualmente a maioria dos pipelines de processamento de EEG incluem um filtro passa-banda para atenuar as altas frequências e o nível de tensão contínua (DC) do sinal. Na maioria das vezes, inclui-se também um filtro notch para a redução do ruído da rede. ${ }^{(12)}$ Os artefatos oculares costumam ser retirados através da coleta simultânea da atividade do olho ou pela aplicação de algum algoritmo de reconhecimento de padrões como a análise de componentes independentes (ICA - Independent Component Analysis). ${ }^{(30)}$ Neste trabalho utilizamos também a ICA para a remoção de artefatos e descreveremos a seguir mais detalhes sobre $\mathrm{o}$ algoritmo.

A ICA é um método multivariável que tem por objetivo separar um sinal em fontes estatisticamente independentes entre si. A hipótese é que o sinal resultante consiste em uma combinação linear dos sinais de cada uma das fontes. $O$ algoritmo se fundamenta no Teorema do Limite Central, que enuncia que a soma de variáveis independentes com variâncias finitas e identicamente distribuídas, quaisquer que sejam suas distribuições, converge para uma distribuição gaussiana. ${ }^{(31)}$ Como decorrência do teorema, no caso de fontes não gaussianas, a combinação do sinal de fontes distintas é mais gaussiana que os sinais originais. Esta propriedade é incorporada pelo método, pois ele busca minimizar uma função que mede a 
gaussianidade do sinal. ${ }^{(32)}$ A ICA nada mais é do que uma transformação linear do sinal multivariado, e, portanto, o seu resultado contém um número de dimensões igual à dimensão do sinal de entrada. Cada uma dessas dimensões é denominada componente independente (IC - Independent Component). Ao decompormos o sinal de EEG com a ICA, observamos que muitas delas caracterizam ruídos. A contribuição destas componentes é então zerada e o sinal resultante, livre destes artefatos tem sua dimensão reduzida. O sinal de EEG é bastante complexo e existe uma gama de algoritmos que exploram suas propriedades para estudar a atividade cerebral tais como a análise espectral, o potencial evocado e a reconstrução de fontes. Nesta tese utilizaremos uma análise de reconstrução de fontes a fim de determinarmos as áreas cuja atividade é predominante durante o processo de tomada de decisão.

\subsubsection{0 eletroencefalograma como uma ferramenta de neuroimagem: a reconstrução de fontes}

A inferência de quais regiões do cérebro modulam sua atividade em associação com aspectos cognitivos/comportamentais é de grande importância em estudos neurocientíficos. Devido a avanços recentes no campo de processamento de sinais, o sinal de EEG é cada vez mais utilizado como uma ferramenta de neuroimagem para o imageamento e mapeamento, fornecendo informações espaçotemporais sobre a função cerebral. ${ }^{(15)}$ Neste contexto, foram criados modelos matemáticos que almejam utilizar o potencial elétrico medido com o EEG para inferir a distribuição espacial das fontes de corrente no cérebro. A análise das séries temporais das fontes de corrente é interessante pois não depende da referência utilizada na coleta do EEG e já incorpora em sua modelagem a atividade elétrica correlacionada de eletrodos vizinhos. A reconstrução de fontes calculada a partir do EEG tem uma baixa resolução espacial quando comparada à alcançável na ressonância magnética, porém caracteriza a dinâmica do cérebro com uma melhor resolução temporal.

As correntes são matematicamente representadas através de entidades chamadas dipolos, que quantificam a polaridade geral dentro de uma região do cérebro. O cálculo da distribuição espacial das fontes de corrente é iniciado pelo chamado problema direto (forward problem), no qual calcula-se a distribuição resultante de um conjunto de dipolos hipotéticos que se propagam em um modelo volumétrico da 
cabeça. $^{(33)}$ O próximo passo é denominado problema inverso (inverse problem), no qual o potencial computado no problema direto é combinado com o sinal do EEG real, em diferentes locais do escalpo, o que possibilita a inferência de um conjunto de fontes de corrente que potencialmente produziriam distribuições de campo elétrico condizentes com o das medições. ${ }^{(34)}$ No entanto, o problema inverso é indeterminado, i.e., distribuições de corrente distintas poderiam gerar os mesmos campos elétricos medidos. Portanto, um conjunto complementar de premissas/restrições é adicionado, visando uma solução única. Atualmente, muitos algoritmos já foram propostos para realizar a reconstrução de fontes do EEG, e, além de algumas diferenças matemáticas, eles podem adotar premissas/restrições distintas ao resolver o problema inverso. ${ }^{(34,35)}$

Dentre eles, destacamos a família de algoritmos tomografia eletromagnética cerebral de baixa resolução (LORETA - Low Resolution Brain Electromagnetic Tomography), amplamente utilizada na literatura. O algoritmo LORETA aproxima uma solução para o problema inverso com a suposição a priori de que fontes adjacentes tendem a ter a mesma magnitude e orientação. Assim, o algoritmo seleciona a solução mais suave possível e, portanto, o resultado tem uma resolução espacial comprometida. Além disso, supõe-se que nenhuma corrente se origine da substância branca. ${ }^{(36,37)}$ O algoritmo original foi aprimorado, donde surgiram derivações, tais como o LORETA padronizado (sLORETA - standard LORETA), ${ }^{(38)}$ que emprega uma normalização das densidades de corrente. Essa modificação permitiu a caracterização da fonte sem viés de localização em condições com ruído. Posteriormente, outra derivação foi proposta: LORETA exato (eLORETA - exact LORETA), ${ }^{(39,40)}$ que apresenta um erro zero de localização.

No entanto, a análise também depende de outros parâmetros: Brodbeck et al. ${ }^{(41)}$ demonstrarem que métodos de reconstrução de fontes podem atingir valores de sensibilidade e especificidade comparáveis aos da ressonância magnética estrutural, da tomografia por emissão de pósitron (PET - Positron Emission Tomography) e da tomografia computadorizada por emissão de fóton único (SPECT Single Photon Emission Computed Tomography) em registros com um elevado número de eletrodos (128-256 canais) e com o modelo da cabeça obtido a partir de uma imagem estrutural. Porém, este mesmo trabalho reporta uma queda substancial tanto na sensibilidade quanto na especificidade com o uso de um menor número de canais (<32 canais) e de um template para a modelagem da cabeça. Neste trabalho utilizamos 
a análise de reconstrução de fontes para avaliar a atividade de regiões do cérebro ao contrastarmos a atividade em repouso com a tomada de decisão. Mais especificamente, avaliamos a atividade diferencial referente a cada uma das classes de microestados, recuperados a partir da análise revisada na Seção 1.3.

\subsection{Estados cerebrais e microestados}

Existem algumas discussões sobre o que seria um "estado" cerebral, ${ }^{(42)}$ mas, no contexto de sinais de EEG, uma abordagem comum é considerar o cérebro como um sistema dinâmico, descrito a partir de seu "estado" - a combinação de todas as variáveis que descrevem o sistema em um instante de tempo $t$ - e de sua dinâmica - ou como os "estados" mudam ao longo do tempo. Assim, para estudar a dinâmica do sistema avaliam-se as modificações nas características de um estado, tais como sua duração e frequência de ocorrência. ${ }^{(43)}$ Segundo Michel et al. $^{(13)}$ as formulações matemáticas de um "estado" baseadas no EEG se relacionam com as não estacionaridades do sinal e podem ser classificadas em duas grandes linhas. $\mathrm{Na}$ primeira, um "estado" cerebral é derivado a partir de atributos temporais do sinal do EEG, avaliando o intervalo no qual a dinâmica atende critérios estabelecidos de estacionaridade. Esta definição analisa as relações entre as variações na distribuição espectral e o comportamento, tais como vigília, sonolência, sono, dentre outros. Já a segunda entende o "estado" como um atributo espacial, ou seja, cada "estado" seria o resultante da atividade de um conjunto de fontes/subredes, que modulariam sua atividade assumindo uma dinâmica temporalmente similar. Dessa maneira, a ênfase estaria na modalidade da rede (sensório, motora, etc.) e no possível conteúdo que este "estado" mental representa.

A proposta de Lehmann et al. ${ }^{(44)}$ adota a segunda formulação, e se baseia na observação de alguns fenômenos interessantes em um conjunto de dados de EEG de sujeitos em repouso filtrados na banda alfa: os autores montaram mapas topográficos do potencial elétrico no escalpo e notaram que os máximos e mínimos locais do campo se estabilizavam por uma janela de tempo em torno de um eletrodo, quando então transicionavam abruptamente para uma região ao redor de outro eletrodo, onde permaneciam por mais uma janela de tempo. Eles notaram também que as mudanças de polaridade entre máximos e mínimos eram coincidentes com a 
frequência dominante da oscilação do EEG. Assim, eles relacionaram estas transições com mudanças na atividade neuronal: diferentes topografias seriam originadas por uma distribuição distinta da atividade de fontes/geradores no cérebro. Porém, apesar de não atribuírem um significado funcional a estes intervalos de tempo, os autores explicitaram que o modelo é concordante com teorias de processamento cognitivo discreto e interpretaram que cada intervalo corresponderia a um 'pacote de pensamento', ou seja, seria a manifestação de uma etapa de processamento cerebral. Em suma, os autores sugerem que estes períodos de estabilidade ou microestados correspondem a diferentes estados funcionais do cérebro, que são os blocos fundamentais do processamento de informação e que potencialmente operacionalizam o fluxo da consciência. Pascual-Marqui et al. ${ }^{(45)}$ expandiram essas análises, observando não apenas a posição com relação à região de um único eletrodo, mas sim a topografia geral da cabeça. Devido à similaridade entre as topografias e sua aparente repetição, o modelo de microestados consiste na interpretação do EEG como uma série de padrões topográficos estáveis e recorrentes ao longo do tempo. ${ }^{(43)}$ Segundo este modelo, os padrões topográficos são a resultante da atividade simultânea e de uma série de fontes espacialmente distribuídas e em sincronia, cujas oscilações se sobrepõem, ou seja, correspondem a "estados" transitórios de sincronização do EEG em que as fontes assumem uma dinâmica temporal parecida. Alterações na dinâmica das fontes refletiriam no padrão topográfico observado no escalpo. ${ }^{(13)}$

Desde então, várias evidências reforçam que tanto o modelo quanto suas propriedades teóricas são condizentes com observações comportamentais. Por exemplo, Wackermann et al. ${ }^{(46)}$ observaram que as janelas de estabilidades não apareciam quando o dado era submetido a permutações aleatórias e Britz et al. ${ }^{(47)}$ não encontraram correlação entre a duração de um microestado e a potência das bandas espectrais do EEG, apesar de Milz et al. ${ }^{(48)}$ demonstrarem que a maioria das fontes que determinam as topografias oscilam em alfa. Estas observações sugerem que microestados são propriedades emergentes do sinal de EEG.

Além disso, as topografias foram observadas em diversos estudos, tanto em indivíduos saudáveis quanto em pacientes ${ }^{(49)}$ e em diversas faixas etárias, com variações compatíveis aos diferentes estágios de desenvolvimento. ${ }^{(50)}$ Também é possível observar que a modulação dos parâmetros dinâmicos dos microestados tem relação com o comportamento e com a percepção, ${ }^{(51-54)}$ se altera em algumas 
doenças, ${ }^{(43,49,55,56)}$ com o uso de alguns medicamentos ${ }^{(43,57)}$ e em estados alterados de consciência. ${ }^{(43,58)}$ A grande maioria dos trabalhos utiliza quatro classes de microestados canônicos, nomeados de $A$ até $D$, pois apesar de eles nem sempre serem marcadamente distintos, são robustos e seus padrões topográficos já foram amplamente reproduzidos em um grande número de estudos (Figura 3).

Assim, segundo este modelo, os microestados são correlatos eletrofisiológicos da atividade coordenada de diferentes assembleias neuronais no cérebro e mudanças nas topografias indicam mudanças na coordenação global da atividade neuronal ao longo do tempo. Dessa maneira, a dinâmica dos microestados possibilitaria estudar a interação do indivíduo com o ambiente, seus estados internos e conhecimento prévio numa escala de milissegundos. ${ }^{(50)}$ Nesta seção revisaremos o construto teórico e as hipóteses que permeiam o modelo, algumas evidências que fortalecem a plausibilidade do modelo de microestados e tentativas de associar as categorias de microestados com comportamento. 


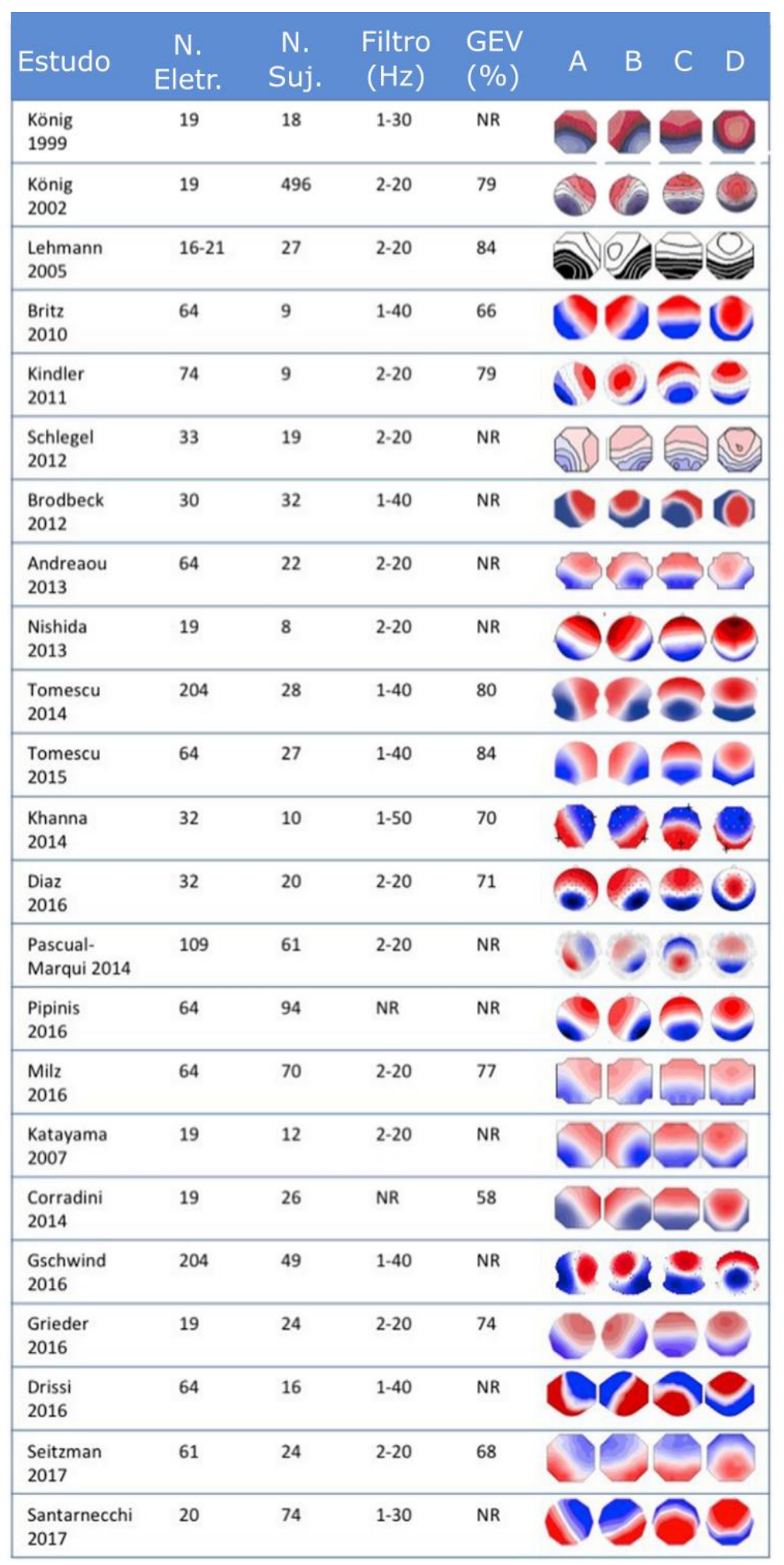

A escala de cores representa a diferença de potencial, na qual as cores "quentes" são associadas a potenciais positivos, e as "frias", aos negativos.

Fonte: Traduzido de Michel CM, Koenig T. EEG microstates as a tool for studying the temporal dynamics of whole-brain neuronal networks: a review. Neuroimage. 2018;180 Pt B:57793. ${ }^{(13)}$

Figura 3. Microestados reportados por uma série de trabalhos na literatura 


\subsubsection{Microestados: como inferir?}

Apesar de a topografia da cabeça permanecer estável dentro de uma janela de tempo, é possível observar que, durante estes intervalos, existem variações da força do campo elétrico. ${ }^{(59)}$ Assim, uma das estratégias mais utilizada para a determinação dos pontos de transição entre mapas topográficos é pelo cálculo do Poder de Campo Global (GFP - Global Field Power) (Equação 1), que quantifica a força do campo elétrico em toda a extensão do escalpo para cada instante de tempo: ele é computado a partir da raiz da média da diferença de potencial entre cada um dos eletrodos $-V_{i}(t)$ - e o potencial médio instantâneo de todos os $\mathrm{K}$ eletrodos $-V_{\text {médio }}(t)$. Em outras palavras, o GFP é numericamente igual ao desvio padrão de todos os eletrodos em um dado instante de tempo. O GFP caracteriza mudanças rápidas na atividade cerebral: os máximos locais da curva do GFP representam instantes de força de campo mais forte e, portanto, onde a topografia apresenta uma maior relação sinalruído ${ }^{(43)}$ e é uma medida que não sofre influência da referência utilizada para o registro do EEG. ${ }^{(60)}$

$$
G F P=\sqrt{\frac{\sum_{\mathrm{i}}^{\mathrm{K}}\left(\mathrm{V}_{i}(t)-\mathrm{V}_{\text {médio }}(t)\right)^{2}}{\mathrm{~K}}}
$$

Equação 1. Cálculo do poder de campo global

Desta maneira, tradicionalmente, o sinal é segmentado nos pontos de máximo do GFP e as topografias correspondentes a estes instantes são consideradas os estados discretos do EEG. A observação das topografias resultantes após a segmentação revela que muitas são bastante similares entre si, porém com polaridade invertida. Assim, classicamente, o próximo passo é utilizar um algoritmo não supervisionado para agrupar as topografias em classes de microestados, ou seja, determinando a posteriori quais topografias são mais parecidas entre si mas ignorandose a polaridade dos mapas (Figura 4). Os algoritmos mais comuns são o K-means (modificado para desconsiderar a polaridade) e o Atomize and Agglomerate Hierarchical Clustering $(\mathrm{AAHC}),{ }^{(60)}$ mas algumas abordagens alternativas são definir os microestados a partir da ICA. ${ }^{(61,62)}$ A maioria dos estudos com indivíduos em repouso 
reporta os quatro microestados canônicos (A-D). Finalmente, calculam-se parâmetros referentes à dinâmica dos microestados, sendo os mais comuns: i) duração, ou quanto tempo cada microestado permanece dominante; ii) ocorrência, ou quantas vezes em média uma determinada classe ocorre por unidade de tempo, e; iii) cobertura, ou qual a porcentagem do tempo dominada por um tipo de microestado. Outros parâmetros bastante analisados na literatura são a topografia característica de cada classe; a sintaxe, ou sequência de microestados; a variância global explicada por cada microestado e a probabilidade de transição entre classes. ${ }^{(43)}$

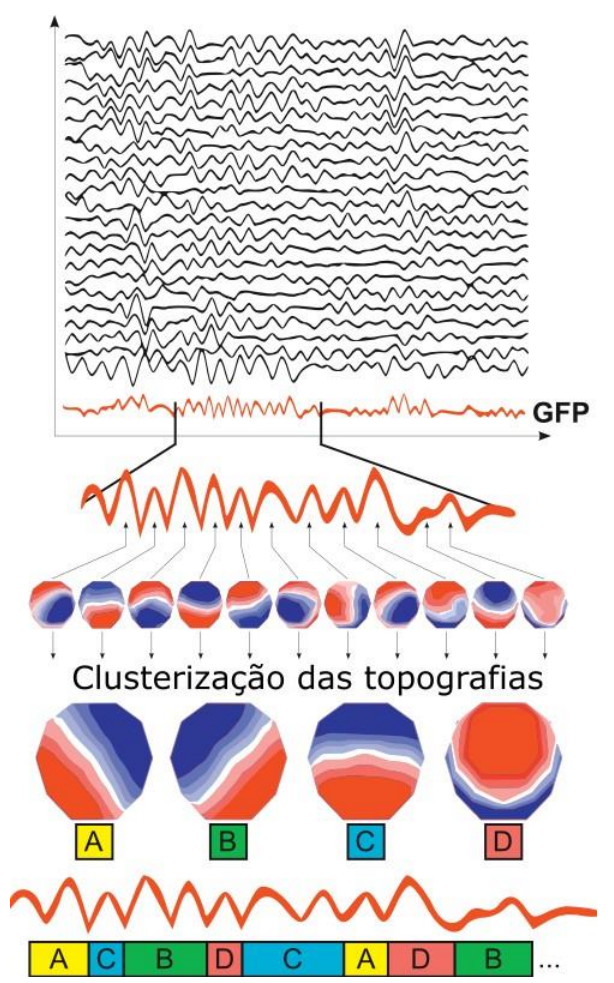

Fonte: Traduzido de Khanna A, Pascual-Leone A, Michel CM, Farzan F. Microstates in resting-state EEG: current status and future directions. Neurosci Biobehav Rev. 2015;49:105-13. ${ }^{(43)}$ Reproduzido com autorização da Elsevier.

Figura 4. Segmentação e clusterização do sinal de eletroencefalograma a partir dos máximos do poder de campo global, em busca de topografias representativas que melhor expliquem a variância de cada cluster

Em suma, após a filtragem, remoção de artefatos e rereferenciamento utilizando a média de todos os canais (pré-processamento), a pipeline clássica da análise de microestados é composta basicamente por duas etapas: a primeira consiste em determinarmos o template dos mapas topográficos (que representa o centro dos clusters) e a segunda consiste em aplicar este padrão aos dados (Figura 5). Existem ligeiras diferenças com relação ao uso de técnicas de suavização e estratégias para a filtragem e remoção de artefatos do EEG, que podem 
influenciar o resultado. No entanto, Khanna et al. ${ }^{(63)}$ sugerem que os resultados finais permaneceram estáveis a diferenças nos algoritmos de clusterização e a variações no número de eletrodos.

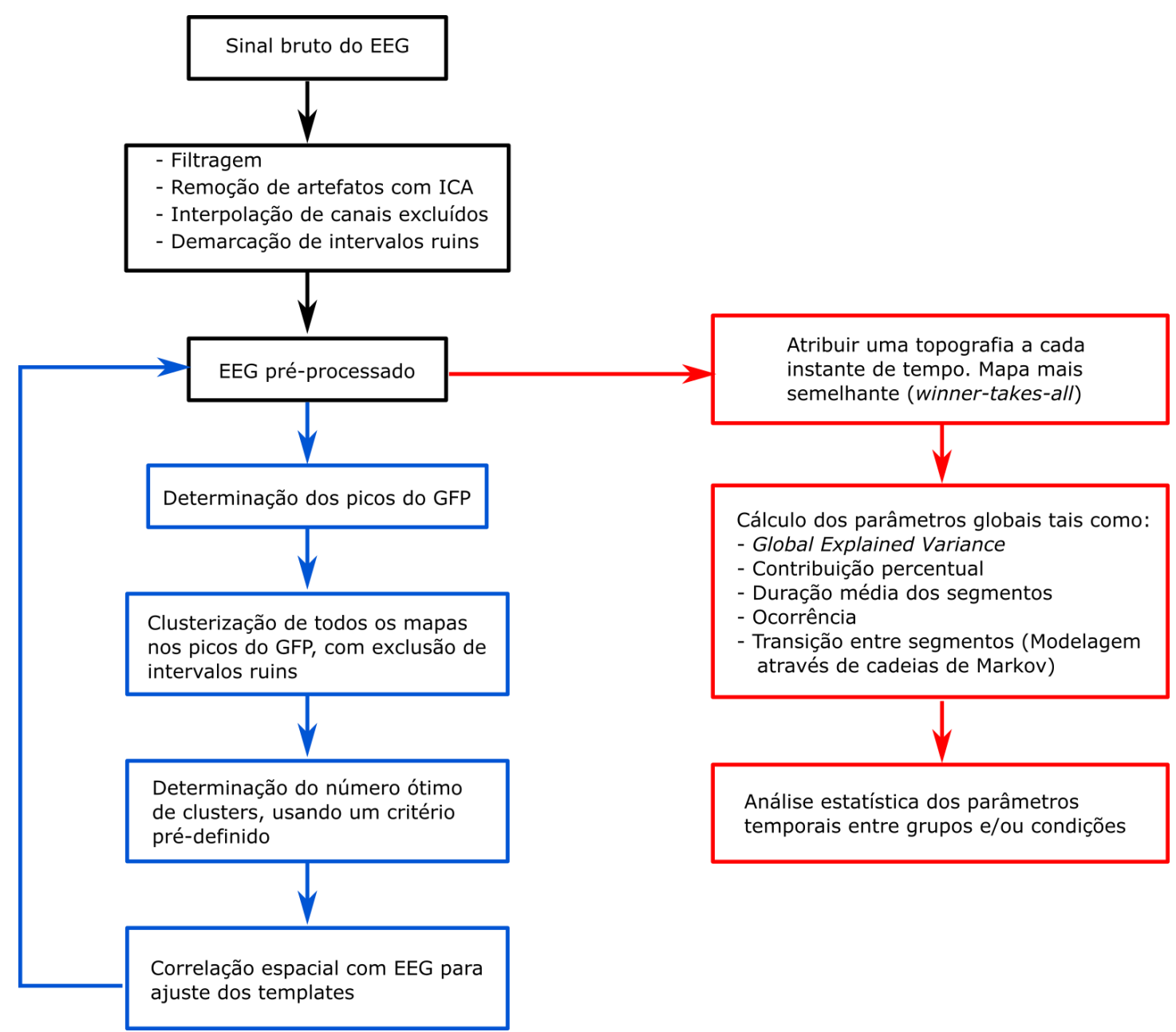

A pipeline clássica é composta pelo pré-processamento (em preto) e por mais duas etapas: i) determinação dos templates (em azul); e ii) backfitting dos dados (em vermelho).

Fonte: Traduzido de Michel CM, Koenig T. EEG microstates as a tool for studying the temporal dynamics of whole-brain neuronal networks: a review. Neuroimage. 2018;180 Pt B:577-93. ${ }^{(13)}$

Figura 5. Representação do passo-a-passo para a análise de microestados

\subsubsection{Microestados: quantas classes de microestados existem?}

Tendo em vista que a maioria dos métodos que computam microestados utilizam algoritmos de clusterização não supervisionados, uma das perguntas em aberto consiste em determinar quantas classes de microestados existem. De maneira geral, há uma relação de compromisso entre especificidade e generalidade dos resultados: quanto maior o número de mapas, maior a porcentagem da variância 
do sinal que eles conseguem explicar - Variância global explicada (GEV - Global Explained Variance), porém, também maior é a variabilidade entre indivíduos e condições e, portanto, maior a dificuldade de generalização dos resultados..$^{(13,60)}$ Alguns critérios de otimização endereçam esta relação de compromisso, como o critério de Cross-Validation ${ }^{(45)}$ ou medidas baseadas no critério de Krzanowski-Lai ${ }^{(64)}$ (para mais detalhes conferir Murray et al. ${ }^{(60)}$ ), no entanto, a maioria dos estudos se baseia nos quatro microestados canônicos, com a justificativa de manter a consistência com a maior parte de estudos previamente realizados e a literatura demonstra que, de maneira geral, os quatro microestados canônicos explicam aproximadamente $70 \%$ dos dados (Figura 3). Seitzman et al. ${ }^{(65)}$ analisou de maneira sistemática a variância, considerando o intervalo de 2 a 22 classes, reportando que de 2 para 4 classes a variância explicada aumenta aproximadamente $10 \%$ e que para um novo incremento de $10 \%$ faz-se necessário o uso de aproximadamente 15 classes. $O$ estudo era fatorial, controlando a abertura ou não dos olhos e a execução ou não de uma tarefa cognitiva e o resultado se manteve independentemente da combinação dos fatores.

Apesar disso, a distinção das quatro topografias canônicas nem sempre é trivial, particularmente a distinção das classes C e D. Segundo Michel et al. ${ }^{(13)}$ isto se deve aos $\sim 30 \%$ de variância remanescentes, que podem advir de diferenças individuais e de condições experimentais. Custo et al. ${ }^{\left({ }^{66)}\right.}$ defendem a determinação de topografias caso a caso. Seus resultados apontam que algumas classes possuem fontes em comum e que se o número de topografias características é reduzido há a tendência de elas se fundirem. Isto implica na distorção das topografias, o que impacta diretamente a quantificação dos parâmetros dinâmicos.

Logo, a presença de distorções é um risco inerente da análise de microestados que pode levar a uma classificação errônea das topografias. Estas distorções podem ocorrer em diferentes condições experimentais/grupos, pois a atividade de um conjunto de fontes pode ser prevalente e alterar a topografia de maior variância num determinado conjunto de dados. Algumas propostas no sentido de amenizar este risco são o uso de templates efetuados em condições padronizadas e por um grande número de indivíduos. ${ }^{(50,66)}$ Portanto, a associação de cada topografia com uma rede de repouso (RSN - Resting State Network) (ver próxima seção) e uma interpretação funcional deve deve ser efetuada com cautela. 


\subsubsection{Microestados, cognição e dinâmica}

O estudo da dinâmica temporal do processo cognitivo e seus neurocorrelatos é tradicionalmente pautado em função das propriedades do estímulo e das demandas da tarefa: neste contexto, a atividade espontânea do cérebro é modelada como um ruído. No entanto, esta abordagem tem se modificado e cresce o entendimento de que a atividade espontânea é funcionalmente significativa, que influencia como determinado estímulo é processado e associa-se com a variabilidade de respostas observada em múltiplas execuções da mesma tarefa. ${ }^{(52,67)}$ Assim, esta perspectiva reforça a ideia de que o cérebro não se encontra em um nível mínimo de atividade e desengajado quando um indivíduo está em repouso, mas sim que neste estado sua dinâmica se configura de maneira tal que o permita responder a um estímulo vindouro de maneira ótima. ${ }^{(66)}$

Portanto, tentativas de atribuir um significado funcional às classes de microestados buscam estabelecer uma relação com as RSNs, redes características da atividade espontânea do cérebro durante o repouso. A hipótese é que a dinâmica das RSNs é de fato muito mais rápida do que a presumida a partir de aquisições de ressonância magnética funcional (RMf) e que os microestados seriam sua assinatura eletrofisiológica. ${ }^{(47)}$ Assim, o objetivo é identificar quais áreas sincronizam sua atividade durante a ocorrência de cada um dos microestados. ${ }^{(66)}$ Uma das abordagens neste sentido explora a aquisição simultânea de EEG e RMf, exemplificada pelos estudos a seguir.

Britz et al. ${ }^{(47)}$ adquiriram simultaneamente dados de EEG e RMf em repouso, computaram o template dos microestados a nível de grupo e convoluíram a ocorrência de cada classe de microestado com a função hemodinâmica padrão. Um Modelo Linear Generalizado (GLM - General Linear Model) foi utilizado para evidenciar as redes correspondentes a cada uma das quatro topografias canônicas, e, uma análise das áreas de maior atividade sugere que elas estavam espacialmente correlacionadas com quatro RSNs previamente associadas ao processo auditivo (microestado A), ao processo visual (microestado $B$ ), redes de saliência (microestado C) e com a atenção (microestado D) (Figura 6). Já Musso et al. ${ }^{(61)}$ utilizaram uma abordagem a nível individual, fixando templates de microestados para os dados de EEG de cada participante, que serviram de regressores em um GLM evento- 
relacionado. O resultado foi comparado com a resultante de uma reconstrução de fontes a partir dos dados de EEG e, em média, metade das topografias de repouso computadas a partir da RMf tinham padrões espaciais semelhantes aos usualmente observados nas RSNs. Por sua vez, Yuan et al., ${ }^{(62)}$ reportaram uma associação entre algumas ICs das análises de RMf com as ICs dos dados de EEG: Todas as componentes do EEG foram correlacionadas a uma ou mais RSNs da RMf. Apesar de utilizarem metodologias diferentes, os estudos apontam que há uma relação entre as classes de microestados e as RSNs definidas a partir da RMf e que algumas áreas participam de mais de uma rede. ${ }^{(66)}$

A

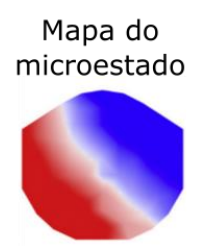

B

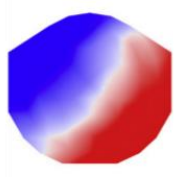

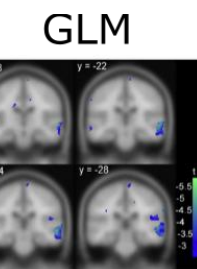

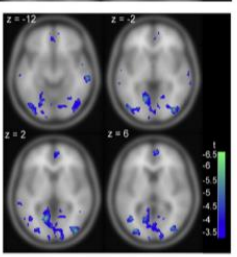

ICA
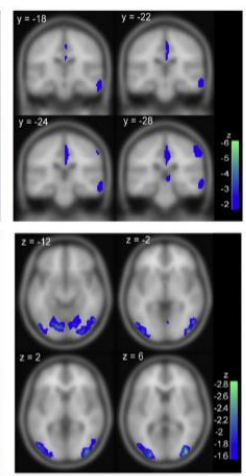

C

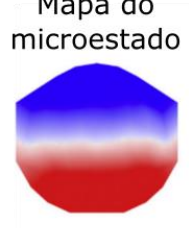

D

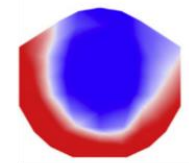

GLM
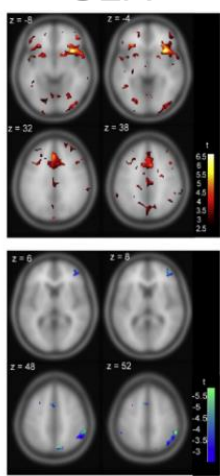

ICA
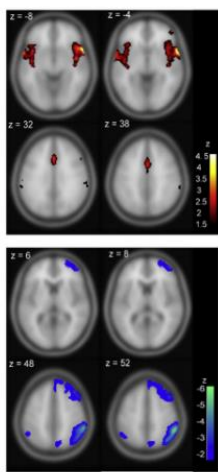

Fonte: Traduzido de Britz J, Van De Ville D, Michel CM. BOLD correlates of EEG topography reveal rapid resting-state network dynamics. Neuroimage. 2010;52(4):1162-70. ${ }^{(47)}$ Reproduzido com autorização da Elsevier.

Figura 6. Redes obtidas a partir da convolução da ocorrência de cada classe de microestados com a função hemodinâmica padrão

Uma segunda abordagem consiste em estimar as áreas correspondentes à presença de cada microestado a partir da reconstrução de fontes de dados de EEG. Custo et al. ${ }^{(66)}$ analisam dados em repouso e reportam 7 classes de microestados e que algumas áreas são consistentemente ativadas em todas elas: regiões ao longo do eixo medial anterior/posterior, na ínsula e no córtex parietal superior, todas densamente conectadas anatômica e funcionalmente, o que sugere um envolvimento em uma ampla gama de processos cognitivos de diferentes domínios funcionais e que elas atuam como pontos centrais (hubs) na dinâmica de redes cerebrais em larga escala (Figura 7). Segundo os autores, o fato de existirem áreas em comum com todas as classes de microestados assim como áreas atribuídas a um processamento específico é condizente com o modelo de Dehaene et al., ${ }^{(68)}$ denominado Neuronal Workspace, que prevê um modelo de consciência com um 
substrato comum ou global cognitive workspace, atuando como um canal de comunicação entre muitas outras redes funcionais modulares. Neste modelo, neurônios de diversas áreas se co-ativam em padrões globais de atividade, gerando o processo cognitivo através de uma sucessão de estados discretos. Apenas um destes padrões de atividade sincronizada pode ocorrer por vez e as transições entre padrões distintos é bem marcada e rápida. ${ }^{(69)}$ Estes achados retomam as afirmações de Lehmann et al. ${ }^{(44)}$ de que a cognição é discreta, ainda que os aspectos temporais da representação neural da cognição ainda não sejam um consenso na literatura. ${ }^{(70-74)}$
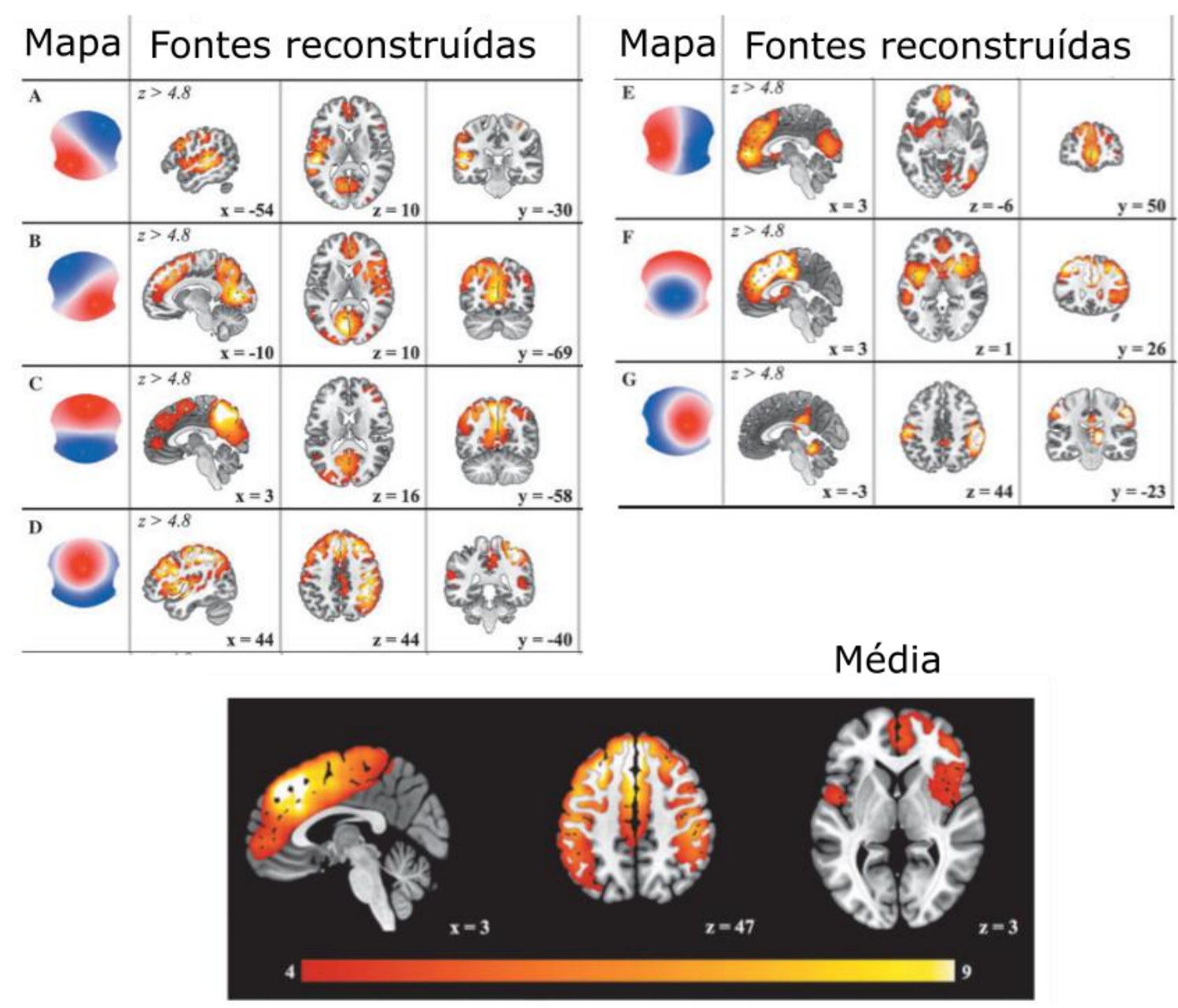

A média de todos os microestados evidencia uma rede compartilhada por todas as classes que inclui regiões ao longo do eixo anterior-posterior medial, a ínsula e o córtex parietal superior.

Fonte: Traduzido de Custo A, Van De Ville D, Wells WM, Tomescu IM, Brunet D, Michel C. Eletroencephalografic resting-state networks: source localization of microstates. Brain Connectivity. 2017;7(10):brain.2016.0476. ${ }^{(66)}$ Reproduzido com autorização da Mary Ann Liebert, Inc.

Figura 7. Áreas associadas à atividade de 7 classes de microestados

Recentemente, Bréchet et al. ${ }^{(75)}$ também efetuaram uma caracterização semelhante, mas com mais precisão espacial, ao utilizarem na 
reconstrução de fontes imagens estruturais individuais de alta resolução (coletadas num aparelho de 7 T) em 6 classes de microestados. Porém, eles expandiram a análise para considerar não só dados de repouso, mas também em outras tarefas cognitivas (cálculo mental e memória), reportando grande semelhança entre mapas associados à mesma classe, mas recuperados em atividades cognitivas diferentes; e mapas significativamente diferentes quando atribuídos a classes distintas. Os autores observarem áreas semelhantes às de Custo et al. ${ }^{(66)}$ (Figura 8 ) e reportaram uma sobreposição espacial entre as redes dos microestados e sub-redes calculadas a partir da RMf. O microestado A apresentou atividade lateralizada no giro temporal superior (esquerdo), no córtex pré frontal medial (mPFC - medial prefrontal cortex) e no giro occipital (OCG - occipital gyrus). O microestado B, no OCG, e na parte medial do córtex parietal (precúneo e córtex retrosplenial). As fontes do microestado $\mathrm{C}$ se encontram bilateralmente na parte lateral do córtex parietal, contemplando os giros supramarginal e angular. Já as do microestado D estão predominantemente em áreas bilaterais do giro frontal inferior e da parte dorsal do ACC, além do lobo parietal superior e do sulco intraparietal. Para o microestado $E$ as fontes se concentraram no mPFC direito, e para o F, no mPFC bilateral.
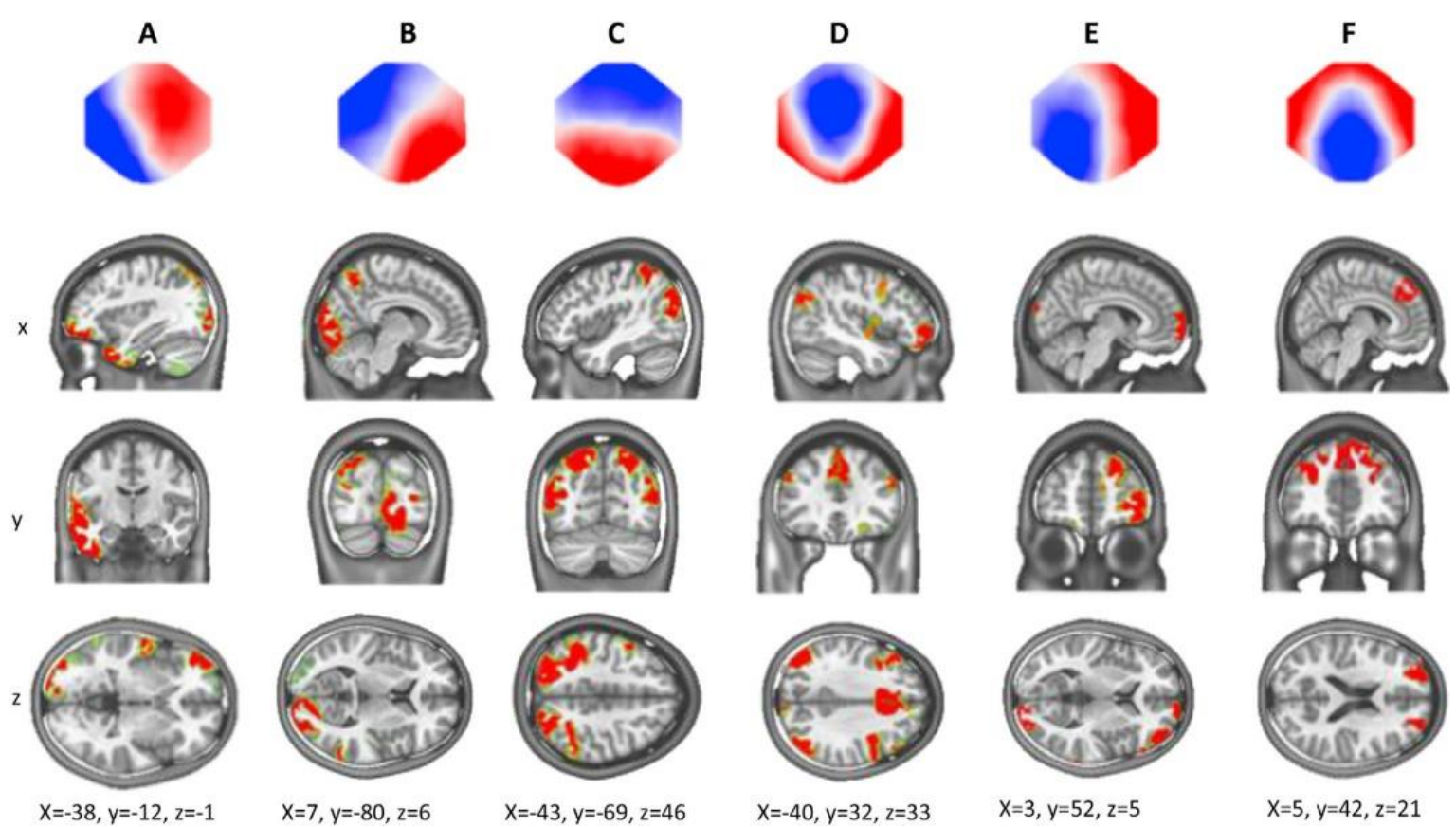

$X=7, y=-80, z=6$

$X=-43, y=-69, z=46$

$X=-40, y=32, z=33$

$x=3, y=52, z=5$

$x=5, y=42, z=21$

Fonte: Bréchet L, Brunet D, Birot G, Gruetter R, Michel CM, Jorge J. Capturing the spatiotemporal dynamics of self-generated, task-initiated thoughts with EEG and fMRI. Neuroimage. 2019;194(February):82-92. ${ }^{(75)}$ Reproduzido com autorização da Elsevier.

Figura 8. Áreas associadas à atividade de 6 classes de microestados, computados a partir da reconstrução de fontes de dados de eletroencefalograma para uma tarefa de evocação de memória 
As propriedades dinâmicas dos microestados também reforçam uma associação com as RSNs. Em primeiro lugar, a maioria dos estudos reporta uma duração média para as classes de microestados na janela de 60 a $120 \mathrm{~ms},{ }^{(13)}$ o que é congruente com a escala temporal de um conjunto de respostas fisiológicas. Por exemplo, este intervalo é da mesma ordem de um percept - intervalo mínimo entre estímulos sequenciais para que um seja percebido como diferente de outro (de 70 a $100 \mathrm{~ms})^{(76)}$ ou ainda para que um não mascare a percepção de outro ( 100ms). ${ }^{(70)}$ Além disso, os potenciais pós-sinápticos no cérebro de mamíferos estão normalmente na janela de $80-200 \mathrm{~ms}^{(77)}$ Outro exemplo refere-se aos mecanismos de interação tálamocorticais: Acredita-se que a o acoplamento entre as oscilações lentas, em alfa, no tálamo e rápidas, em gamma, no córtex exerçam um papel nos processos de percepção. ${ }^{(70)}$ As ondas alfa tendem a ser mais globais, viajando por todo o córtex, e são a frequência dominante das principais fontes ativas que geram as topografias dos microestados, ${ }^{(48)}$ sendo, portanto, compatíveis com janelas discretas de processamento de $\sim 100 \mathrm{~ms} .{ }^{(70)}$

Outro aspecto explorado referente à dinâmica é a transição entre estados. A análise revela que as sequências de microestados apresentam duas propriedades em concordância com o esperado quando modelamos o cérebro como um sistema dinâmico:(13) i) Metaestabilidade, definida como a flexibilidade de um sistema em transicionar de um estado para outro, independentemente da recepção de estímulos externos. Esta propriedade se relacionaria, por exemplo, à modulação da atenção, que pode ser atraída por estímulos ambientais ou por processos internos do indivíduo; ii) Criticalidade, ou um sistema que apresenta uma dinâmica livre de escalas, Scale-free-dynamics, que está associada à responsividade a informações oriundas de uma ampla gama de fontes, à rápida reorganização e adaptação de redes funcionais no cérebro. ${ }^{(78)}$ Van De Ville et al. ${ }^{(79)}$ demonstraram que as sequências de microestados são livres de escalas na faixa de $256 \mathrm{~ms}$ até $16 \mathrm{~s}$. Isto quer dizer que a observação das sequências em diferentes escalas temporais revela a mesma informação. Assim, fica estabelecida uma relação entre a informação contida na série temporal de microestados e a informação da RMf, em uma escala temporal maior. ${ }^{(43)}$ Van De Ville et al. ${ }^{(79)}$ demonstram também que a dinâmica livre de escalas se mantém mesmo quando permutamos aleatoriamente a rotulação da sequência dos microestados, mas se perde quando fixamos as durações, o que indica que a duração temporal é o 
parâmetro determinante. Isso fortalece que o cérebro é um sistema complexo, que não opera de maneira estática, mas dinâmica, e que ele se adapta e integra informações em diferentes escalas temporais. Além disso, observamos alterações na dinâmica ao contrastarmos pacientes com controles saudáveis, o que indica que o modelo potencialmente caracteriza mudanças nos processos associados a doenças mentais e condições psicológicas:(13) por exemplo, as probabilidades de transição entre classes não são aleatórias em indivíduos saudáveis - mas se tornam em pacientes com Alzheimer, e são alteradas em pacientes com esquizofrenia. ${ }^{(43)}$

No entanto, apesar das evidências apontando a associação entre os microestados e funções cognitivas específicas, apenas recentemente o modelo foi utilizado para embasar não somente as mudanças nos parâmetros dinâmicos de microestados em patologias, mas também sua modulação durante tarefas cognitivas e a possível influência dos conteúdos mentais. Demonstrou-se que os parâmetros dinâmicos dos microestados são modulados por tarefas cognitivas, ${ }^{(65,75,80)}$ e que eles se correlacionam com a expertise dos indivíduos. ${ }^{(81)}$

Milz et al. ${ }^{\left({ }^{80)}\right.}$ compararam a duração, a ocorrência e a cobertura de um grupo de indivíduos durante a visualização de objetos, a visualização espacial, a habilidade verbal e o repouso. Já Seitzman et al. ${ }^{(65)}$ buscaram modular os parâmetros através de uma tarefa de subtração mental e de manipulações na abertura e fechamento dos olhos. Finalmente, Bréchet et al. ${ }^{(75)}$ tinham por objetivo estudar a atividade mental espontânea (repouso) e sua relação com memória episódica. Além disso, uma condição complementar de cálculo mental de operações aritméticas foi adicionada, já que ela desativa seletivamente regiões autobiográficas no processo de invocação de memória.

Os resultados de Milz et al. ${ }^{\left({ }^{(0)}\right.}$ sugerem uma relação da classe $A$ com a visualização e da classe $B$ com a verbalização, em contraposição aos achados de Britz et al., ${ }^{(47)}$ que os associavam ao processamento fonológico e ao processamento visual, respectivamente. Seitzman et al. ${ }^{(65)}$ também relataram um aumento dos parâmetros associados à classe $B$ quando os participantes abrem e fecham os olhos. Já Bréchet et al. ${ }^{(75)}$ observaram um aumento na ocorrência do microestado $B$ em comparação à aritmética mental e a reconstrução de fontes aponta um aumento de atividade em áreas do córtex visual e parietal medial, áreas que estão envolvidas na construção mental de cenas visuais. A partir de achados que apontam que lesões no 
córtex parietal medial levam a perda de memória e reconhecimento visual, mas não alteram a auto-consciência, os autores propõem então que o microestado B é composto de duas sub-redes, uma que visualiza a cena em si, e outra que visualiza o sujeito na cena.

Com relação ao microestado $\mathrm{C}$, Britz et al. ${ }^{(47)}$ observaram uma relação com a rede de saliência, com o cíngulo anterior e a ínsula. No entanto, a rede de saliência é associada com a performance, ${ }^{(13)}$ e, portanto, seus parâmetros deveriam aumentar durante tarefas cognitivas. Tanto Milz et al. ${ }^{(80)}$ quanto Seitzman et al. ${ }^{(65)}$ reportaram diminuições nos parâmetros associados à classe $C$, o que seria contraintuitivo. Esta observação somou-se ao fato da região do cíngulo anterior ser um hub proeminente da rede de modo padrão (DMN - Default Mode Network), levando Seitzman et al. ${ }^{(65)}$ a relacionarem a classe $\mathrm{C}$ com a DMN. Os resultados de Bréchet et al. ${ }^{(75)}$ reforçam este ponto já que não só eles observam a diminuição dos parâmetros para a aritmética mental, em concordância com Seitzman et al., ${ }^{(65)}$ mas também notam a sobreposição anatômica das fontes do microestado $\mathrm{C}$ com partes laterais do lobo parietal (bilateralmente) e do giro temporal médio, áreas associadas à DMN. Além disso, Bréchet et al. ${ }^{(75)}$ não encontraram modulações neste microestado na tarefa de evocação de memória em comparação ao repouso, e sugerem que isso advém do processo de evocação de memória também estar presente na atividade mental espontânea.

Finalmente, à classe $\mathrm{D}$, Britz et al. ${ }^{(47)}$ relacionam a rede de atenção dorsal, o que foi corroborado pelo aumento dos parâmetros na aritmética mental em contraste com o repouso nos experimentos de Seitzman et al. ${ }^{(65)}$ e de Bréchet et al. ${ }^{(75)}$ e pela reconstrução das fontes de Bréchet et al. ${ }^{(75)}$ No entanto, cabe ressaltar que existe uma ligeira diferença entre as topografias encontradas por Britz et al. ${ }^{(47)} \mathrm{e}$ Bréchet et al. ${ }^{(75)}$ das de Seitzman et al. ${ }^{(65)}$ Em contrapartida, Milz et al. ${ }^{\left({ }^{(0)}\right.}$ observam um aumento nos parâmetros durante o repouso em contraste com as atividades, o que conduziu a uma associação deste microestado a aspectos da atenção ligados ao processamento subjetivo e interoceptivo. Bréchet et al. ${ }^{(75)}$ propõe também que 0 microestado $D$ e o microestado $C$ estariam respectivamente associados a cognição orientadas externamente e internamente, e que se ativariam de maneira antagônica, já que ativam a rede de controle pré-frontal e a DMN.

Em suma, as evidências sugerem uma associação funcional entre 
microestados e comportamento. No entanto, existem indícios que as RSNs não são completamente independentes entre $\mathrm{si}^{\left({ }^{(66)}\right.}$ o que requer cautela ao relacionarmos classes de microestados a funções cerebrais de forma unívoca. ${ }^{(13)}$ Por exemplo, Pedroni et al. ${ }^{(54)}$ analisaram as características temporais durante intervalos de repouso em uma bateria de atividades de tomada de decisão e gerenciamento de risco, não encontrando os quatro microestados canônicos. Ainda assim, eles foram capazes de estabelecer uma relação causal entre a porcentagem de tempo dispendida em cada uma das classes e a decisão tomada pelo participante alguns instantes depois.

Alguns trabalhos analisam também os perfis topográficos emergentes no sinal de EEG em relação a um determinado estímulo (e não mais com/em contraste com a atividade espontânea). As evidências apontam que mudanças na topografia de todo o escalpo podem ser relacionadas à mudança na percepção, na cognição e no processamento da informação pelo cérebro. Desta maneira, não apenas parâmetros médios da dinâmica das topografias são relevantes, mas a topografia ativa no instante de tempo de interesse. Por exemplo, Müller et al. ${ }^{(51)}$ analisaram a percepção de movimento ilusória emergente a partir de uma série de estímulos alternados; Britz et al., ${ }^{(82)}$ mudanças de percepção referentes a um estímulo ambíguo (cubo de Necker); e Britz et al., ${ }^{(83)}$ a imagem percebida quando estímulos conflitantes são fornecidos aos olhos. Estes estudos são interessantes, pois os estímulos seguem um padrão ao longo de todo o experimento e, portanto, mudanças na percepção são associadas exclusivamente à modulações internas da atividade cerebral, inerentes a cada participante. No primeiro estudo os autores correlacionaram mudanças na probabilidade de ocorrência de uma classe de microestado com a percepção e nos demais, foi possível correlacionar os instantes que ocorriam mudanças na topografia com alterações na percepção.

Em suma, este conjunto de evidências sugere uma estreita relação entre o modelo de microestados e cognição. Neste trabalho exploramos pela primeira vez a aplicação deste modelo em um cenário ecológico, dinâmico e complexo para acessar a neurofisiologia e a cognição de operadores em situações desafiadoras. Neste trabalho, utilizaremos como estudo de caso pilotos de helicóptero de alta performance. Queremos observar se a modulação dos microestados em uma situação real e com alta demanda cognitiva se assemelha aos achados efetuados em laboratório. Na próxima seção descrevemos a manobra de autorrotação (AR), estudada 
nesta tese.

\subsection{Autorrotação ao redor da "curva do homem morto"}

A AR é um estado do voo em que o rotor de uma aeronave de asa rotativa (helicóptero) não mais gira por meio da ação do motor, mas pela ação do ar subindo em sua direção. Para sua execução, o piloto deve manualmente desacoplar o eixo do motor do eixo do rotor e direcionar a aeronave para um pouso em segurança. $A$ AR faz parte do programa padrão de treinamento de pilotos, já que ela é majoritariamente utilizada no pouso de emergência da aeronave no caso de falhas de motor ou do rotor de cauda. ${ }^{(84-86)}$

No entanto, existe um conjunto de condições de voo em que a execução da $A R / p o u s o$ se tornam muito difíceis ou impossíveis, e portanto, a operação da aeronave é restringida para evitá-las. Estas condições são mapeadas por meio de um diagrama altura $X$ velocidade, e a curva que limita as regiões de operação é conhecida como "curva do homem morto", curva altura-velocidade ou envelope de altura-velocidade (Figura 9). ${ }^{(84-86)}$

A

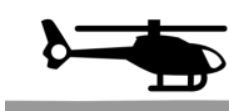

B

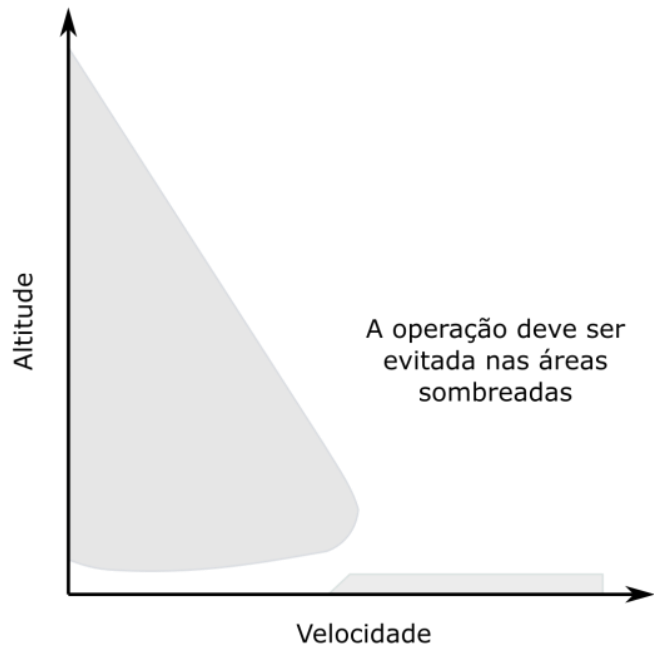

(A) Manobra de autorrotação. (B) Curva do homem morto. O diagrama mostra combinações de altura e velocidade onde a autorrotação e o pouso são (em branco) ou não (em cinza) recomendados

Fonte: Traduzido e adaptado de Federal Aviation Administration. Helicopter flying handbook [Internet]. Washington (DC): Federal Aviation Administration; 2019 [cited 2020 May 20]. Available from: https://www.faa.gov/regulations_policies/handbooks_manuals/aviation/helicopter_flying_handbook/ ${ }^{(86)}$

Figura 9. Representação esquemática da manobra de autorrotação e da curva do homem morto 
A demarcação da curva leva em conta que um piloto com um "nível mínimo de habilidade" operando fora das regiões proibidas conseguiria realizar o pouso em segurança. No entanto, a definição do que seria considerado um "nível mínimo de habilidade", como ele poderia ser mensurado e como emular as condições de ensaio de maneira mais realística ainda são tópicos de extenso debate na indústria aeronáutica. ${ }^{(87)}$

Um dos principais problemas reside no fato de a ocorrência de eventos adversos que requeiram a execução da manobra de AR serem raros em comparação com outros tipos de eventos. ${ }^{(88,89)}$ Assim, a aeronave permanece em queda livre durante o intervalo de tempo extra que incorpora os processos fisiológicos de percepção e tomada de decisão e este intervalo precisa ser incorporado na demarcação da curva. ${ }^{(87)}$

Atualmente, este intervalo é definido a partir de muitos ensaios, mas ainda tomando por base critérios subjetivos. Porém, o número de acidentes causados por falhas de execução da manobra motiva a exploração de maneiras objetivas e embasadas na fisiologia para a escolha dos parâmetros de segurança. Assim, neste projeto, efetuamos a caracterização da neurofisiologia do operador enquanto operando nesta situação limítrofe através da análise de microestados.

Existem evidências que os microestados são neurocorrelatos associados ao processo cognitivo. No entanto, até onde pudemos verificar, a literatura carece de sua avaliação em condições ecológicas. Neste trabalho exploramos de maneira pioneira a modulação dos microestados durante a manobra de AR.

Nossa hipótese é que os parâmetros temporais da modulação do microestado $D$, associado à rede de atenção e controle cognitivo, serão maiores durante a tarefa mental em oposição ao repouso.

\subsection{Objetivos}

1. Demonstrar que microestados são neurocorrelatos robustos para o estudo de situações realísticas e que podem ser reconstruídos em ambientes limítrofes e intrinsecamente ruidosos em que o indivíduo pode se movimentar livremente;

2. Avaliar a neurofisiologia de pilotos experientes durante a manobra 
de autorrotação e tomada de decisão, através da modulação dos parâmetros dinâmicos dos microestados;

3. Analisar a dinâmica de transição entre microestados, comparando o estado de repouso com os instantes ao redor da manobra;

4. Avaliar as diferenças topográficas dos microestados durante a autorrotação em contraste com o estado de repouso;

5. Efetuar uma reconstrução das fontes geradoras de cada microestado e verificar se elas correspondem a áreas tradicionalmente associadas a redes funcionais de atenção. 


\section{MÉTODOS}

Esta seção descreve a metodologia utilizada na aquisição de um conjunto de dados fisiológicos sincronizados com o sistema de telemetria de uma aeronave de asa rotativa. Além disso, trazemos mais detalhes sobre os participantes do projeto e sobre as técnicas computacionais utilizadas no processamento dos resultados.

\subsection{Aspectos éticos}

Este trabalho foi aprovado pelo comitê de ética do Instituto Israelita de Ensino e Pesquisa do Hospital Israelita Albert Einstein (Projeto 3103-17). Todos os voluntários concordaram em participar e assinaram o termo de consentimento livre e esclarecido. Ressaltamos que, apesar de este projeto envolver riscos para os participantes, eles já executariam este conjunto de manobras como parte de uma missão especial dentro do escopo de suas atividades profissionais e nosso projeto envolveu apenas o sensoriamento complementar das respostas fisiológicas (em mais detalhes ao longo desta seção).

\subsection{Descrição experimental}

Os ensaios em voo foram executados em São José dos Campos São Paulo no Instituto de Pesquisa em Ensaios em Voo (IPEv), um aeródromo homologado em um helicóptero AS-350 de propriedade da Força Aérea Brasileira (FAB), com capacidade para 6 ocupantes. A aeronave estava instrumentada com telemetria completa, além de sensoriamento adicional em todos os sistemas e instrumentos da aeronave, comandos de voo, câmeras de alta velocidade, sensores de proximidade do rotor-fuselagem, sensores de altitude e velocidades e acelerações angulares. Todas as informações estavam sincronizadas e eram amostradas a $64 \mathrm{~Hz}$ (Figura 10). 
A

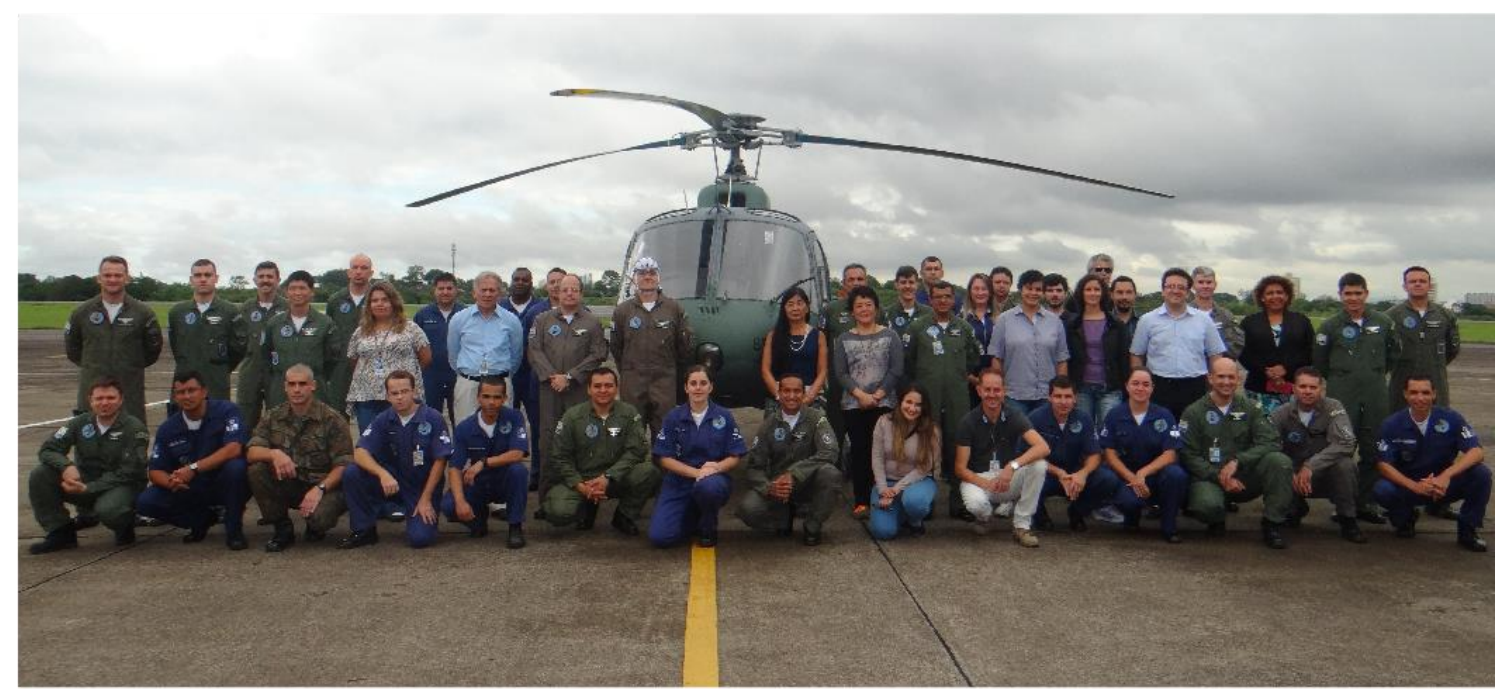

B

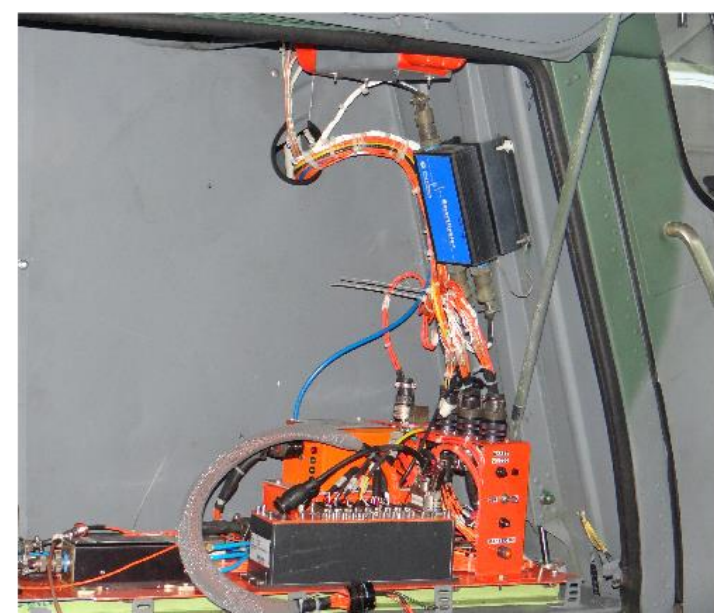

C

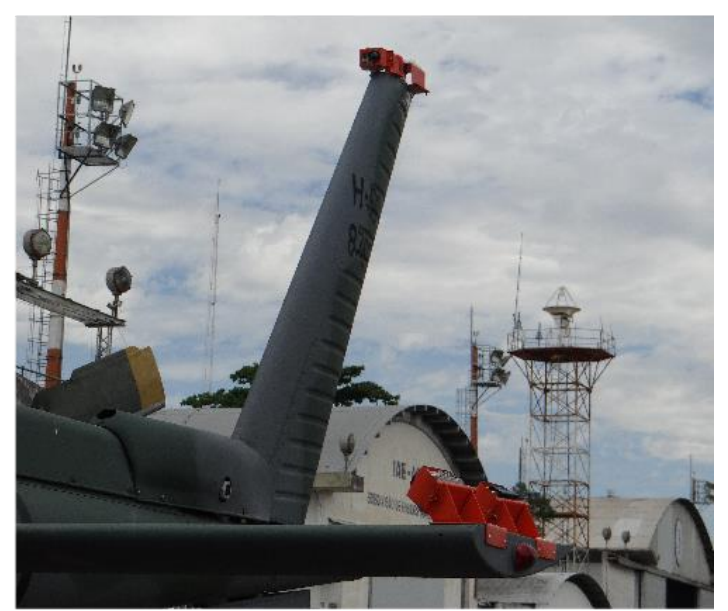

A) Aeronave AS-350 e os envolvidos no projeto; B) Parte do sistema de aquisição de dados no bagageiro lateral direito; C) Parte do sistema de aquisição de imagens (câmeras GoPro).

Figura 10. Aeronave e parte da telemetria

Nesta campanha, coletamos os dados de 11 pilotos da FAB e do Exército Brasileiro (EB), todos muito experientes em pilotagem, mas com diferente níveis de experiência em AR, como pode ser verificado na tabela 2. Apesar de o estudo contar com apenas 11 participantes, ressaltamos que este é um número bastante expressivo para um estudo exploratório devido ao alto custo de uma hora de ensaio em voo e ao reduzido número de centros de formação de instrutores. ${ }^{(90)}$ Todos os pilotos são saudáveis e passam por check-ups anuais. 
Tabela 2. Descrição da amostra: parâmetros referentes à experiência de cada um dos pilotos

\begin{tabular}{cccccccc}
\hline \multirow{2}{*}{ ID } & Idade & \multicolumn{3}{c}{ Horas de voo } & Instrutor & $\begin{array}{c}\text { Piloto de } \\
\text { prova }\end{array}$ & $\begin{array}{c}\text { Experiência em } \\
\text { autorrotação }\end{array}$ \\
\cline { 3 - 6 } Suj 01 & 41 & $4006: 05$ & $2660: 40$ & $1441: 00$ & Sim & Sim & Sim \\
Suj 02 & 37 & $2592: 25$ & $2337: 20$ & $1740: 55$ & Sim & Sim & Sim \\
Suj 03 & 37 & $3308: 40$ & $1411: 25$ & $178: 35$ & Não & Sim & Sim \\
Suj 04 & 38 & $1746: 45$ & $1588: 30$ & $133: 20$ & Não & Sim & Sim \\
Suj 05 & 46 & $3500: 10$ & $1988: 30$ & $1479: 15$ & Sim & Sim & Sim \\
Suj 06 & 48 & $3730: 10$ & $2580: 30$ & $1725: 10$ & Sim & Sim & Sim \\
Suj 07 & 37 & $1755: 45$ & $1755: 45$ & $1430: 00$ & Não & Sim & Sim \\
Suj 08 & 37 & $2242: 40$ & $1037: 10$ & $234: 20$ & Não & Não & Não \\
Suj 09 & 35 & $1384: 00$ & $1219: 20$ & $722: 55$ & Não & Não & Não \\
Suj 10 & 41 & $2750: 35$ & $2155: 00$ & $1120: 50$ & Não & Não & Não \\
Suj 11 & 42 & $3650: 05$ & $2350: 40$ & $1130: 00$ & Não & Não & Não \\
\hline
\end{tabular}

A tripulação contava com um piloto de prova no comando, um instrutor de voo na supervisão, e um engenheiro de ensaios na coordenação do voo. Além disso, um especialista em segurança em voo participou do planejamento da campanha, um especialista em instrumentação atuou na gerência da aeronave e um time de mecânicos especializados estava de plantão. Os pontos de manobra foram préselecionados de maneira a varrer as imediações da curva do homem morto, como demonstrado na figura 11. Como se tratava de um ensaio em voo, o motor não foi completamente desligado, mas teve sua potência reduzida até que a aeronave perdesse sua sustentação e sempre havia a possibilidade de arremetida. Os testes de motor cortado foram sempre executados a uma altitude segura, com reacendimento do motor em voo. Os padrões de fadiga dos pilotos eram constantemente avaliados seguindo as normas do IPEv. Toda a tripulação se reunia antes de cada voo para repassar o planejamento da missão (briefing) e após sua execução para revisar a execução das manobras (debriefing). 


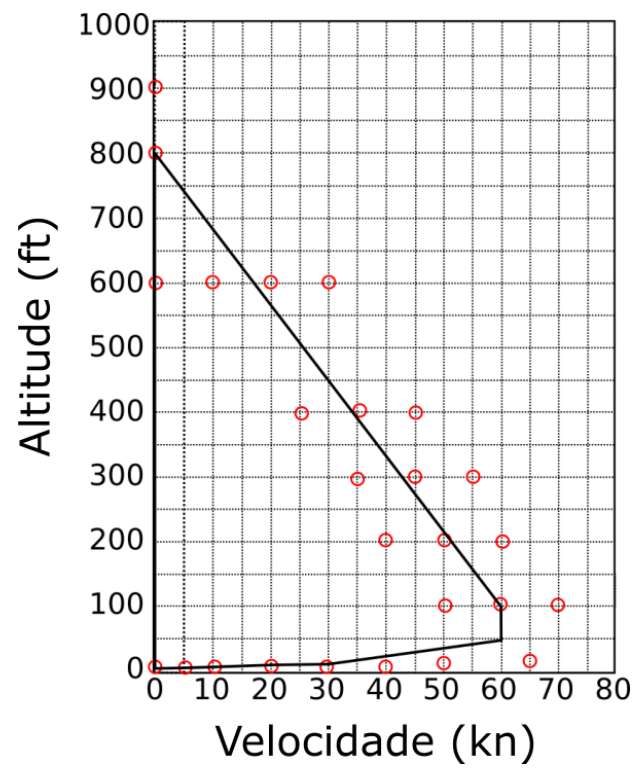

Figura 11. Pontos ao redor da curva do homem morto selecionados para avaliação

Com relação à fisiologia, coletamos sinais de EEG, batimento cardíaco através do (ECG - eletrocardiograma), respiração, Atividade eletrodérmica (EDA - Electrodermal Activity) e da atividade muscular do tríceps do braço esquerdo (EMG- relacionado ao movimento do coletivo) numa frequência de amostragem de $500 \mathrm{~Hz}$ (Brain Products, Gilching DE) (Figura 12). Os sinais fisiológicos foram sincronizados com o sistema de telemetria da aeronave por um trigger de um push button, acionado pelo engenheiro de voo no início de cada manobra. Além disso, a movimentação do olho do piloto foi registrada por um sistema de Eye tracker (Tobii) e sua expressão facial foi registrada com câmeras de alta resolução. Nesta tese analisaremos apenas os dados de EEG.

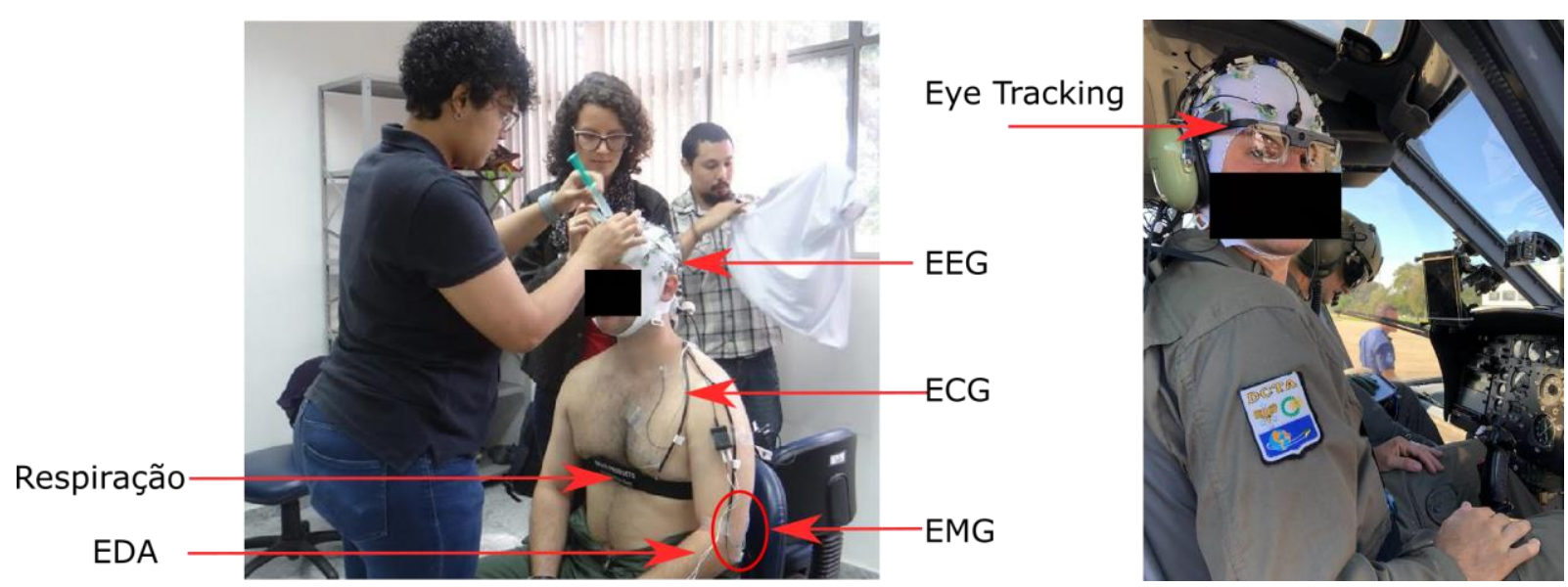

ECG: Eletrocardiograma; EDA: Atividade eletrodérmica; EEG: Eletroencefalograma; EMG: Eletromiograma.

Figura 12. Sensoriamento dos pilotos para aquisição de dados fisiológicos 
Neste teste, optamos por utilizar o setup de 32 eletrodos ativos comercial LiveAmp da Brain Products. O sistema de eletrodos molhados é o padrão ouro na literatura, por apresentar menor susceptibilidade à ruídos. Além disso, o sistema ativo permite um maior o controle de impedância entre os eletrodos e o escalpo. Este setup foi escolhido, pois o amplificador é portátil. Além disso, o sistema é desenhado para medições de EEG em movimento e já possui um sistema de acelerômetros integrados. A impedância foi mantida abaixo de $25 \mathrm{k} \Omega$. Os eletrodos foram posicionados seguindo o padrão 10/20 e para a aquisição utilizamos o software BrainVision Recorder (Brain Products, Gilching DE).

Durante este experimento, coletamos dados dos sujeitos em repouso em dois cenários distintos: antes e após cada voo. Em ambos os casos, o participante permanecia com os olhos abertos por um minuto e era instruído a fixar seu olhar a uma cruz projetada em uma tela a sua frente, relaxar e procurar não se movimentar.

A aquisição de dados fisiológicos tinha início poucos instantes antes da decolagem e só era desligada após o pouso. Porém, neste estudo, analisamos apenas os segmentos ao redor das manobras de AR. Estes instantes foram definidos a partir dos pontos em torno das demarcações do engenheiro de voo e combinadas com o sistema de telemetria, como o primeiro instante em que a potência do motor se torna inferior a $65 \%$. Tivemos o cuidado de solicitar aos pilotos que reduzissem os diálogos durante os instantes específicos ao redor da manobra, o que reduziu a contaminação dos dados de EEG. Observe que existem diferentes pontos de manobra ao redor da curva do homem morto (Figura 11), que podem se associar a diferentes níveis de dificuldade. Além disso, algumas execuções ocorreram de maneira inesperada para o piloto, mas foram premeditadas pela tripulação. Apesar dessas diferenças, neste estudo atribuímos o mesmo peso a todas as manobras, a fim de aumentar o poder estatístico final, uma vez que temos poucas realizações de cada ponto e um baixo número de participantes no contexto de um estudo eletrofisiológico.

\subsection{Processamento dos dados de eletroencefalograma}

Nesta seção descreveremos todas as etapas do processamento do EEG, passando pela estratégia de remoção de ruído, pela análise de microestados e 
pela reconstrução de fontes.

\subsubsection{Pré-processamento: remoção de artefato do eletroencefalograma}

Para cada execução da manobra, segmentamos os dados de voo em uma janela de um minuto ao redor da falha de motor. A seguir, os dados de AR e de repouso foram pré-processamos no software BrainVision Analyser versão 2.1.0.137. Inicialmente, fizemos uma inspeção semi-automática dos dados, para excluir trechos descontínuos devido a artefatos de movimento do voluntário ou da fiação.

A seguir, todos os conjuntos de dados (ao redor da manobra ou durante o repouso) foram filtrados com um filtro passa-banda de Butterworth (0.5$50 \mathrm{~Hz}$ ), sem deslocamento de fase e com um filtro rejeita faixa em $60 \mathrm{~Hz}$, ambos de quarta ordem. Na sequência, realizamos a ICA, semi-automática implementada no programa. Este método é tradicionalmente utilizado para a extração de artefatos oculares e musculares, porém, ele também é eficiente para caracterizar algumas assinaturas adicionais de ruído durante o voo. Ao decompormos o sinal de EEG com o ICA durante a manobra de AR, observamos uma série de ICs associadas a ruídos do ambiente no sinal, como exemplificado na figura 13. Isso já era esperado já que este estudo lida com um experimento ecológico. Assim, a fim de diminuir a quantidade de componentes zeradas e consequentemente, reduzirmos excessivamente a dimensão resultante, optamos por restringir ainda mais os dados que seguirão para a análise de microestados, focando no intervalo de $-2 \mathrm{~s}$ a $3 \mathrm{~s}$ ao redor da falha de motor, pois é a janela em que ocorre a tomada de decisão. Desta maneira, apenas as componentes que caracterizaram ruídos nesta janela de tempo foram zeradas. Para finalizar, os canais foram referenciados com relação a seu valor médio. A estratégia de préprocessamento foi esquematizada na figura 14. 


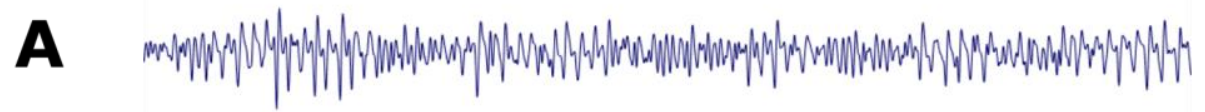
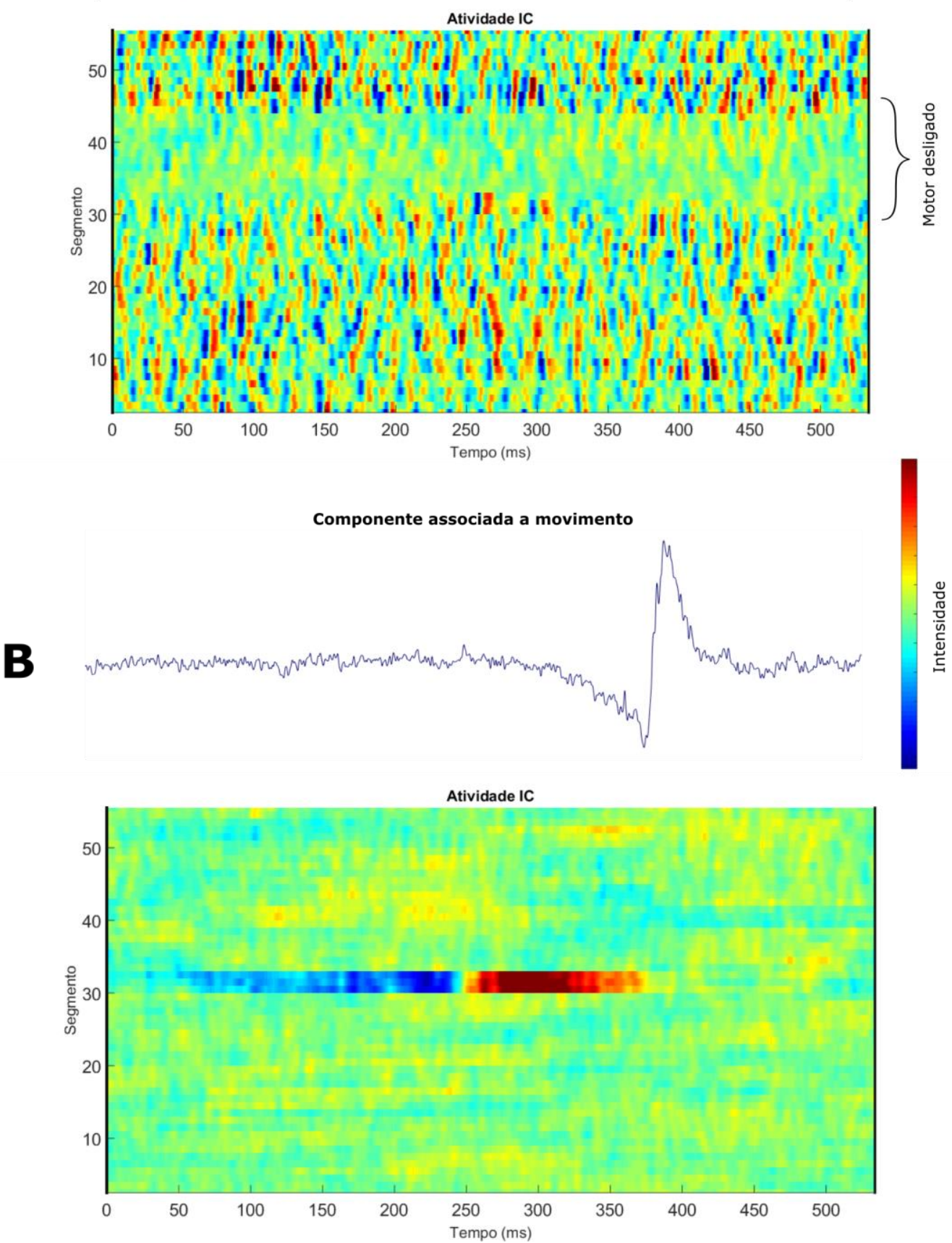

Exibimos um segmento característico da componente, assim como uma representação visual da atividade correspondente em um minuto de dado. $O$ dado foi dividido em segmentos para facilitar a visualização. A falha de motor acontece ao redor do segmento 30 . Observe em (A) uma componente associada ao motor, cuja atividade assume padrões periódicos e que cessam no momento em que o motor é desligado. Em (B) ilustramos uma componente associada ao movimento, e é possível notar um pico no componente que é restrito a um instante de tempo. A fim de não diminuirmos excessivamente a dimensão dos dados, zeramos apenas a contribuição de componentes ruidosas na janela de $-2-3 s$ ao redor da falha de motor.

Figura 13. Alguns exemplos de ruídos caracterizados pela análise de componentes independentes no pré-processamento do sinal 


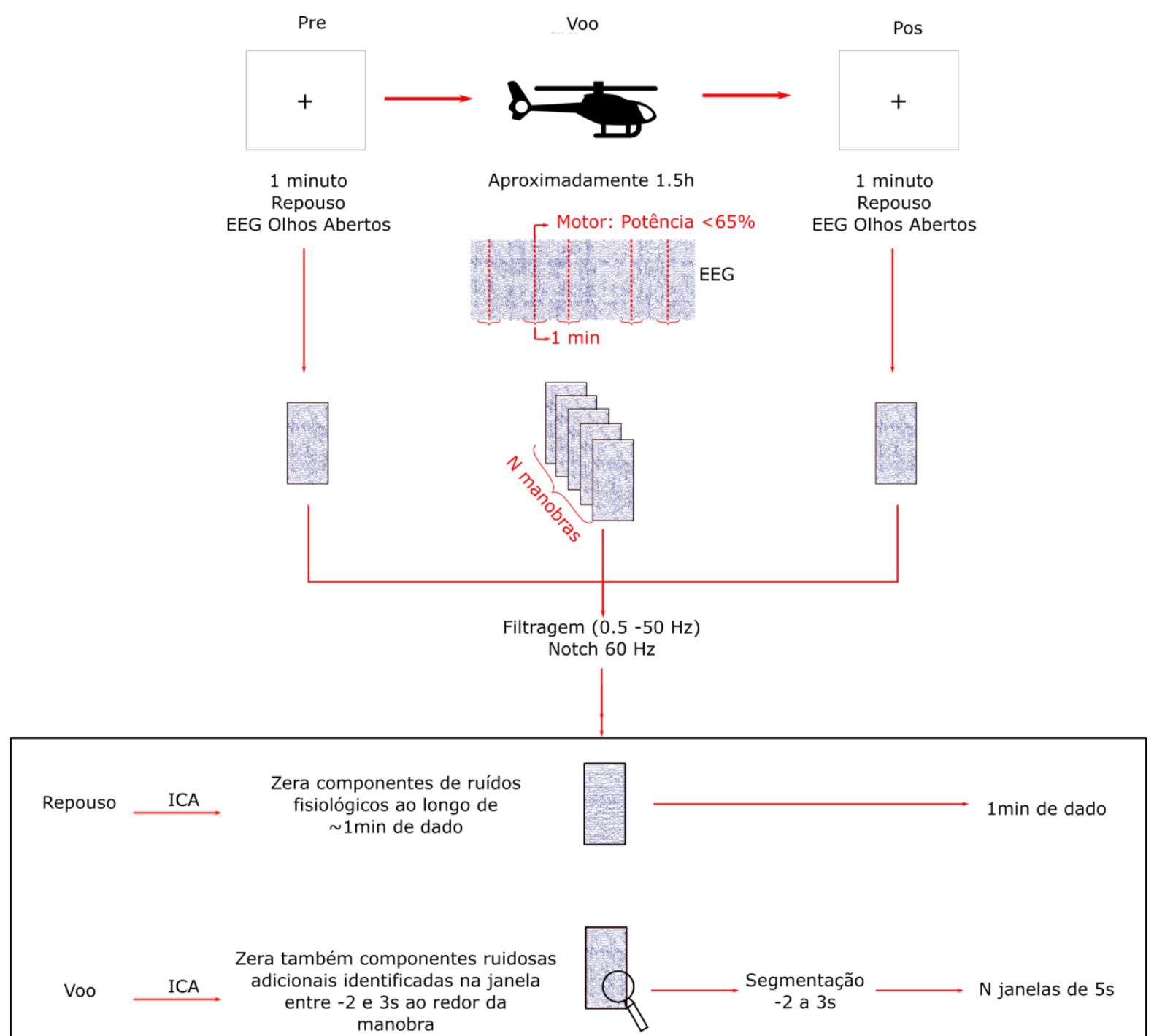

Enquanto os dados de repouso foram aproveitados em toda sua extensão, para os dados de voo utilizamos apenas uma janela ao redor da falha de motor, a fim de restringir o efeito de artefatos.

Figura 14. Desenho esquemático do pré-processamento dos dados de eletroencefalograma

\subsubsection{Análise de microestados}

Para a análise de microestados, utilizamos o plugin ${ }^{1}$ implementado por Thomas König versão 1.2. O plugin é compatível com o toolbox EEGlab, ${ }^{(91)}$ que é amplamente utilizado para a análise de EEG. Aqui utilizamos o EEGlab na versão 14.1.2. Nesta proposta, a pipeline para a análise de microestados é composta pelas seguintes etapas: i) identificação dos mapas topográficos a nível de um dataset individual; ii) confecção de mapas médios ao longo dos conjuntos de dados; iii) homogenização da sequência dos mapas ao longo dos datasets; iv) quantificação dos parâmetros dos microestados. Descreveremos a seguir a maneira como estas etapas

\footnotetext{
${ }^{1}$ Disponível em http://www.thomaskoenig.ch
} 
foram implementadas nesta tese.

Cabe ressaltar que métodos de clusterização tais como o K-means, utilizado neste trabalho, possuem resultados instáveis quando recebem uma pequena quantidade de dados para discriminar padrões. Assim, a fim de aumentar o poder do classificador na confecção dos templates dos mapas topográficos, desconsideramos as diferenças entre os voos e concatenamos os dados, conforme esquematizado na figura 15. Optamos por este algoritmo uma vez que ele é o mais utilizado na literatura para este tipo de análise. A seguir, estes dados concatenados retornam um template a nível de individuo de $N$ microestados. No entanto, cabe observar que a sequência dos mapas em cada indivíduo e sua correspondência é, a princípio, aleatória. A próxima etapa consiste na elaboração de um template médio, com $N$ mapas, mas a nível de grupo. A solução proposta pelo toolbox para buscar a máxima comunalidade entre os sujeitos é permutar as sequências individuais e buscar pela solução que maximiza a variância comum entre participantes. ${ }^{(92)}$ Dessa maneira, calculamos 3 conjuntos de templates médios, com $N$ mapas, correspondentes a cada um dos momentos analisados: Repouso antes do voo (RSpre), durante a execução da manobra (Flight) e no repouso após o voo (RSpos).

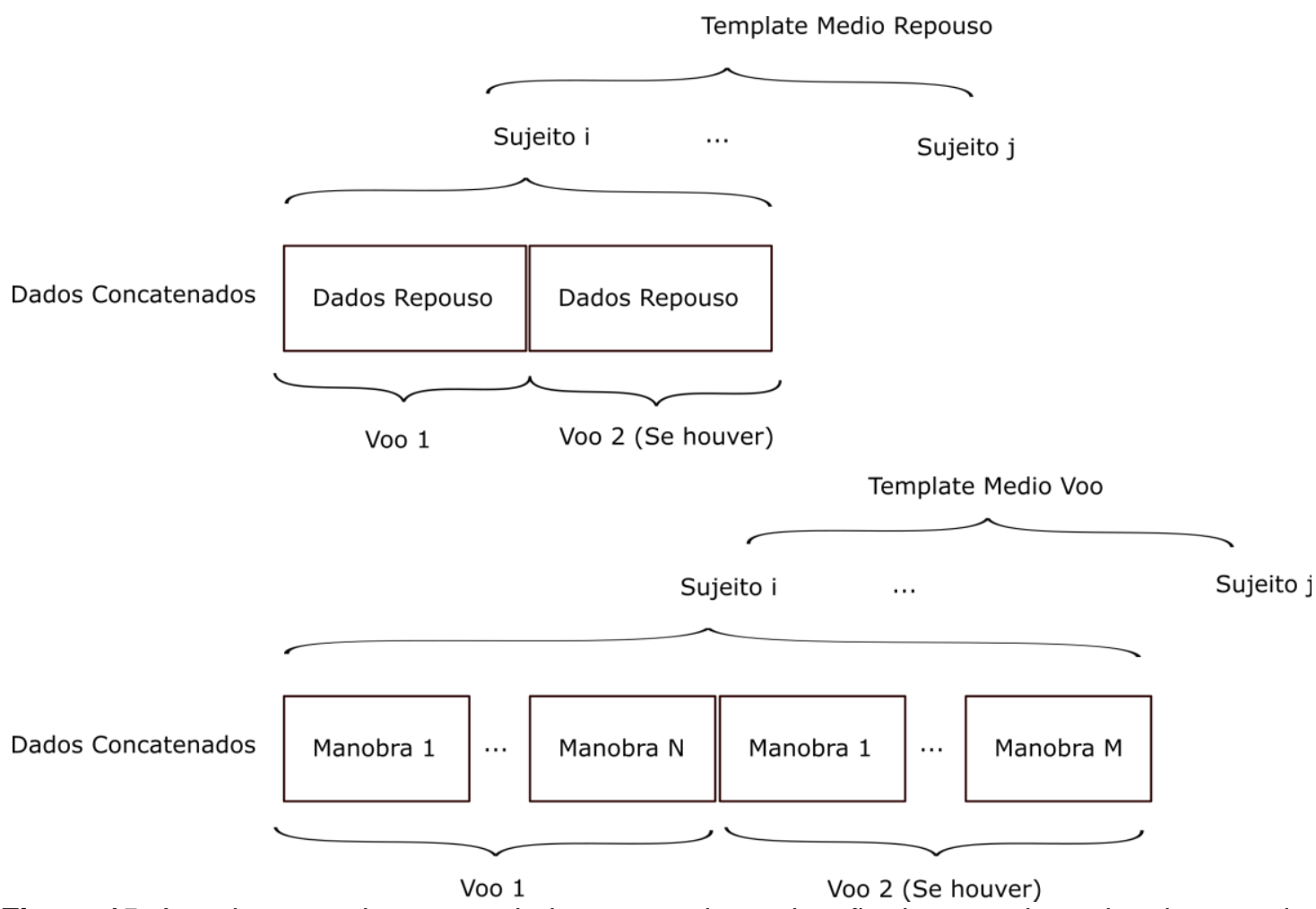

Figura 15. Arranjo montado com os dados para a determinação dos templates de microestados 
A seguir, estes três templates foram agrupados em um segundo nível, gerando uma "Grande Média". Esta sequência também é aleatória e, sua reordenação foi efetuada tendo por referência a normativa de Koenig et al.,(50) confeccionada com 496 indivíduos, entre 6 e 80 anos. A etapa final consiste em computar os parâmetros relativos à dinâmica dos microestados. O toolbox oferece a opção de escolha entre os conjuntos de templates, que podem utilizar o template a nível de indivíduo, ou seja, calculado exclusivamente a partir dos dados de um participante; a nível de grupo, considerando todos os participantes; e utilizando a referência normativa de Koenig et al. ${ }^{(50)}$ Nesta tese tomamos por base a "Grande Média", computada a partir da média da junção dos dados de nossos participantes em todas as condições experimentais (RSpre, Flight, RSpos). Os parâmetros dinâmicos foram computados com 4, 5 e com 6 classes de microestados, pois apresentam resultados interessantes.

Além dos parâmetros dinâmicos dos microestados (duração, ocorrência e cobertura), a toolbox também computa a proporção de transição entre classes distintas. No entanto, a proporção nominal é uma medida enviesada já que depende da ocorrência de cada classe, pois os microestados mais frequentes possuem mais transições. Assim, o autor propõe uma correção que consiste no cálculo do valor esperado para as transições tendo em vista apenas as ocorrências de cada classe. $O$ resultado final, a diferença entre as probabilidades de transição observada e esperada, é exibido num formato matricial $T(i, j)$, que representa o valor corrigido referente à transição do microestado $i$ para o microestado $j$.

\subsubsection{Microestados: análise estatística}

Neste experimento, nossos dados apresentam uma estrutura hierárquica, ou seja, as medidas repetidas estão sempre aninhadas para os participantes. Logo, para a análise estatística, precisamos considerar que existe uma dependência entre as observações efetuadas no mesmo indivíduo. Portanto, neste trabalho, modelamos os parâmetros da população como efeitos fixos e adicionamos efeitos aleatórios para ampliar nossa capacidade de inferência além desta amostra específica de sujeitos.

Assim, para a estatística deste trabalho, utilizamos um modelo de 
efeito misto, já que ele dá conta tanto de efeitos fixos quanto de efeitos aleatórios. Mais especificamente, optamos pelo uso de um modelo linear. A expressão pode ser verificada a seguir, descrita através da notação de Wilkinson et al.., ${ }^{(93)}$ onde MSparam corresponde ao valor do parâmetro do microestado, Condition está associado aos três momentos analisados (RSpre, Flight ou RSpos) e Subject é a ponderação associada aos participantes (Equação 2).

\section{MSparam $\sim 1+$ Condition $+(1 \mid$ Subject $)$}

Equação 2. Modelo linear de efeitos mistos

A análise foi efetuada com as funções da toolbox Statistics and Machine Learning do Matlab ${ }^{\circledR}$. A estimativa dos parâmetros do modelo foi efetuada a partir da máxima verossimilhança restrita (REML), a fim de evitarmos vieses de variância do modelo. A hipótese associada ao modelo, de uma distribuição normal de resíduos foi verificada através de um gráfico quantil-quantil e do teste de Shapiro-Wilk. Quando a distribuição de resíduos não era normal, nós inserimos um operador logaritmo na equação 2 .

\subsubsection{Análise de reconstrução de fontes}

Para a análise de reconstrução de fontes utilizamos o algoritmo sLORETA, a partir da implementação Key-LORETA de Roberto D. Pascual Marqui, versão $201906172^{2}$. Esta implementação utiliza o template MNI152 para a modelagem da cabeça ${ }^{(94)}$ e restringe o volume cerebral apenas às regiões de substância cinzenta, como preconizado pelo atlas probabilístico de Tailarach. ${ }^{\left({ }^{95)}\right.} \mathrm{O}$ volume é então dividido em 6239 voxels de $5 \mathrm{~mm}^{3}$. Para a resolução do problema direto, as coordenadas de cada eletrodo de EEG são associadas a uma coordenada no referencial de Tailarach e uma matriz de transformação para o sLORETA é computada. Finalmente, seguimos para a solução do problema inverso, que computa a distribuição cortical tridimensional das fontes.

Como descrito na seção anterior, as classes de microestados foram

\footnotetext{
${ }^{2}$ Disponível em http://www.uzh.ch/keyinst/loreta.htm
} 
inicialmente computadas a nível de participante (Figura 15) a partir dos mapas espaciais momentâneos, correspondentes a cada pico do GFP no EEG. O algoritmo de reconstrução de fontes foi então alimentado com as topografias referentes às classes de microestados a nível individual, em cada um dos três momentos de interesse (repouso antes e após o voo e durante a manobra - RSPre, Flight e RSPos).

\subsubsection{Reconstrução de fontes: análise estatística}

A próxima etapa consiste na análise estatística a partir dos mapas computados. Nosso objetivo foi evidenciar áreas com maior atividade no voo em contraste com o basal. Nós computamos um teste $t$ pareado, contrastando o resultado da manobra (Flight) com o de repouso (RSPre) para cada uma das classes de microestados. Utilizamos como controle o contraste entre as duas condições de repouso (RSPos - RSPRe). O dado foi normalizado a nível de sujeito. Para o tratamento de falsos positivos, utilizamos a feature de mapeamento estatístico não paramétrico, ou Statistical non-Parametric Mapping (SnPM) disponibilizada no programa para a correção dos valores-p. ${ }^{(96)}$ Em linhas gerais, a metodologia endereça o problema de múltiplas comparações através de uma randomização não paramétrica, preserva o máximo valor encontrado e o utiliza no caso multivariado. 


\section{RESULTADOS}

O objetivo deste trabalho é a caracterização da topografia e da dinâmica de microestados em um cenário ecológico. Assim, a primeira meta é demonstrar a robustez da análise, ainda que em um ambiente desafiador. Para isso, exibiremos não só as topografias dos microestados, mas um perfil do sinal de EEG e sua relação com os artefatos. Dando continuidade, demonstramos que os perfis topográficos obtidos neste trabalho são congruentes com alguns achados na literatura, assim como as áreas observadas a partir da reconstrução de fontes. Finalmente, na Seção 4 fazemos uma discussão destes achados, estabelecendo relações com outros trabalhos e as contribuições que eles representam.

\subsection{Análise de artefatos}

A primeira etapa do projeto envolveu uma análise de viabilidade do sinal no interior da aeronave. Existe uma série de desafios complementares na remoção de artefatos em um sinal de EEG coletado nestas condições: além de alguns artefatos característicos como suor e o movimento serem mais proeminentes, temos a presença complementar dos harmônicos correspondentes aos modos de vibração estrutural da aeronave, como pode ser observado na figura 16. Assim, como descrito na seção 2.3.1, para remoção de ruído, além de filtros, optamos por alterar a referência de todos os canais para o valor médio e aplicamos a ICA. O uso da referência média é particularmente interessante neste cenário, já que nos permite atenuar o efeito de componentes que atuem em todos os eletrodos, como os ruídos estruturais e de motor. Observe na figura 16 o efeito da alteração de referência no espectro do EEG e sua comparação com um dado do sujeito em repouso. 


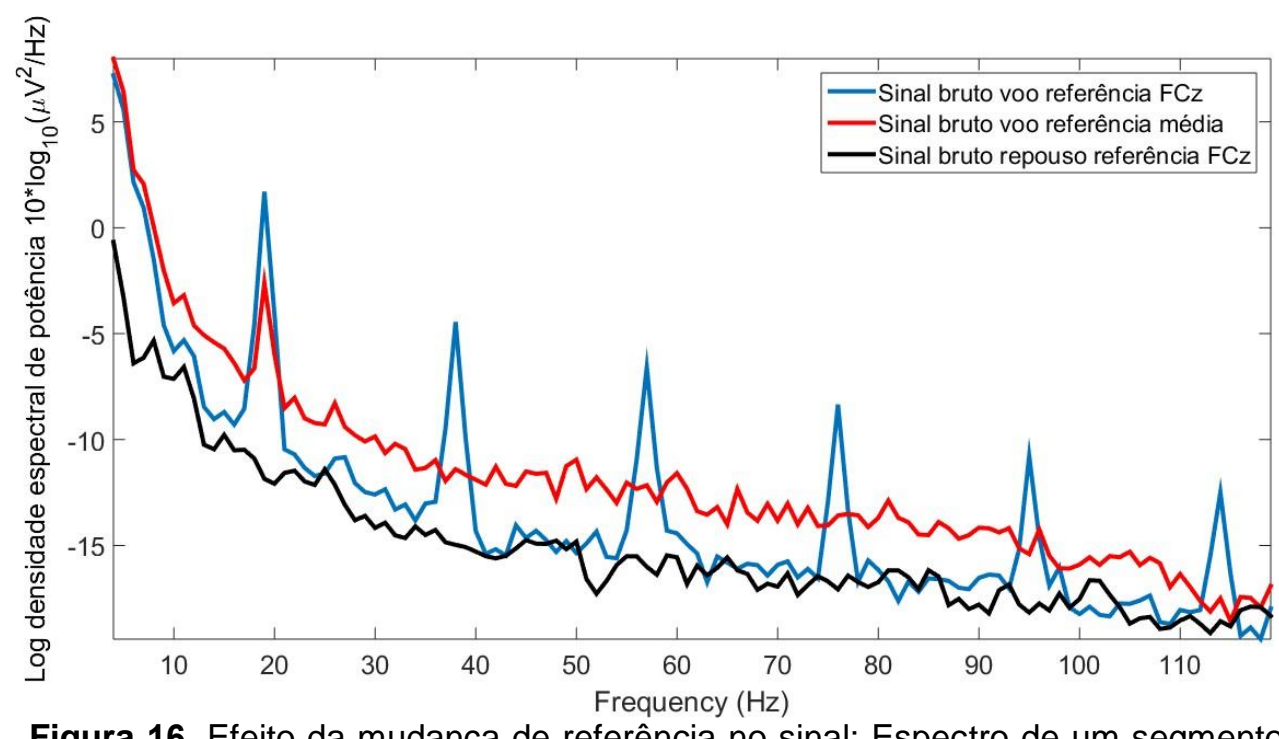

Figura 16. Efeito da mudança de referência no sinal: Espectro de um segmento do eletroencefalograma bruto do eletrodo $\mathrm{Cz}$ antes e durante o voo

Complementarmente, nossa estratégia envolveu segmentar o dado em uma janela de um minuto em torno da manobra e restringir a remoção de ICs apenas a artefatos ativos na janela de interesse, entre $-2-3 s$. Dessa maneira fazemos uma relação de compromisso entre preservar um segmento de dado grande o suficiente para caracterizar o processo cognitivo de tomada de decisão, mas evitamos descartar uma quantidade muito grande de ICs, o que poderia prejudicar a qualidade do sinal resultante. Um exemplo de componente ruidosa foi apresentado na figura 13. A tabela 3 mostra um apanhado geral para os voos: quantos canais foram excluídos da análise, de quantas manobras foi possível recuperar o sinal de EEG para cada participante e qual o número de ICs zeradas nas execuções das manobras. Por esta tabela é possível verificar que nossa estratégia semi-automática de tratamento de artefatos permitiu a que $\sim 95 \%$ das manobras registradas (219/232) seguissem para as etapas posteriores de análise, ainda que com uma dimensionalidade reduzida (no pior cenário a redução de dimensionalidade foi de 32 para 23). O principal fator responsável pela completa exclusão dos dados de uma manobra foi a presença de artefatos de movimento que não puderam ser filtrados. Além disso, outros fatores que impactaram o número total de registros foram as falhas nos sensores fisiológicos (1 voo), e as falhas na aeronave que requisitaram uma interrupção prematura do plano de voo ou prejudicaram o cronograma inicial do projeto, tais como danos estruturais e fogo na bateria. 
Tabela 3. Panorama geral do experimento com relação aos dados de eletroencefalograma

\begin{tabular}{|c|c|c|c|c|c|c|c|c|}
\hline \multicolumn{5}{|c|}{ Flight } & \multicolumn{2}{|c|}{ RSPre } & \multicolumn{2}{|c|}{ RSPos } \\
\hline ID & Voos & $\begin{array}{l}\text { Número de manobras } \\
\text { com EEG válido } \\
\text { (Voo1/Voo2) }\end{array}$ & $\begin{array}{l}\text { Júmero de canais } \\
\text { excluídos } \\
\text { (0Ch,1Ch,2Ch) }\end{array}$ & $\begin{array}{c}\text { Número de IC excluídas } \\
(1 \mathrm{IC}, 2 \mathrm{IC}, 3 \mathrm{IC}, 4 \mathrm{IC}, 5 \mathrm{IC}, 6 \mathrm{IC}, 7 \mathrm{IC}, 8 \mathrm{IC})\end{array}$ & $\begin{array}{l}\text { Número de } \\
\text { canais } \\
\text { excluídos }\end{array}$ & $\begin{array}{l}\text { Número de IC } \\
\text { excluídas }\end{array}$ & $\begin{array}{l}\text { Número de } \\
\text { canais } \\
\text { excluídos }\end{array}$ & $\begin{array}{l}\text { Número de } \\
\text { IC } \\
\text { excluídas }\end{array}$ \\
\hline Sub1 & 2 & $18 / 7$ & $(18,0,0) /(7,0,0)$ & $(0,6,8,3,1,0,0,0) /(0,0,3,2,0,2,0,0)$ & $0 / 0$ & $0 / 1$ & $0 / 0$ & $4 / 1$ \\
\hline Sub2 & 1 & $-/ 13$ & $-/(13,0,0)$ & $-/(0,0,0,0,6,6,1,0)$ & $-/ 0$ & $-/ 7$ & $-/ 0$ & $-/ 4$ \\
\hline Sub3 & 2 & $14 / 9$ & $(14,0,0) /(0,7,2)$ & $(0,0,0,3,4,5,1,1) /(0,0,0,0,0,5,3,1)$ & $0 / 1$ & $4 / 3$ & $0 / 1$ & $5 / 7$ \\
\hline Sub4 & 2 & $14 / 10$ & $(14,0,0) /(10,0,0)$ & $(0,0,0,1,3,6,2,2) /(0,2,5,2,0,1,0,0)$ & $0 / 0$ & $3 / 1$ & $0 / 0$ & $2 / 2$ \\
\hline Sub5 & 2 & $8 / 4$ & $(8,0,0) /(4,0,0)$ & $(0,0,3,3,2,0,0,0) /(0,1,0,3,0,0,0,0)$ & $0 / 0$ & $2 / 2$ & $0 / 0$ & $4 / 1$ \\
\hline Sub6 & 1 & $-/ 23$ & $-/(15,8,0)$ & $-/(0,0,0,1,4,10,7,1)$ & $-/ 0$ & $-/ 4$ & $-/ 0$ & $-/ 5$ \\
\hline Sub7 & 2 & $13 / 6$ & $(13,0,0) /(3,3,0)$ & $(0,0,0,2,7,4,0,0) /(0,0,0,0,2,3,1,0)$ & $0 / 0$ & $7 / 7$ & $0 / 0$ & $9 / 8$ \\
\hline Sub8 & 2 & 10/11 & $(9,1,0) /(4,7,0)$ & $(0,0,4,4,2,0,0,0) /(0,2,1,4,3,1,0,0)$ & $0 / 0$ & $6 / 4$ & $0 / 0$ & $4 / 3$ \\
\hline Sub9 & 2 & $11 / 9$ & $(11,0,0) /(7,2,0)$ & $(0,3,2,2,3,1,0,0) /(0,1,2,3,3,0,0,0)$ & $0 / 0$ & $1 / 3$ & $0 / 0$ & $3 / 2$ \\
\hline Sub10 & 2 & $3 / 12$ & $(3,0,0) /(12,0,0)$ & $(1,0,1,0,1,0,0,0) /(0,3,2,3,2,2,0,0)$ & $0 / 0$ & $1 / 2$ & $0 / 0$ & $2 / 1$ \\
\hline Sub11 & 2 & $12 / 12$ & $(12,0,0) /(12,0,0)$ & $(0,0,4,5,2,0,1,0) /(0,0,1,4,4,3,0,0)$ & $0 / 0$ & $2 / 3$ & $0 / 0$ & $2 / 2$ \\
\hline
\end{tabular}


Finalmente, uma última evidência que ressalta o sucesso da estratégia de remoção de artefatos emerge dos resultados da própria análise de microestados. É possível verificar que as topografias características de microestados obtidos com vários números de classes são congruentes com alguns trabalhos, como evidenciado a seguir.

\subsection{Análise de microestados}

Após o pré-processamento, seguimos a pipeline de análise de microestados, computando o template de microestados correspondente a cada uma das três condições (RSpre, Flight, RSpos), além do template correspondente à "Grande Média”. É possível observar que as topografias preservam uma similaridade entre si para diferentes números de classes, mesmo que em diferentes condições e que estes resultados apresentam semelhanças com a literatura, como demonstrado a seguir.

\subsubsection{Quatro classes}

Apesar de as quatro classes encontradas neste trabalho diferirem das topografias canônicas, observamos que elas são bastante similares às reportadas por Pedroni et al. ${ }^{(54)}$ em um estudo que avalia a atividade espontânea do cérebro antecedendo a tomada de decisão em uma tarefa de gerenciamento de risco. $O$ resultado pode ser observado na figura 17.

Com relação à dinâmica dos microestados, mensuramos a duração, a ocorrência e a cobertura e a matriz de transição das quatro classes, como verificado na figura 18. Ressaltamos que a visualização com o erro padrão da média foi utilizada para dar uma ideia do comportamento dos dados e, para isso, computamos as médias com os valores de uma mesma condição para um mesmo sujeito. Para a estatística, no entanto, utilizamos o modelo linear de efeitos mistos, descrito na seção 2.3.2.1. Nossos resultados sugerem uma modulação diferenciada das classes 3 e 4 no voo em relação ao repouso: Todos os parâmetros (duração, ocorrência e contribuição) referentes à classe 3 apresentam uma queda significativa, enquanto os da classe 4, uma subida. Além disso, observamos uma mudança no perfil das transições do voo em relação aos 
dados em repouso: há uma maior probabilidade das classes transicionarem para 0 microestado 4; uma queda na probabilidade das classes 1 e 2 transicionarem para a classe 3 , e das classes 3 e 4 para a classe 1 .

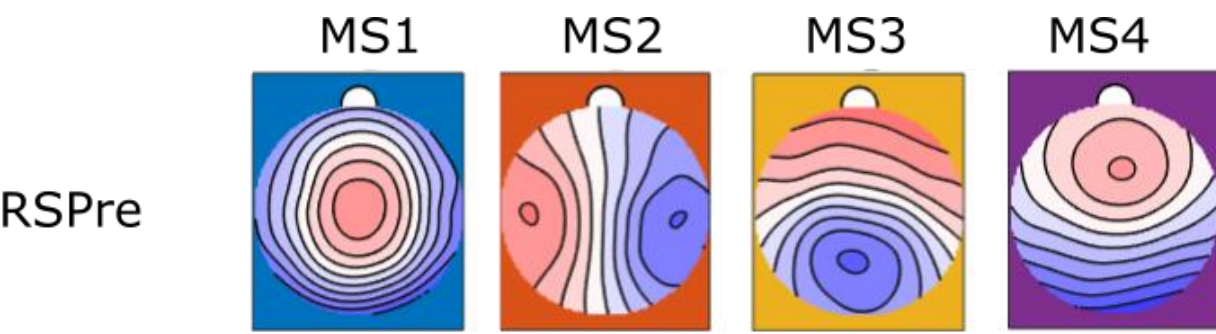

Flight
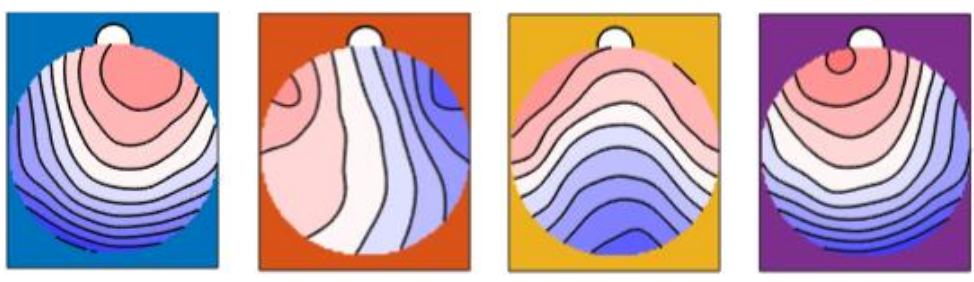

RSPos
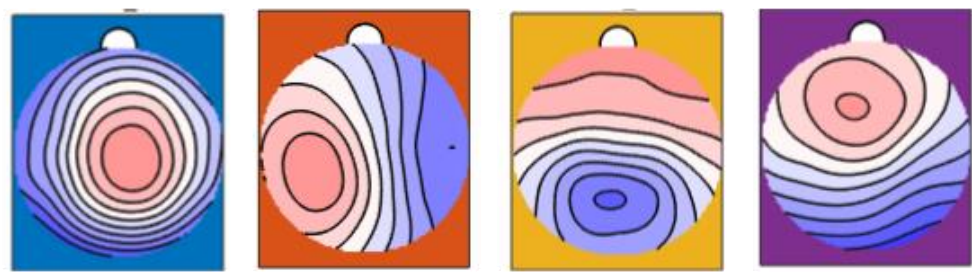

\section{GrandMean}
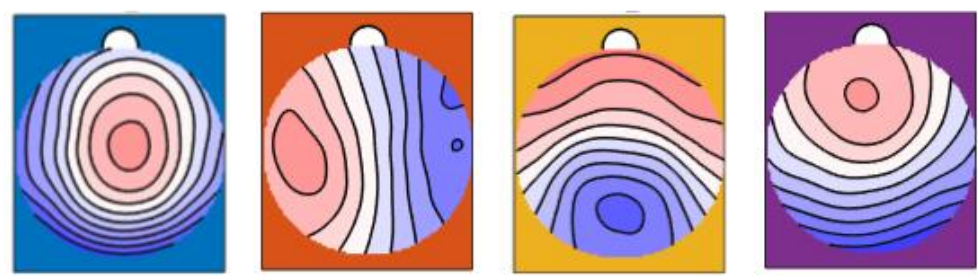

\section{Pedroni et} al. 2017
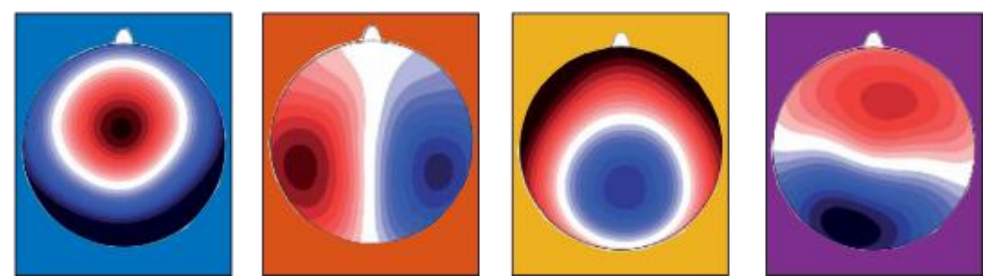

Fonte: Adaptado de Pedroni A, Gianotti LR, Koenig T, Lehmann D, Faber P, Knoch D. Temporal Characteristics of EEG Microstates Mediate Trial-by-Trial Risk Taking. Brain Topogr. 2017;30(1):149-59. ${ }^{(54)}$ Reproduzido com autorização da Springer Nature.

Figura 17. Topografia média dos microestados para 4 classes 

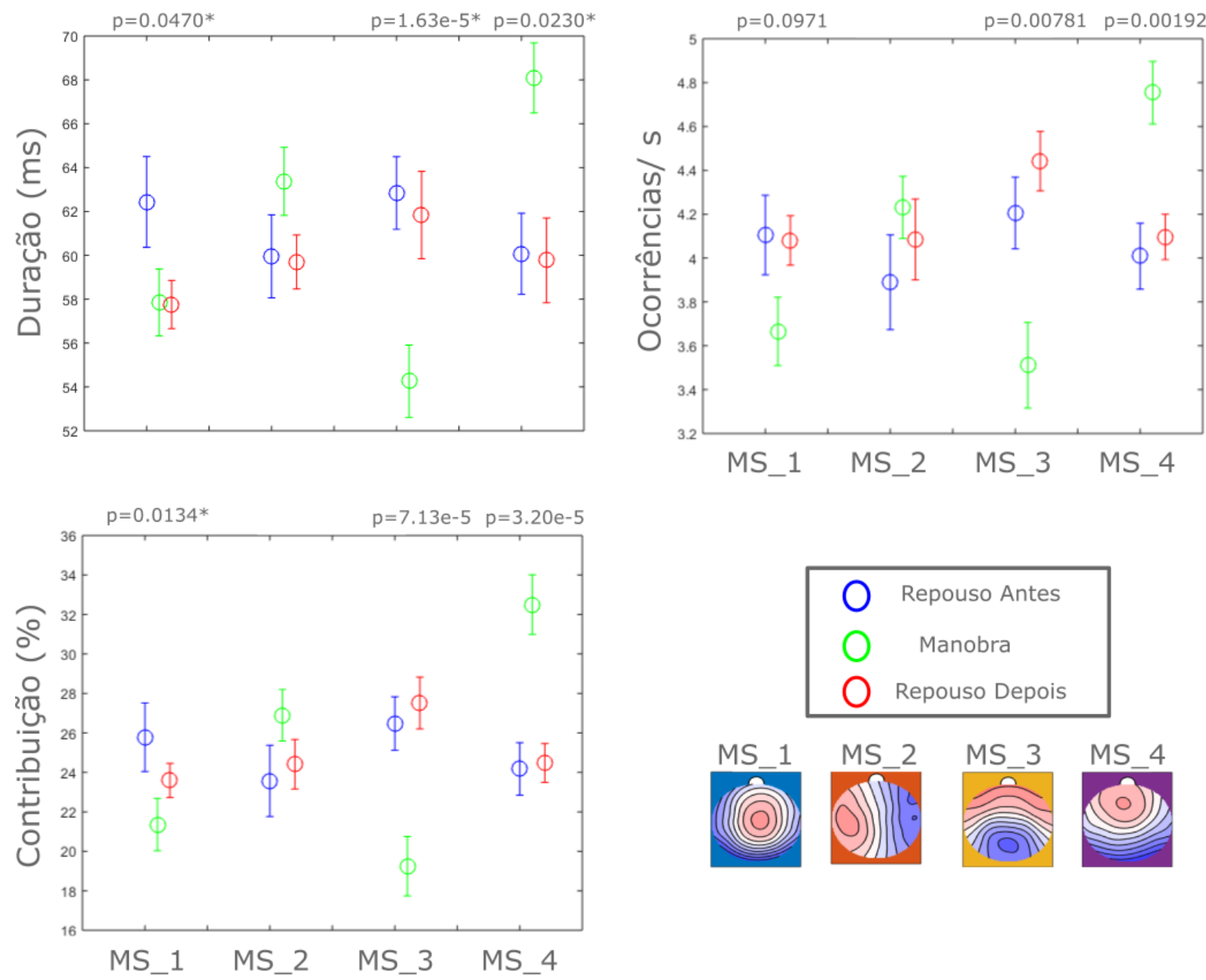

Matriz de transição
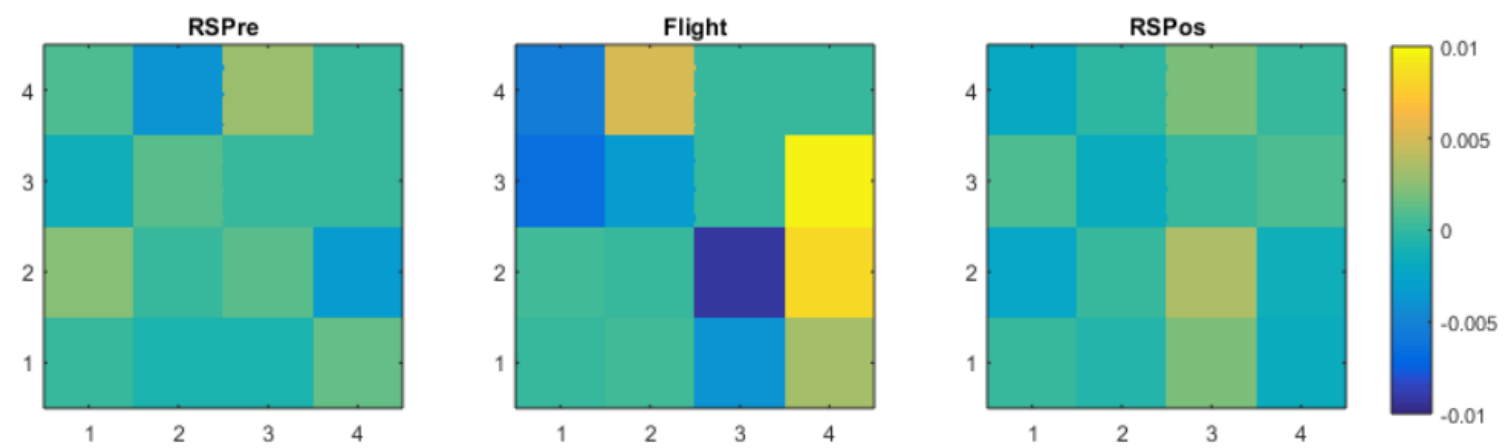

A demarcação com um $\left(^{*}\right)$ indica que o modelo linear misto teve a hipótese de normalidade de resíduos violada e, portanto, a estatística foi refeita com o operador logarítmico.

Figura 18. Dinâmica dos microestados correspondentes a 4 classes

\subsubsection{Cinco classes}

Efetuamos também uma análise com 5 classes, devido à similaridade de nosso resultado com o de Koenig et al., ${ }^{(50)}$ cujos templates foram calculados a partir de dados de 496 sujeitos em diferentes faixas etárias. Assim como 
com 4 classes, as topografias das 5 classes preservaram uma grande similaridade entre si nas três condições (RSpre, Flight, RSpos), que refletiu na forma do template correspondente à "Grande Média", como pode ser observado na figura 19.

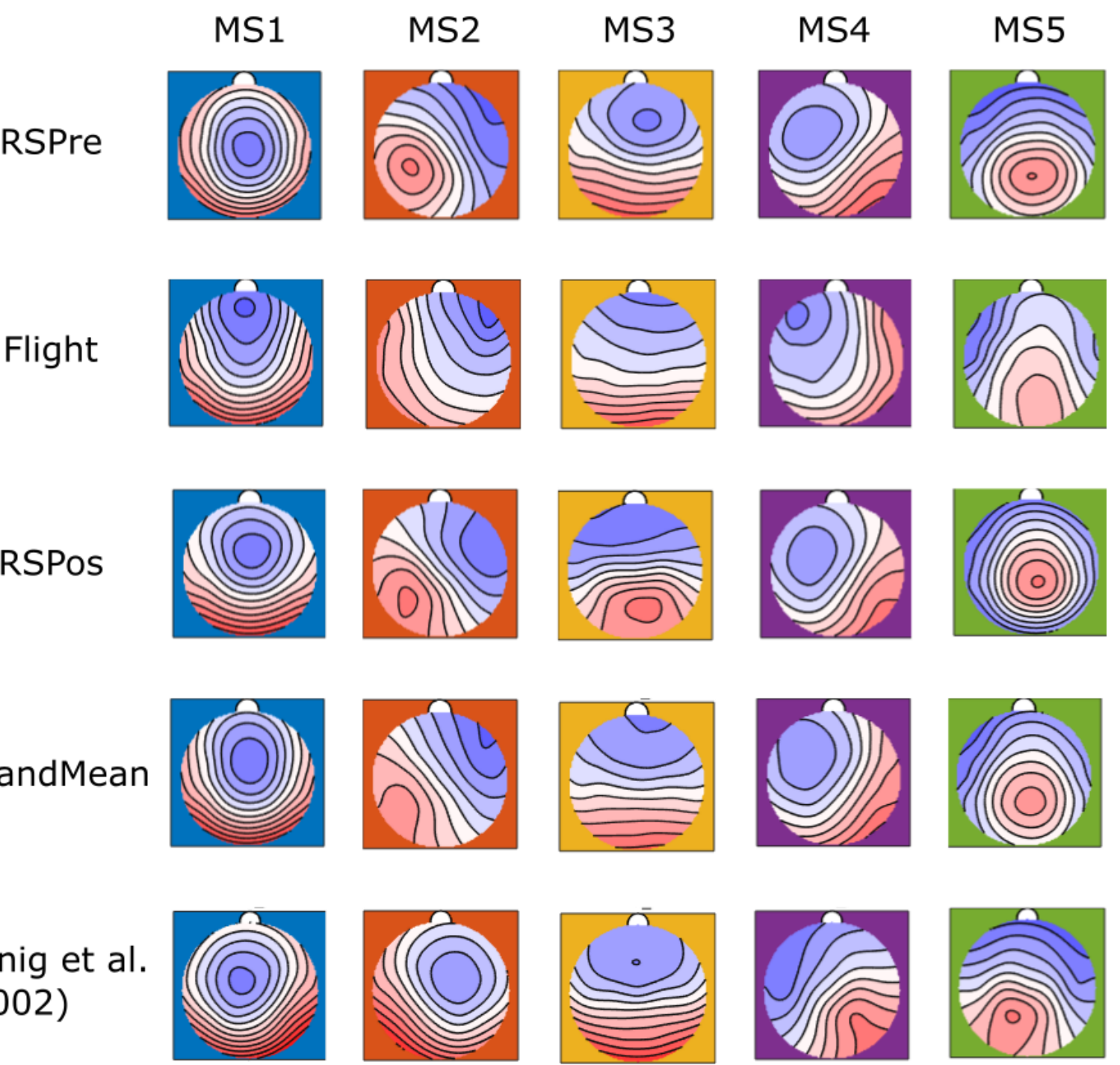

Figura 19. Topografia média dos microestados para 5 classes

A inclusão de mais uma classe representou uma alteração na dinâmica com relação à consideração de 4 classes (Figura 20). Agora observamos que apenas a classe 5 apresenta uma queda significativa em todos os parâmetros (Duração, ocorrência e contribuição) quando comparamos os dados em voo com os obtidos em repouso (antes e após o voo). É interessante notar também que, neste caso, o microestado 5 apresenta uma topografia muito similar ao microestado $\mathrm{D}$ de Seitzman et al. ${ }^{(65)}$ Porém, em oposição ao achado destes autores, que reportaram um 
aumento nos parâmetros dinâmicos do microestado $D$ em uma tarefa de atenção, nossos resultados apontam para uma diminuição. Finalmente, a matriz de transições deixa de apresentar um padrão característico global, que distingue o voo dos estados de repouso. Porém, os maiores valores de probabilidade ocorrem durante a manobra, mas de uma maneira não tão demarcada.
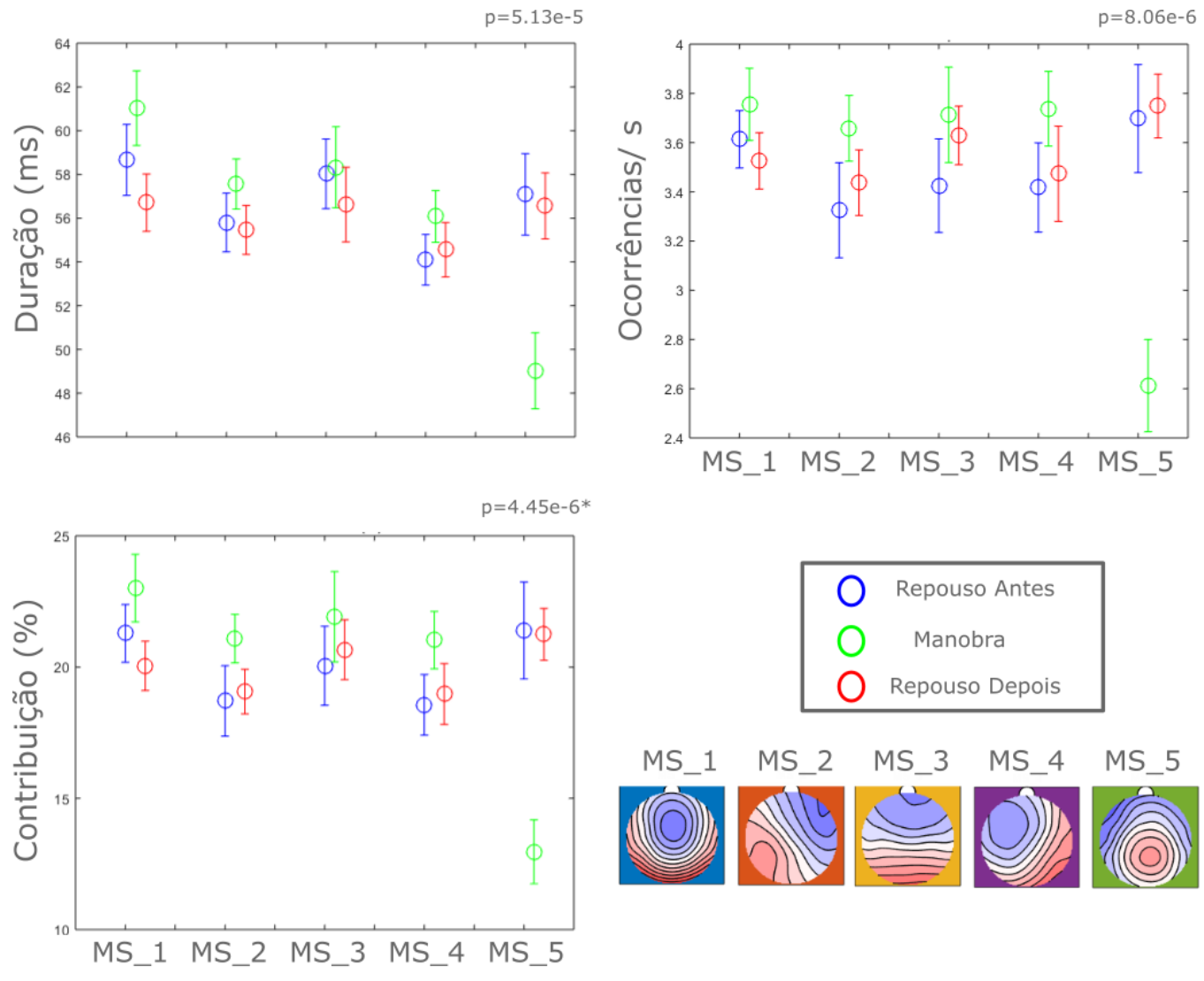

Matriz de transição
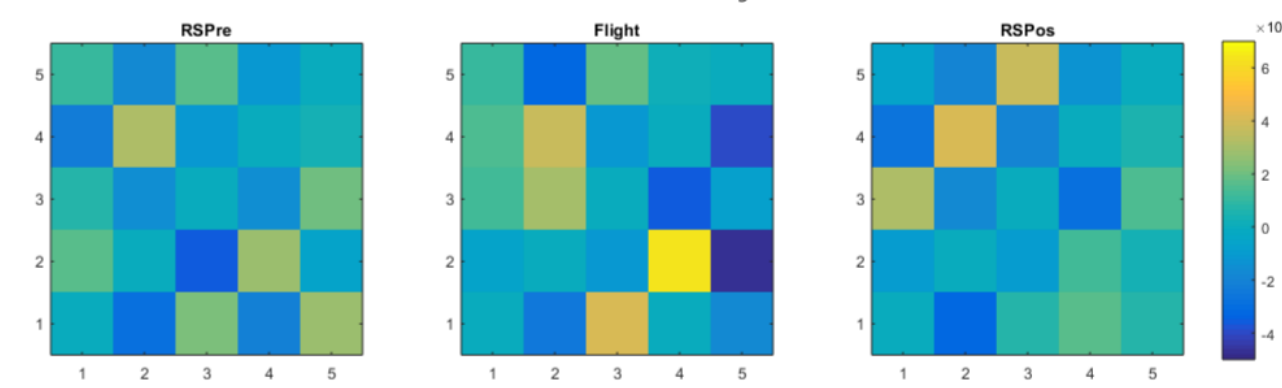

A demarcação com um $\left({ }^{*}\right)$ indica que 0 modelo linear misto teve a hipótese de normalidade de resíduos violada e, portanto, a estatística foi refeita com o operador logarítmico

Figura 20. Dinâmica dos microestados correspondentes a 5 classes 


\subsubsection{Seis classes}

A seguir, efetuamos uma análise com 6 classes, devido à semelhança não só com a referência normativa de Koenig et al., ${ }^{(50)}$ mas também à semelhança com os padrões de Bréchet et al., ${ }^{(75)}$ que avaliou as modulações de um mesmo grupo de participantes em três condições distintas: repouso, evocação de uma memória pessoal e subtração mental. Assim como observado anteriormente para 4 e 5 classes e em concordância com o resultado de Bréchet et al., ${ }^{(75)}$ notamos a preservação da semelhança topográfica das diferentes classes de microestados nas três condições, como pode ser observado na figura 21.

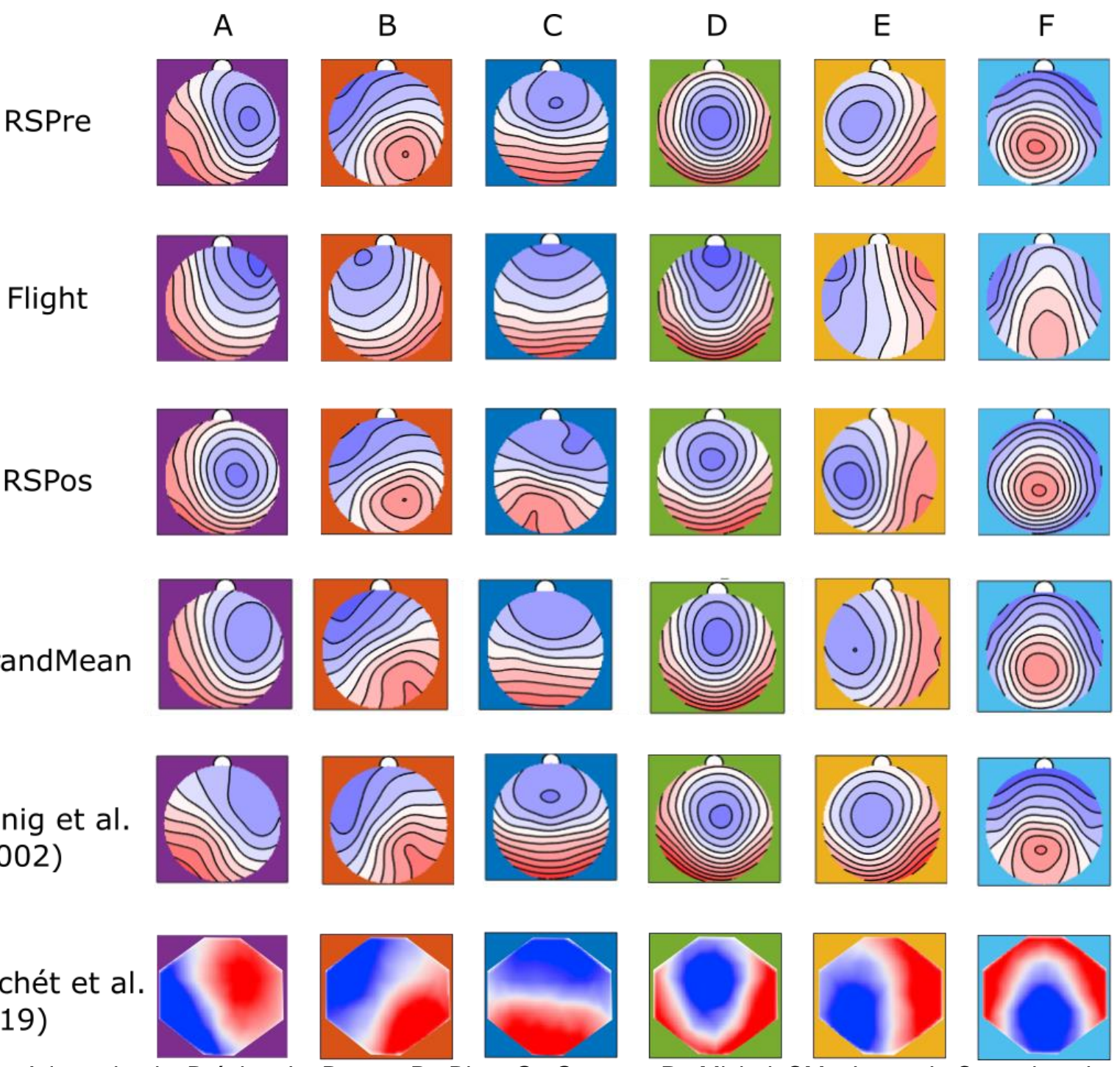

Brechét et al. (2019)

Fonte: Adaptado de Bréchet L, Brunet D, Birot G, Gruetter R, Michel CM, Jorge J. Capturing the spatiotemporal dynamics of self-generated, task-initiated thoughts with EEG and fMRI. Neuroimage. 2019;194(February):82-92. ${ }^{(75)}$ Reproduzido com autorização da Elsevier.

Figura 21. Topografia média dos microestados para 6 classes 
Desta vez, foi possível observar que a inserção da sexta classe de microestados preservou o padrão dinâmico observado no resultado com 5 classes (Figura 22): Aqui, a queda dos parâmetros dinâmicos em relação ao repouso também é marcante para o sexto microestado, cuja topografia se assemelha ao do quinto microestado quando consideramos um total de 5 classes (Figura 20). Além da já mencionada semelhança topográfica ao microestado $D$ de Seitzman et al., ${ }^{(65)}$ também é marcante que esta classe se assemelha à topografia F de Custo et al. ${ }^{(66)}$ (Figura 7) e de Bréchet et al. ${ }^{(75)}$ No entanto, observamos que a modulação encontrada em nosso trabalho - na sexta classe- difere do aumento nos parâmetros da quarta classe (microestado D) reportado tanto por Bréchet et al. ${ }^{(75)}$ quanto por Seitzman et al. ${ }^{(65)}$ em ambientes controlados. Novamente observamos que a matriz de transições não apresenta um padrão característico global. 

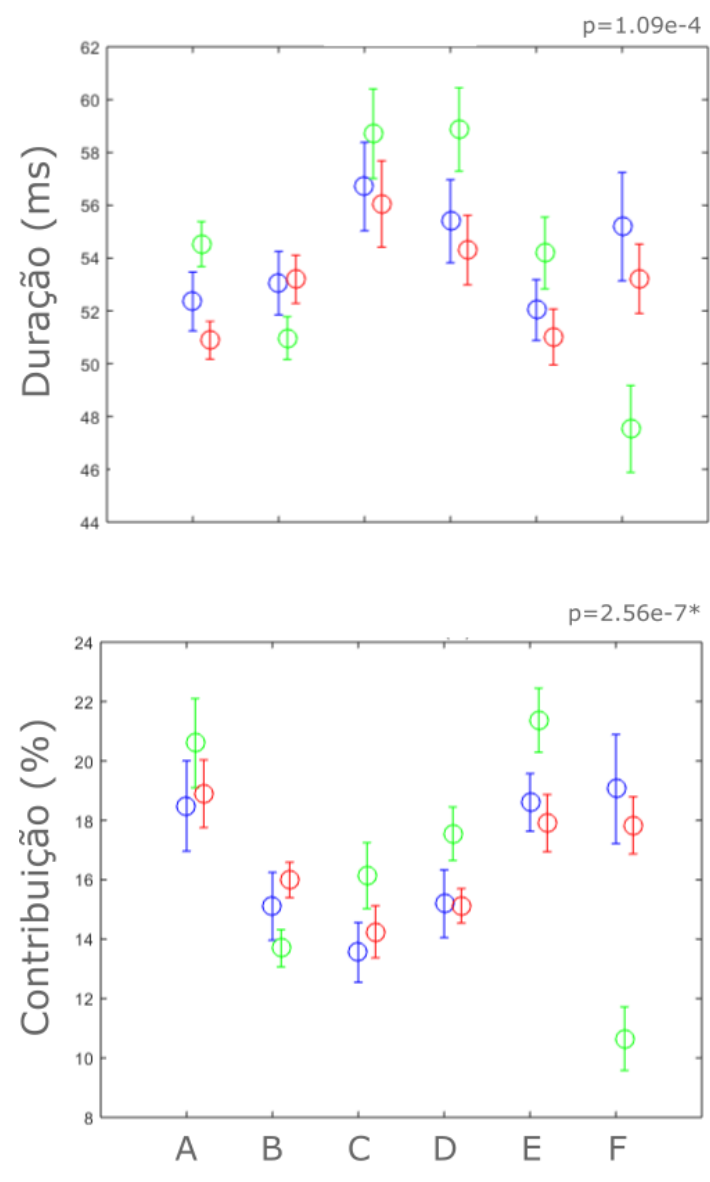

Matriz de transição
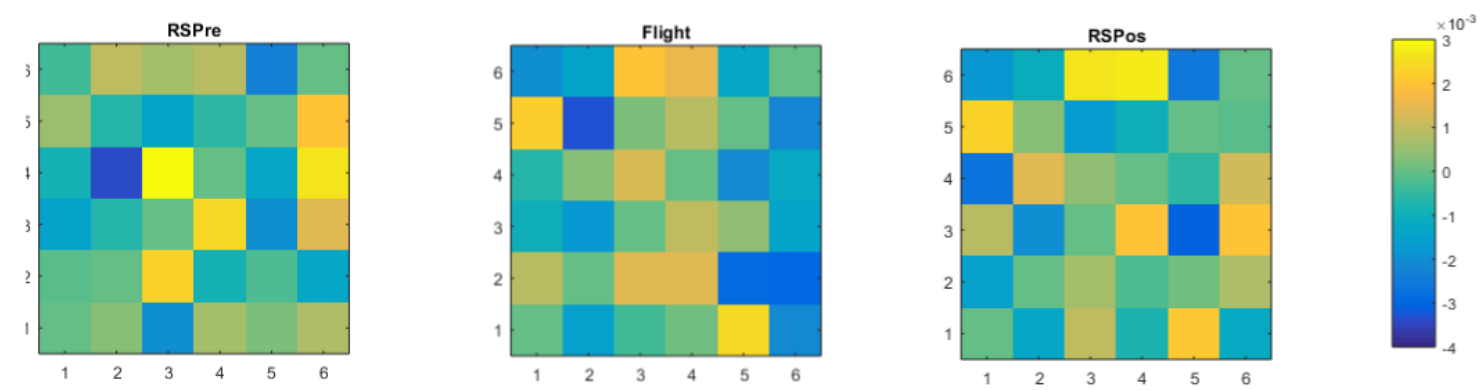

A demarcação com um (*) indica que o modelo linear misto teve a hipótese de normalidade de resíduos violada e, portanto, a estatística foi refeita com o operador logarítmico.

Figura 22. Dinâmica dos microestados correspondentes a 6 classes

\subsection{Análise de reconstrução de fontes}

Finalmente, encerramos as análises com a reconstrução de fontes visando comparar a atividade entre o repouso e o voo nas classes de microestados que apresentaram modulação nos parâmetros dinâmicos. Direcionamos nossa análise ao resultado obtido com 6 classes, uma vez que a quinta topografia no resultado com 5 classes apresenta modulação e formato semelhantes à topografia $F$, observada no 
caso de 6 classes. Além disso, para as 6 classes nossas topografias se assemelham às reportadas por Bréchet et al., ${ }^{(75)}$ e este trabalho é interessante pois além de realizar uma série de atividades cognitivas, também fornece uma reconstrução de fontes que utilizaremos para fins de comparação (Figura 8).

O sLORETA foi aplicado à primeira componente principal dos mapas momentâneos de EEG nos picos de GFP, de cada participante. O resultado foi aplicado à classe $F$ no contraste RSPre-Flight, corrigido para múltiplas comparações e evidenciou um cluster no córtex pré-frontal esquerdo $(t(10)>5.482, p<0,05)$ (Figura 23), englobando regiões nas áreas de Broadmann 11 e 47, com o pico $(X, Y, Z)$ nas coordenadas MNI correspondente a $(-30,30,-10)$.

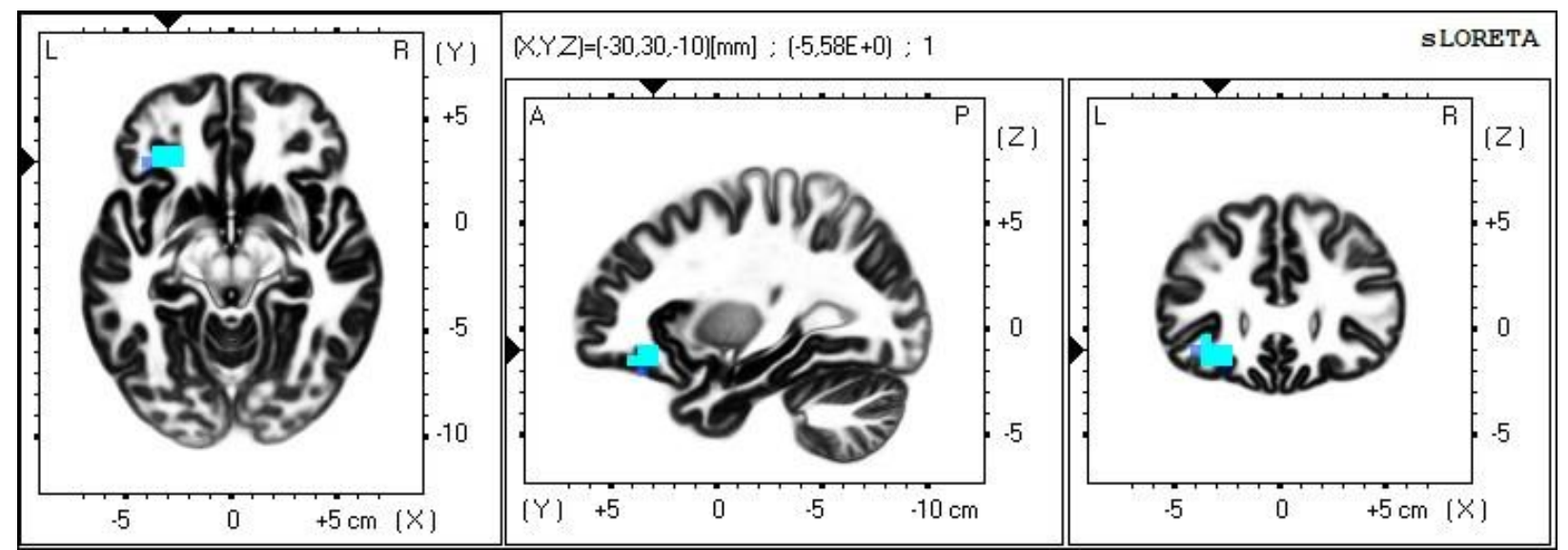

Contraste RSPre-Flight na sexta topografia após a aplicação do teste t pareado $(p<0,05)$. Um cluster foi determinado no córtex pré-frontal esquerdo, em azul, correspondendo a uma maior atividade em voo em relação ao repouso.

Figura 23. Localização das fontes utilizando o sLORETA 


\section{DISCUSSÃO}

A relevância de mais estudos com indivíduos em ambientes dinâmicos e complexos está na compreensão da relação entre o processo de tomada de decisão e a performance. Neste contexto, destacamos o entendimento das estratégias cognitivas em curso a cada momento, como é construído um modelo de CS e, principalmente, como estas informações podem ser empregadas para o design de equipamentos e procedimentos mais seguros e confiáveis. ${ }^{(3)}$ Neste trabalho exploramos a eletrofisiologia da tomada de decisão em um ambiente desta categoria, contrastando uma situação ecológica com o repouso. Para tanto, coletamos o EEG de um grupo de pilotos de helicóptero altamente especializados nas seguintes condições: i) repouso imediatamente antes do voo; ii) durante a execução de manobras de recuperação de falha de motor; iii) repouso imediatamente após o voo. A seguir, comparamos os parâmetros de microestados referentes a cada uma das três condições e efetuamos uma reconstrução de fontes. Os resultados apresentados nesta tese são, até onde pudemos verificar, inéditos na literatura, uma vez que estudos ecológicos com o EEG são escassos. Nossos resultados demonstram a robustez da análise de microestados em um ambiente intrinsecamente ruidoso, fortalecem a utilização destes neurocorrelatos e expandem o horizonte de aplicação da técnica para o estudo da cognição em condições mais realísticas. Nesta seção discutimos em mais detalhes os principais achados deste trabalho.

\subsection{Microestados são neurocorrelatos robustos, mesmo em situações extremas}

Um dos grandes desafios no tratamento de dados de EEG em um ambiente dinâmico e complexo advém da elevada susceptibilidade da técnica a artefatos. ${ }^{(30)}$ Mesmo assim, já existe um conjunto razoável de trabalhos demonstrando que estratégias de processamento e filtragem produzem um sinal viável mesmo em cenários desafiadores, sendo o principal exemplo a aquisição simultânea de EEG e RMf. ${ }^{(97)}$ Neste trabalho complementamos este conjunto de evidências, ao demonstramos a viabilidade de sinais de EEG para a análise de microestados em um cenário ecológico. Ressaltamos, no entanto, que nem todo o dado pode ser 
recuperado: muitos trechos estavam contaminados por artefatos sem uma assinatura espectral característica, o que inviabilizou sua remoção e, consequentemente, restringiu nossa análise a janelas menores. Artefatos de movimento foram os mais comuns devido à própria natureza da atividade de pilotagem, que requer uma comunicação constante entre a tripulação e com a torre de comando. Escolhemos a ICA como estratégia de remoção de artefatos devido a sua larga utilização em etapas de pré-processamento de sinais. ${ }^{(91,97,98)}$ inclusive em pipelines de microestados, ${ }^{(13)}$ além de sua eficácia em apontar fontes independentes de ruído, ${ }^{(32)}$ como exemplificado na figura 13. Apesar de nosso ambiente ser intrinsecamente ruidoso nos obrigando a zerar um maior número de ICs (Tabela 3), já foi descrito na literatura que a análise de microestados se mostra robusta a variações no número de eletrodos utilizados na coleta, ${ }^{(63)}$ o que nos fez supor que também permaneceria robusta a uma redução de dimensionalidade no sinal de entrada, já que retirar uma componente independente reduz a dimensionalidade do conjunto de dados tal como a retirada de um canal.

Além disso, a análise de microestados possui como premissa que cada classe/topografia característica é um correlato da atividade simultânea de um conjunto de redes no cérebro, que interagem funcionalmente por um intervalo de tempo. ${ }^{(50)}$ Esta premissa motiva a aplicação de algoritmos de clusterização no cálculo das topografias características, seguidas pela classificação do dado a posteriori. Portanto, é interessante observar que a análise de microestado já inclui em sua essência uma etapa que a torna inerentemente mais robusta a ruídos externos, pois a atribuição de cada instante de tempo a uma das classes pré-definidas já desconsidera as variações momentâneas em favor de um padrão globalmente observável.

Nossos resultados indicam que a abordagem de remoção de artefatos deste trabalho foi bem sucedida, pois as topografias obtidas em voo (Figuras 17, 19 e 21) se assemelham às caracterizadas para os mesmos participantes em repouso em dois momentos distintos, além de apontarem congruência com outros relatos na literatura. ${ }^{(50,54,65,66,75)}$ Além disso, nossos resultados sugerem que os microestados são neuro correlatos robustos, já que eles são recuperados mesmo na realização de uma tarefa de alta complexidade em um ambiente hostil. Finalmente, ressaltamos que não existe uma estratégia única para a remoção de artefatos, mas é importante que exista uma preocupação com a validação desta etapa especialmente quando empregamos um novo método ou operamos em condições experimentais não 
usuais, pois o sinal de EEG é repleto de particularidades e não-linearidades. ${ }^{(12)}$ Além disso, sempre que possível, é recomendável a adoção de guidelines e pipelines préestabelecidas para o tratamento do sinal já que isto maximiza a possibilidade de comparação de novos trabalhos com resultados já publicados.

\subsection{A modulação dos microestados num cenário ecológico: concordâncias e discordâncias com condições controladas}

Ainda não conseguimos identificar uma estrutura neurológica que atue como integradora das diferentes modalidades de informação, no papel de agrupálas e dar origem a nossas percepções e consciência. Este paradoxo, conhecido como binding problem na literatura em inglês, fortalece teorias de que o processamento das informações é efetuado em paralelo por uma série de redes neuronais distribuídas. Compreender a sinergia destas redes torna-se relevante no estudo da estrutura temporal do processo cognitivo, que, por sua vez, é um atributo chave nos processos de percepção, motor, aprendizado e no processamento de informações. ${ }^{(70,71,99,100)}$ Neste sentido, há um conjunto crescente de evidências que apontam que processos de sincronização e acoplamento entre oscilações na atividade elétrica atuam como mecanismos para a coordenação temporal e integração da informação no cérebro. ${ }^{(6,20,101-103)}$ Assim, diversas redes funcionais estão associadas a diferentes tarefas comportamentais e a padrões distintos de sincronização entre regiões cerebrais funcionalmente especializadas.

Neste trabalho exploramos a sinergia entre redes funcionais durante o processo de tomada de decisão por meio da modulação dos parâmetros dinâmicos dos microestados. O uso deste tipo de análise em tarefas cognitivas e o estabelecimento de relações com conteúdos mentais ainda é um campo recente na literatura e nosso objetivo é expandir os horizontes de aplicações da técnica em cenários mais realistas.

Um fator crucial na caracterização da dinâmica de microestados é determinar o conjunto de topografias para o backfitting dos dados. Como já discutido na seção 1.3.2 existe um compromisso entre maximizar a variância total que um conjunto de topografias consegue explicar (especificidade) e sua generalidade a nível de grupo. Assim, a utilização de templates a nível de indivíduo, ou seja, calculado exclusivamente 
a partir dos dados de um participante; a nível de grupo, considerando todos os participantes; e utilizando uma referência normativa vão gradativamente aumentando sua generalidade e diminuindo a especificidade. Como tínhamos por objetivo caracterizar uma população peculiar em uma condição não usual, neste trabalho optamos por um balanço entre as opções, calculando os templates a nível de grupo a partir dos dados de nossos participantes e utilizando o menor número possível de topografias características. Esta abordagem foi contra nossa expectativa inicial de recuperar as quatro topografias canônicas para fins de maior comparação com a literatura, como pode ser observado na figura 17, apesar de elas serem muito similares às topografias reportadas por Pedroni et al. ${ }^{(54)}$

É interessante observar que a tarefa comportamental de Pedroni et al. ${ }^{(54)}$ relaciona a dinâmica dos microestados com a tomada de risco em um momento posterior, em uma tarefa de aposta (gambling task), e nos permite estabelecer uma paralelo entre a tomada de risco em um experimento controlado versus um cenário real. Os autores associaram a tomada de risco com a modulação de dois microestados: o aumento na duração média do microestado 1 foi observado após o indivíduo perder a aposta, portanto, sendo associado à atenuação da tomada de risco na próxima execução da atividade. Por sua vez, o aumento da duração média do microestado 4 foi observado após apostas bem-sucedidas, o que foi associado a uma maior aceitação do risco. Nossos resultados também apontam para a modulação antagônica de duas classes de microestados quando comparamos as dinâmicas de repouso e de voo (Figura 18), porém, aqui observamos que estas diferenças são demarcadas para as classes 3 e 4 . Nossos resultados corroboram com os de Pedroni et al. ${ }^{(54)}$ no que tange a modulação do microestado 4, reforçando a associação desta classe com a preparação para uma atividade de risco, guardadas as devidas proporções entre as condições experimentais. Além disso, tendo em vista que para o nosso participante a aversão ao risco não é uma escolha, não esperávamos verificar uma modulação no microestado 1 como a reportada pelos autores. Porém, não estávamos esperando por uma modulação do microestado 3.

Como já discutido na seção 1.3.2, a determinação do número total de classes de microestados não é um consenso na literatura, em particular devido às conhecidas ambiguidades na rotulação dos microestados canônicos C e D. ${ }^{(13)}$ Portanto, exploramos a variabilidade de nossos achados para 5 e 6 topografias características. 0 
aumento no número de classes tornou nossos templates bastante similares à referência normativa de Koenig et al. ${ }^{(50)}$ e ao trabalho de Bréchet et al., ${ }^{(75)}$ como demonstrado nas figuras 19 e 21. É interessante observar que neste subconjunto parece ser possível estabelecermos uma relação com as quatro topografias canônicas como originalmente desejado. Nossa hipótese inicial era de que a tomada de decisão durante a execução da manobra de autorrotação fosse mediada por redes de atenção e de controle cognitivo, uma vez que os pilotos reportam um aumento percebido na carga de trabalho para a execução da manobra. Assim, esperávamos observar uma modulação significativa nos parâmetros associados ao microestado $D$, não observada neste trabalho.

Custo et al. ${ }^{(66)}$ sugerem que algumas classes possuem fontes em comum, e que se o número de classes é restringido há a tendência das topografias adicionais se fundirem. Para um conjunto de dados, eles determinam um valor ótimo de 7 classes (Figura 7), nomeando-as de A a G e exploram como o agrupamento em 4 classes justifica algumas distorções na forma das topografias canônicas. É interessante comparar nossos templates com os de Custo et al. ${ }^{(66)}$ (Figura 7), onde é possível estabelecer uma relação aproximada de nossas quatro classes (Figura 17) com as topografias $D, E, F$ e $C$ (com ressalvas), respectivamente; com as topografias $D, A, C$, B e $F$ para nossas cinco classes (Figura 19); e A, B, C, D, E, F para nossas seis classes (Figura 21). Ao compararmos as modulações entre o repouso e voo tanto para quatro (Figura 18) quanto para cinco (Figura 20) e seis classes (Figura 22) notamos que há uma queda em todos os parâmetros dinâmicos para a topografia similar ao microestado $\mathrm{F}$ de Custo et al. ${ }^{(66)}$ e de Bréchet et al. ${ }^{(75)}$ Nota-se também que nossa topografia $\mathrm{F}$ se assemelha à do microestado em que Seitzman et al. ${ }^{(65)}$ reportam modulação durante uma tarefa de subtração mental (neste paper, classificado como microestado D). No entanto, os autores reportam um aumento nos parâmetros da classe $D$ e diminuição na classe $C$, enquanto nossos resultados apontam para uma diminuição do microestado F. Apesar de contarem com topografias diferentes, Bréchet et al. ${ }^{(75)}$ corroboraram as modulações nas classes C e D para a mesma tarefa de subtração mental, e não só contrastaram as modulações dos microestados durante o repouso, mas também durante a evocação de memória. Neste trabalho, as atividades recuperadas pelo EEG através da reconstrução de fontes foram corroboradas por registros de RMf de alta resolução. No entanto, cabe ressaltar que em nenhuma das 
três condições experimentais os autores reportaram uma modulação associada à topografia F, como verificado em nosso resultado.

Custo et al. ${ }^{(66)}$ ressaltam que existem nuances para a classificação dos microestados quando mais classes de microestados são consideradas: Eles observaram que a classe C canônica (ou seja, quando apenas 4 classes são consideradas) é uma combinação das classes $\mathrm{C}$ e $\mathrm{F}$ e que, na literatura, as topografias classificadas como $\mathrm{C}$ podem ser topograficamente semelhantes ora à classe $\mathrm{C}$, ora à classe F. Assim, seus resultados sugerem que, de maneira geral, duas topografias ( $\mathrm{C}$ e F) são consideradas como representações do mesmo estado e rede quando o número de classes diminui. Seitzman et al. $^{(65)}$ encontraram uma queda nos parâmetros dinâmicos associados à classe $\mathrm{C}$ e discute que diferentemente da proposta de Britz et al., ${ }^{(47)}$ que associava esta topografia à rede de saliência, ela deveria estar associada à DMN já que ela era a única rede task-negative reportada na literatura de RMf. Complementarmente, Seitzman et al. ${ }^{(65)}$ também associaram o microestado $D$ ao sistema de atenção dorsolateral, o que corroboraria com o aumento dos parâmetros dinâmicos observado em seu trabalho, uma vez que esta rede é task-positive. Os achados de Bréchet et al. ${ }^{(75)}$ reforçam uma associação funcional da classe $\mathrm{C}$ com a DMN e a classe D com redes no córtex pré-frontal.

A topografia $F$ de Custo et al. ${ }^{(66)}$ é associada ao córtex dorsal anterior (córtex cingulado anterior e à área de Broadman 32) e bilateralmente no giro frontal e na ínsula. Estes resultados foram corroborados estendidos por Bréchet et al., ${ }^{(75)}$ que associam esta classe ao mPFC (bilateral). Nossos resultados apontam congruência neste sentido, uma vez que a reconstrução de fontes aponta que durante o voo existe um cluster de maior atividade no córtex pré-frontal esquerdo (Figura 23). Nosso resultado se torna ainda mais interessante ao considerarmos as limitações que tivemos para a aplicação desta técnica, já que, como mencionado na Seção 1.2.4, há um decaimento significativo na qualidade da reconstrução de fontes para dados com poucos eletrodos e que se utilizam de um template para a cabeça. Além disso, contamos com um número de participantes relativamente pequeno.

Custo et al. ${ }^{(66)}$ afirma que o mPFC é uma área que participa da maioria das classes de microestados e os autores interpretam esta região como um hub principal na integração de redes de larga escala. Além disso, cabe ressaltar que o mPFC, particularmente sua parte ventral, é um importante elemento no circuito de 
regulação emocional, em associação com a amígdala. ${ }^{(104-106)}$ Ambas as regiões têm influência no eixo hipotalâmico-pituitário-adrenal, que, dentre outras funções, estão envolvidas nas reações ao estresse. ${ }^{(107)}$ O mPFC modula a amígdala de cima para baixo (top-down, na literatura em inglês), assim, o aumento da atividade no mPFC tende a inibir a atividade da amígdala e, portanto, atenua rapidamente a resposta emocional atrelada a eventos negativos. ${ }^{(107)}$ Nossos resultados apontam que, apesar de a atividade no mPFC aumentar durante a manobra (Figura 23), a duração, ocorrência e contribuição ainda são significativamente menores na janela de tomada de decisão em relação ao nível basal. Isto parece corroborar com uma noção de que a tomada de decisão neste caso esteja mais associada a respostas límbicas, o que pode explicar comportamentos de paralisia de alguns pilotos mesmo após o amplo treinamento para que refinem sua CS.

Porém, reforçamos a necessidade de cautela ao estabelecermos interpretações funcionais diretas para classes de microestados, já que este estudo foi de caráter exploratório. Além disso, o modelo de microestados encara a cognição como uma sequência de um número finito de estados cerebrais, no qual em um determinado momento apenas uma das redes está ativa. Na prática, isto é uma simplificação já que, há um nível de sobreposição das redes e existe uma porcentagem da variância do sinal que não é contemplada pelo modelo. ${ }^{(75)} \mathrm{O}$ modelo de microestados ainda tem alguns pontos não esclarecidos, tais como elucidar quais os sistemas responsáveis pela dominância de uma determinada classe de microestados sob as demais e compreender a transição abrupta de uma classe para a seguinte. ${ }^{(13)}$ Por fim, nossos resultados também reforçam que pode haver mais do que quatro microestados canônicos e corroboram com relatos de que a manipulação cognitiva de microestados é possível. Complementarmente, este trabalho estende o horizonte de experimentos para condições mais realísticas e desafiadoras, uma vez que os microestados parecem ser neurocorrelatos robustos.

\subsection{Limitações e trabalhos futuros}

O entendimento da operação cognitiva e dos processos de tomada de decisão em ambientes dinâmicos e complexos é relevante para embasar o desenvolvimento de estratégias de mitigação de risco e redução de erro. Apesar das 
particularidades de cada cenário, existe uma gama de profissionais em ambientes desta natureza, tais como pilotos de avião/helicóptero, controladores de tráfego aéreo, equipes de profissionais da saúde em unidades de terapia intensiva (UTIs), em resgates/emergências e durante a realização de procedimentos cirúrgicos. Acreditamos que este estudo abre perspectivas para que a fisiologia da tomada de decisão seja explorada em ambientes mais realísticos.

Neste trabalho observamos que a atividade de pilotagem está potencialmente associada a redes de regulação emocional. Esta relação ainda precisa ser corroborada por trabalhos futuros, mas pode levar à introdução de treinamentos de regulação emocional no programa de formação de pilotos a fim de aumentar sua eficiência.

Embora a quantidade de pilotos utilizadas neste trabalho seja significativa frente à quantidade de pessoas com este nível de habilidade a nível global, ainda temos poucos sujeitos para superar a variabilidade intrínseca de medidas fisiológicas, de maneira que seja possível estabelecer relações diretas e estatisticamente representativas entre a dinâmica dos microestados e o desfecho de cada manobra ou o grau de treinamento do participante. Acreditamos que uma descrição multimodal da manobra de $A R$, que utilize outros sensores fisiológicos tais como o EDA, O ECG, o EMG e o Eye Tracker podem nos permitir novos horizontes para descrever a CS durante a manobra. Além disso, apesar de no contexto aeronáutico o total de manobras por participante ser representativo tendo em vista o custo de uma hora de voo com telemetria completa, este valor ainda é muito menor do que o número de repetições da atividade que os participantes geralmente executam em experimentos controlados de fisiologia. O balanço entre as necessidades destes dois tipos de universo é um dos principais desafios no processamento de dados de situações realísticas.

À medida que novas tecnologias de simulação e realidade virtual evoluem, abre-se também uma nova janela de oportunidade para o estudo da CS, onde um pouco do realismo é comprometido em prol de um estudo mais barato, que englobe um maior número de participantes e em uma gama maior de situações. Para estudos futuros, seria interessante a avaliação de pilotos em simuladores de voo durante diferentes etapas de treinamento, o que possibilitaria um estudo longitudinal.

Finalmente, ressaltamos também que o ruído intrínseco a um experimento nestas condições é um risco e que não necessariamente as estratégias 
disponíveis resultarão em sinais de EEG viáveis em quaisquer contexto experimental. Assim, é importante que todo estudo em um ambiente novo e desafiador seja precedido por análises de viabilidade. 


\section{CONCLUSÕES}

1. Microestados são neurocorrelatos robustos, mesmo em situações extremas;

2. As topografias características recuperadas em um cenário ecológico apresentam semelhança topográfica com os de registros efetuados em ambientes controlados;

3. Microestados apresentam modulação durante atividades cognitivas. Em particular, a atividade de pilotagem parece não modular o microestado $\mathrm{D}$, tradicionalmente associado à rede de controle cognitivo e atenção, mas o microestado $F$, que envolve o córtex pré-frontal medial. Esta rede pode estar potencialmente associada a redes de regulação emocional;

4. Não observamos padrões representativos na transição entre classes (matriz de transição). 


\section{REFERÊNCIAS}

1. Blanchard BS, Fabrycky WJ. System engineering and analysis. 5th ed. London: Pearson; 2014.

2. Federal Aviation Administration. System safety handbook [Internet]. Washington (DC):

Federal Aviation Administration; 2000 [cited 2020 May 20]. Available from:

https://www.faa.gov/regulations_policies/handbooks_manuals/aviation/risk_management/ss_ha ndbook/

3. Endsley MR. Theoretical underpinnings of situational awareness: a critical review. In: Endsley MR, Garland DJ, editors. Situation awareness analysis and measurement. Boca Raton: CRC Press; 2000. p.1:24.

4. Endsley MR. Toward a theory of situation awareness in dynamic systems. Hum Factors. 1995 3;37(1):32-64.

5. Corbetta M, Shulman GL. Control of goal-directed and stimulus-driven attention in the brain. Nat Rev Neurosci. 2002;3(3):201-15.

6. Siegel M, Donner TH, Engel AK. Spectral fingerprints of large-scale neuronal interactions. Nat Rev Neurosci. 2012;13(2):121-34.

7. Petersen SE, Posner MI. The attention system of the human brain: 20 years after. Annu Rev Neurosci. 2012;35(1):73-89.

8. Endsley MR, Garland DJ, editors. Situation awareness analysis and measurement. Boca Raton: CRC Press; 2000.

9. Charles RL, Nixon J. Measuring mental workload using physiological measures: A systematic review. Appl Ergon. 2019;74(74):221-32.

10. Berger H. [Uber das Elektrenkephalogramm des Menschen]. Arch Psychiatr Nervenkr. 1929;87:527-70. German.

11. Nunez PL, Srinivasan R. A theoretical basis for standing and traveling brain waves measured with human EEG with implications for an integrated consciousness. Clin Neurophysiol. 2006;117(11):2424-35.

12. Schomer DL, Silva FH. Niedermeyer's electroencephalography: basic principles, clinical applications, and related fields. Oxônia: Oxford University Press; 2011.

13. Michel CM, Koenig T. EEG microstates as a tool for studying the temporal dynamics of whole-brain neuronal networks: a review. Neuroimage. 2018;180 Pt B:577-93.

14. Smith SJ. EEG in the diagnosis, classification, and management of patients with epilepsy. J Neurol Neurosurg Psychiatry. 2005;76 Suppl 2(Suppl 2):ii2-7.

15. Michel CM, Murray MM. Towards the utilization of EEG as a brain imaging tool. Neuroimage. 2012;61(2):371-85.

16. Collura TF. History and evolution of electroencephalographic instruments and techniques. J Clin Neurophysiol. 1993;10(4):476-504. 
17. Jurcak V, Tsuzuki D, Dan I. 10/20, 10/10, and 10/5 systems revisited: their validity as relative head-surface-based positioning systems. Neuroimage. 2007;34(4):1600-11.

18. Jasper $\mathrm{HH}$. The ten-twenty electrode system of the International Federation.

Electroencephalogr Clin Neurophysiol. 1958;10:370-5.

19. Buzsáki G. Rhythms of the brain [Internet]. New York: Oxford University Press; 2006 [cited 2020 May 20]. Available from:

https://neurophysics.ucsd.edu/courses/physics_171/Buzsaki\%20G.\%20Rhythms\%20of\%20the \%20brain.pdf

20. Hyafil A, Giraud AL, Fontolan L, Gutkin B. Neural cross-frequency coupling: connecting architectures, mechanisms, and functions. Trends Neurosci. 2015;38(11):725-40.

21. Symons AE, El-Deredy W, Schwartze M, Kotz SA, Keitel A, Grandjean D. The functional role of neural oscillations in non-verbal emotional communication. Front Hum Neurosci. 2016;10:239.

22. Fell $\mathrm{J}$, Axmacher $\mathrm{N}$. The role of phase synchronization in memory processes. Nat Rev Neurosci. 2011;12(2):105-18.

23. Klimesch W. EEG alpha and theta oscillations reflect cognitive and memory performance: a review and analysis. Brain Res Brain Res Rev. 1999;29(2-3):169-95.

24. Steriade M, McCormick DA, Sejnowski TJ. Thalamocortical oscillations in the sleeping and aroused brain. Science. 1993;262(5134):679-85.

25. Knyazev GG. Motivation, emotion, and their inhibitory control mirrored in brain oscillations. Neurosci Biobehav Rev. 2007;31(3):377-95.

26. Razavi N, Jann K, Koenig T, Kottlow M, Hauf M, Strik W, et al. Shifted coupling of EEG driving frequencies and fMRI resting state networks in schizophrenia spectrum disorders. PLoS One. 2013;8(10):e76604.

27. Palva S, Palva JM. New vistas for a-frequency band oscillations. Trends Neurosci. 2007;30(4):150-8.

28. Engel AK. Directive minds: how dynamics shapes cognition. In: Stewart J, Gapenne O, Di Paolo E, editors. Enaction: toward a new paradigm for cognitive science. Cambridge: MIT Press; 2010. p. 219-43.

29. Buzsáki G, Wang XJ. Mechanisms of gamma oscillations. Annu Rev Neurosci. 2012;35:203-25.

30. Islam MK, Rastegarnia A, Yang Z. Methods for artifact detection and removal from scalp EEG: a review. Neurophysiol Clin. 2016;46(4-5):287-305.

31. Papoulis A. Probability, random variables and stochastic processes. 3rd ed. New York: McGrawHill; 1991.

32. Hyvarinen A, Oja E. Independent component analysis: algorithms and applications. Neural Netw. 2000;13(4-5):411-30. 
33. Fuchs M, Kastner J, Wagner M, Hawes S, Ebersole JS. A standardized boundary element method volume conductor model. Clinical Neurophysiology. 2002;113(5):702-12.

34. Grech R, Cassar T, Muscat J, Camilleri KP, Fabri SG, Zervakis M, et al. Review on solving the inverse problem in EEG source analysis. J Neuroeng Rehabil. 2008;5:25.

35. Pascual-Marqui RD. Review of methods for solving the EEG inverse problem. Int $\mathrm{J}$ Bioelectromagn. 1999;1(1):75-86.

36. Pascual-Marqui RD, Michel CM, Lehmann D. Low resolution electromagnetic tomography: a new method for localizing electrical activity in the brain. Int J Psychophysiol. 1994;18(1):49-65.

37. Pascual-Marqui RD, Esslen M, Kochi K, Lehmann D. Functional imaging with low-resolution brain electromagnetic tomography (LORETA): a review. Methods Find Exp Clin Pharmacol. 2002;24 Suppl C:91-5.

38. Pascual-Marqui RD. Standardized low-resolution brain electromagnetic tomography (sLORETA): technical details. Methods Find Exp Clin Pharmacol. 2002;24 Suppl D:5-12. 39. Pascual-Marqui RD. Discrete, 3D distributed linear imaging methods of electric neuronal activity. Part 1: exact, zero error localization. arXiv:07103341. 2007; p. 1-16.

40. Pascual-Marqui RD, Lehmann D, Koukkou M, Kochi K, Anderer P, Saletu B, et al. Assessing interactions in the brain with exact low-resolution electromagnetic tomography. Philos Trans A Math Phys Eng Sci. 2011;369(1952):3768-84.

41. Brodbeck V, Spinelli L, Lascano AM, Wissmeier M, Vargas MI, Vulliemoz S, et al. Electroencephalographic source imaging: a prospective study of 152 operated epileptic patients. Brain. 2011;134(Pt 10):2887-97.

42. Brown R. What is a brain state? Philos Psychol. 2006;19(6):729-42.

43. Khanna A, Pascual-Leone A, Michel CM, Farzan F. Microstates in resting-state EEG: current status and future directions. Neurosci Biobehav Rev. 2015;49:105-13.

44. Lehmann D, Ozaki H, Pal I. EEG alpha map series: brain micro-states by space-oriented adaptive segmentation. Electroencephalogr Clin Neurophysiol. 1987;67(3):271-88.

45. Pascual-Marqui RD, Michel CM, Lehmann D. Segmentation of brain electrical activity into microstates: model estimation and validation. IEEE Trans Biomed Eng. 1995;42(7):658-65.

46. Wackermann J, Lehmann D, Michel CM, Strik WK. Adaptive segmentation of spontaneous EEG map series into spatially defined microstates. Int J Psychophysiol. 1993;14(3):269-83.

47. Britz J, Van De Ville D, Michel CM. BOLD correlates of EEG topography reveal rapid resting-state network dynamics. Neuroimage. 2010;52(4):1162-70.

48. Milz P, Pascual-Marqui RD, Achermann P, Kochi K, Faber PL. The EEG microstate topography is predominantly determined by intracortical sources in the alpha band. Neuroimage. 2017;162:353-61.

49. Rieger K, Diaz Hernandez L, Baenninger A, Koenig T. 15 years of microstate research in schizophrenia - Where are we? A meta-analysis. Front Psychiatry. 2016;7(FEB):22. 
50. Koenig T, Prichep L, Lehmann D, Sosa PV, Braeker E, Kleinlogel H, et al. Millisecond by millisecond, year by year: normative EEG microstates and developmental stages. Neuroimage. 2002;16(1):41-8.

51. Müller TJ, Koenig T, Wackermann J, Kalus P, Fallgatter A, Strik W, et al. Subsecond changes of global brain state in illusory multistable motion perception. J Neural Transm (Vienna). 2005;112(4):565-76.

52. Britz J, Michel CM. State-dependent visual processing. Front Psychol. 2011;2:370.

53. Britz J, Díaz Hernàndez L, Ro T, Michel CM. EEG-microstate dependent emergence of perceptual awareness. Front Behav Neurosci. 2014;8:163.

54. Pedroni A, Gianotti LR, Koenig T, Lehmann D, Faber P, Knoch D. Temporal Characteristics of EEG Microstates Mediate Trial-by-Trial Risk Taking. Brain Topogr. 2017;30(1):149-59.

55. Dierks T, Jelic V, Julin P, Maurer K, Wahlund LO, Almkvist O, et al. EEG-microstates in mild memory impairment and Alzheimer's disease: possible association with disturbed information processing. Journal of Neural Transmission. 1997;104(4-5):483-95.

56. Strik WK, Chiaramonti R, Muscas GC, Paganini M, Mueller TJ, Fallgatter AJ, et al. Decreased EEG microstate duration and anteriorisation of the brain electrical fields in mild and moderate dementia of the Alzheimer type. Psychiatry Res. 1997;75(3):183-91.

57. Kinoshita T, Strik WK, Michel CM, Yagyu T, Saito M, Lehmann D. Microstate segmentation of spontaneous multichannel EEG map series under diazepam and sulpiride.

Pharmacopsychiatry. 1995;28(2):51-5.

58. Katayama H, Gianotti LR, Isotani T, Faber PL, Sasada K, Kinoshita T, et al. Classes of multichannel EEG microstates in light and deep hypnotic conditions. Brain Topogr.

2007;20(1):7-14.

59. Michel CM, Koenig T, Brandeis D. Electrical neuroimaging in the time domain. In: Michel CM, Koenig T, Brandeis D, Gianotti LR, Wackermann J, editors. Electrical Neuroimaging. Cambridge: Cambridge University Press; 2017. p. 111-44.

60. Murray MM, Brunet D, Michel CM. Topographic ERP analyses: a step-by-step tutorial review. Brain Topography. 2008;20(4):249-64.

61. Musso F, Brinkmeyer J, Mobascher A, Warbrick T, Winterer G. Spontaneous brain activity and EEG microstates. A novel EEG/fMRI analysis approach to explore resting-state networks. Neuroimage. 2010;52(4):1149-61.

62. Yuan H, Zotev V, Phillips R, Drevets WC, Bodurka J. Spatiotemporal dynamics of the brain at rest-exploring EEG microstates as electrophysiological signatures of BOLD resting state networks. Neuroimage. 2012;60(4):2062-72.

63. Khanna A, Pascual-Leone A, Farzan F. Reliability of resting-state microstate features in electroencephalography. PLoS One. 2014;9(12):e114163.

64. Tibshirani R, Walther G. Cluster Validation by prediction strength. J Comput Graph Stat. 2005;14(3):511-28.

65. Seitzman BA, Abell M, Bartley SC, Erickson MA, Bolbecker AR, Hetrick WP. Cognitive manipulation of brain electric microstates. Neuroimage. 2017;146:533-43. 
66. Custo A, Van De Ville D, Wells WM, Tomescu IM, Brunet D, Michel C. Eletroencephalografic resting-state networks: source localization of microstates. Brain Connectivity. 2017;7(10): brain.2016.0476.

67. Fox MD, Raichle ME. Spontaneous fluctuations in brain activity observed with functional magnetic resonance imaging. Nat Rev Neurosci. 2007;8(9):700-11.

68. Dehaene S, Naccache L. Towards a cognitive neuroscience of consciousness: basic evidence and a workspace framework. Cognition. 2001;79(1-2):1-37.

69. Dehaene S, Changeux J. Neural mechanisms for access to consciousness. Cogn Neurosci. 2003;3(1):1145-58.

70. VanRullen R, Koch C. Is perception discrete or continuous? Trends in Cognitive Sciences. 2003 5;7(5):207-13.

71. Fingelkurts AA, Fingelkurts AA. Timing in cognition and EEG brain dynamics: discreteness versus continuity. Cognitive Processing. 2006;7(3):135-62.

72. Tee J, Taylor DP. Is information in the brain represented in continuous or discrete form? IEEE Trans Mol Biol Multiscale Commun. 2018. p. 1-12. [submitted; arXiv:1805.01631v2].

73. Fekete $\mathrm{T}$, Van de Cruys S, Ekroll V, van Leeuwen C. In the interest of saving time: a critique of discrete perception. Neurosci Conscious. 2018;2018(1):niy003.

74. Doerig A, Scharnowski F, Herzog MH. Building perception block by block: a response to Fekete et al. Neurosci Conscious. 2019;2019(1):niy012.

75. Bréchet L, Brunet D, Birot G, Gruetter R, Michel CM, Jorge J. Capturing the spatiotemporal dynamics of self-generated, task-initiated thoughts with EEG and fMRI. Neuroimage. 2019;194(February):82-92.

76. Efron R. Effect of stimulus duration on perceptual onset and offset latencies. Percept Psychophys. 1970;8(4):231-4.

77. Purpura DP. Discussion: functional studies of thalamic internuclear interactions. Brain Behav Evol. 1972;6(1):203-9.

78. Fontenele AJ, de Vasconcelos NAP, Feliciano T, Aguiar LAA, Soares-Cunha C, Coimbra B, et al. Criticality between Cortical States. Physical Review Letters. 2019;122(20):208101.

79. Van de Ville D, Britz J, Michel CM. EEG microstate sequences in healthy humans at rest reveal scale-free dynamics. Proc Natl Acad Sci U S A. 2010;107(42):18179-84.

80. Milz P, Faber PL, Lehmann D, Koenig T, Kochi K, Pascual-Marqui RD. The functional significance of EEG microstates-associations with modalities of thinking. Neuroimage. 2016;125:643-56.

81. Panda R, Bharath RD, Upadhyay N, Mangalore S, Chennu S, Rao SL. Temporal dynamics of the default mode network characterize meditation-induced alterations in consciousness.

Frontiers in Human Neuroscience. 2016;10(July):1-12.

82. Britz J, Landis T, Michel CM. Right parietal brain activity precedes perceptual alternation of bistable stimuli. Cereb Cortex. 2009;19(1):55-65. 
83. Britz J, Pitts MA, Michel CM. Right parietal brain activity precedes perceptual alternation during binocular rivalry. Hum Brain Mapp. 2011;32(9):1432-42.

84. Jingze Q. From autorotation to safe landing. Procedia Eng. 2011;17:46-51.

85. Johnson W. Helicopter theory. Massachusetts: Courier Corporation; 2012.

86. Federal Aviation Administration. Helicopter flying handbook [Internet]. Washington (DC): Federal Aviation Administration; 2019 [cited 2020 May 20]. Available from:

https://www.faa.gov/regulations_policies/handbooks_manuals/aviation/helicopter_flying_handbo ok/

87. Shapley JJ, Kyker RA, Ferrell KR. The development of an improved method of conducting height-velocity testing on rotary wing aircraft. J Am Helicopter Soc. 2016;15(2):30-8.

88. Helicopter Safety Analysis Team. Helicopter accidents: statistics. trends and causes [Internet]. Kentucky: International Helicopter Safety Team - Commonwealth of Independent States; 2016 [cites 2020 May 20]. Available from: https://pdf4pro.com/cdn/presentation-inst-cis2016-1c2ff2.pdf

89. Tyrrell ST. Autorotations: reality exposed. Rotor. 2017;2017(Spring):68.

90. Wikipedia. List of test pilot schools [Internet]. [S.I.]: Wikipedia; 2019 [cited 2020 May 20; edited 2020 Mar 15]. Available from: https://en.wikipedia.org/wiki/List_of_test_pilot_schools

91. Delorme A, Makeig S. EEGLAB: an open source toolbox for analysis of single-trial EEG dynamics including independent component analysis. J Neurosci Methods. 2004;134(1):9-21.

92. Koenig T, Lehmann D, Merlo MC, Kochi K, Hell D, Koukkou M. A deviant EEG brain microstate in acute, neuroleptic-naive schizophrenics at rest. Eur Arch Psychiatry Clin Neurosci. 1999;249(4):205-11.

93. Wilkinson GN, Rogers CE. Symbolic description of factorial models for analysis of variance. Appl Stat. 1973;22(3):392.

94. Mazziotta J, Toga A, Evans A, Fox P, Lancaster J, Zilles K, et al. A probabilistic atlas and reference system for the human brain: International Consortium for Brain Mapping (ICBM). Philos Trans R Soc Lond B Biol Sci. 2001;356(1412):1293-322.

95. Lancaster JL, Woldorff MG, Parsons LM, Liotti M, Freitas CS, Rainey L, et al. Automated Talairach atlas labels for functional brain mapping. Hum Brain Mapp. 2000;10(3):120-31.

96. Nichols TE, Holmes AP. Nonparametric permutation tests for functional neuroimaging: a primer with examples. Human Brain Mapping. 2002;15(1):1-25.

97. Ritter P, Becker R, Freyer F, Villringer A (Mulert C, Lemieux L, editors). EEG - fMRI: physiological basis, technique, and applications. Heidelberg: Springer-Verlag Berlin Heidelberg; 2010.

98. Soares JM, Magalhães R, Moreira PS, Sousa A, Ganz E, Sampaio A, et al. A Hitchhiker's Guide to functional magnetic resonance imaging. Front Neurosci. 2016;10:515.

99. Evans V. The structure of time: language, meaning and temporal cognition. Amsterdam: John Benjamins Publishing Company; 2005. 
100. Bueno FD, Morita VC, de Camargo RY, Reyes MB, Caetano MS, Cravo AM. Dynamic representation of time in brain states. Sci Rep. 2017;7(April):46053.

101. Fries P. A mechanism for cognitive dynamics: neuronal communication through neuronal coherence. Trends Cogn Sci. 2005;9(10):474-80.

102. Kopell N, Kramer MA, Malerba P, Whittington MA. Are different rhythms good for different functions? Front Hum Neurosci. 2010;4(November):187.

103. Barttfeld P, Uhrig L, Sitt JD, Sigman M, Jarraya B, Dehaene S. Signature of consciousness in the dynamics of resting-state brain activity. Proc Natl Acad Sci U S A. 2015;112(3):887-92.

104. Buchanan TW, Driscoll D, Mowrer SM, Sollers JJ, Thayer JF, Kirschbaum C, et al. Medial prefrontal cortex damage affects physiological and psychological stress responses differently in men and women. Psychoneuroendocrinology. 2010;35(1):56-66.

105. Etkin A, Egner T, Kalisch R. Emotional processing in anterior cingulate and medial prefrontal cortex. Trends in Cognitive Sciences. 2011;15(2):85-93.

106. Marek R, Strobel C, Bredy TW, Sah P. The amygdala and medial prefrontal cortex: partners in the fear circuit. J Physiol. 2013;591(10):2381-91.

107. Urry HL, van Reekum CM, Johnstone T, Kalin NH, Thurow ME, Schaefer HS, et al. Amygdala and ventromedial prefrontal cortex are inversely coupled during regulation of negative affect and predict the diurnal pattern of cortisol secretion among older adults. J Neurosci. 2006;26(16):4415-25. 


\begin{abstract}
Introduction: Situational awareness has consolidated as a major research field within Human Factors, and is especially relevant within dynamic and complex environments. In these conditions, the operator receives a myriad of information that changes over time. Understanding decision-making in such environments is relevant for designing strategies targeting safety improvement and error rate reductions. However, studies evaluating brain dynamics in realistic situations are scarce in the literature. In this project, we assessed the electrophysiology of elite helicopter pilots during engine-failure missions. More specifically, we evaluated the vicinity of the so-called "dead man's curve", which establishes the operational limits for a safe landing after the execution of a recovery maneuver (autorotation). Purpose: To demonstrate that microstates are robust neural correlates in realistic situations; analyze microstate dynamics, comparing the baseline with the maneuver. Methods: The pilots from the Brazilian Air Force flew an AS-350 helicopter in a certified aerodrome and the physiological data was synchronized with the aircraft's telemetry system. Given the evidence that specific microstates may be associated with perception and attention, we assessed these neural correlates during maneuver execution and contrasted their modulations and source reconstructed activity with baseline epochs before and after flights. Results: We show that the topographies of our microstate templates with 4,5 , and 6 classes resemble the literature and that a distinct modulation characterizes decision making intervals. Moreover, the source reconstruction points to a differential activity in the medial prefrontal cortex, which is associated with emotional regulation circuits in the brain. Conclusion: Our results suggest that microstates are robust neural correlates in realistic situations, even in a challenging and intrinsically noisy environment, prone to participant movement. Furthermore, it strengthens their usage and expands their application for studying cognition under more realistic conditions.
\end{abstract}

Keywords: Electroencephalography; Brain mapping 